九州大学学術情報リポジトリ

Kyushu University Institutional Repository

\title{
Cytogenetic Studies On Brassica And Raphanus
}

Fukushima, Eiji

Department of Agriculture, Kyusyu Imperial University

https://doi.org/10.5109/22602

出版情報 : 九州大学大学院農学研究院紀要. 7 (9)，pp. 281-396，1945-05. Kyushu Imperial University バージョン：

権利関係 : 
Journal of the Department of Agriculture, Kyūsyü Imperial University, Vol. 7, No. 9, May 15, 1945

\title{
CYTOGENETIC STUDIES ON BRASSICA AND RAPHANUS
}

\author{
I. STUDIES ON THE INTERGENERIC $F_{1}$ HYBRIDS \\ BETWEEN BRASSICA AND RAPHANUS ${ }^{1}$
}

\section{Eiji FukUshima}

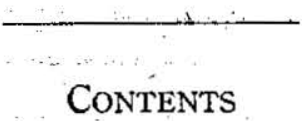

1. Introduction $\ldots \begin{array}{llllllllllllllllll} & \ldots & \ldots & \ldots & \ldots & \ldots & \ldots & \ldots & \ldots & \ldots & \ldots & \ldots & \ldots & \ldots & \ldots & \ldots & 281\end{array}$

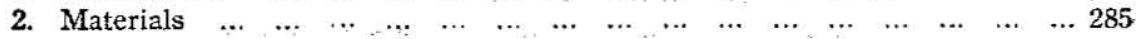

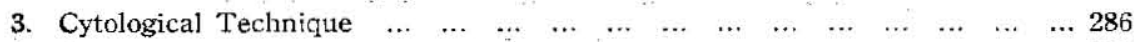

$\begin{array}{lllllllllllllllll}\text { 4. Observations } & \ldots & \ldots & \ldots & \ldots & \ldots & \ldots & \ldots & \ldots & \ldots & \ldots & \ldots & \ldots & \ldots & \ldots & \ldots & 287\end{array}$

Part I. Di.genome $F_{1}$ Hybrids

$R$. sativus $\times B$. oleracea, B. oleracea $\times R$. sativus and $\begin{array}{lllllllll}R \text {. sativus } \times \text { B. alboglabra } & \ldots & \ldots & \ldots & \ldots & \ldots & \ldots & \ldots & 287\end{array}$

Part II. Tri-genome $F_{1}$ Hybrids

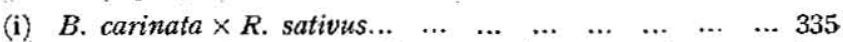

(ii) B. cernua $\times R$. sativus and $B$. juncea $\times R$. sativus $\quad \ldots 349$

$\begin{array}{lllllllllllllll}\text { (1) Crossability } & \ldots & \ldots & \ldots & \ldots & \ldots & \ldots & \ldots & \ldots & \ldots & \ldots & \ldots & \ldots & \ldots & 355\end{array}$

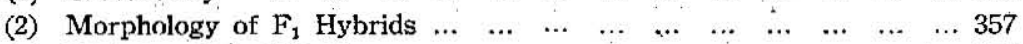

(3) Meiosis of $\dot{F}_{1}$ Hybrids $\ldots \begin{array}{llllllllllllll} & \ldots & \ldots & \ldots & \ldots & \ldots & \ldots & \ldots & \ldots & \ldots & \ldots & \ldots & 358\end{array}$

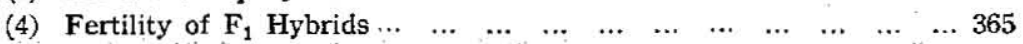

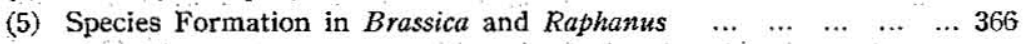

6. Summary $\begin{array}{lllllllllllllllllll} & \ldots & \ldots & \ldots & \ldots & \ldots & \ldots & \ldots & \ldots & \ldots & \ldots & \ldots & \ldots & \ldots & \ldots & \ldots & 387\end{array}$

$\begin{array}{lllllllllllllllll}\text { 7. Acknowledgements } & \ldots & \ldots & \ldots & \ldots & \ldots & \ldots & \ldots & \ldots & \ldots & \ldots & \ldots & \ldots & \ldots & \ldots & 394\end{array}$

$\begin{array}{llllllllllllllllll}\text { Literature } & \ldots & \ldots & \ldots & \ldots & \ldots & \ldots & \ldots & \ldots & \ldots & \ldots & \ldots & \ldots & \ldots & \ldots & \ldots & 395\end{array}$

\section{INTRÓDUCTION}

It is well known that the genus Brassica includes many cultivated species and a vast majority of wild forms. The cytological

1) Contributions from the Institute of Agronomy, Kyūsyū Imperial University, No. 87 . 
investigations on these Brassica species, especially on the cultivated one, have been carried out by many workers. On the basis of their gametic chromosome complements, the various cultivated species and wild forms which have been treated with so far can be classified into the following nine groups (Table 1).

Table 1. Nine groups of Brassica species $^{11}$.

\begin{tabular}{|c|c|c|}
\hline Group & $\begin{array}{l}\text { Number of gametic } \\
\text { chromosomes }\end{array}$ & Species included \\
\hline I & 8 & B. nigra Косн \\
\hline II & 9 & $\begin{array}{l}\text { B. oleracea L., B. alboglabra BAILE, } \\
\text { B. Sinapistrum Botss., B. insularis MoRIs, } \\
\text { B. rupestris RAFIN., B. balearica PERS. }\end{array}$ \\
\hline III & 10 & $\begin{array}{l}\text { B. campestris L., B. rapa L., B. chinensis L., } \\
\text { B. japonica Stra., B. pekinensis RupR., } \\
\text { B. nipposinica BaILEY, B. trilocularis Hook., } \\
\text { B. Tournefortii GoUan }\end{array}$ \\
\hline IV & 11 & B. elongata ЕНRH. \\
\hline $\mathrm{V}$ & 12 & B. Wrightii, $B$. monensis Huds. \\
\hline VI & 17 & B. carinata BRAUN \\
\hline VII & 18 & B. juncea Hemsei., $B$. cernua Coss. \\
\hline VIII & 19 & B. napus L.2), B. Napella ChaIX, B. rugosa PralN. \\
\hline$\tilde{\mathbf{X}}$ & 24 & B. cheiranthos VILL. \\
\hline
\end{tabular}

As will be noticed from Table 1, a special characteristic of the genus is the aneuploidy found in the numbers of chromosomes of its componental species. Though studies on the nature of polyploidy have achieved a steady progress in recent years, there remain various problems still to be solved, especially about aneuploidy. In connection with this problem of chromosomal evolution and also with the difficult taxonomic problems of fixing species boundaries, the remarkable prevalence of aneuploidy throughout the genus makes it a particularly interesting group to study.

During the past few years many attempts have been made by

1) This table was compiled chiefly from the reviews given by $\mathrm{HAGA}_{\mathrm{A}}(1938 \mathrm{~b})$ and Sikka (1940) (Cf. Alam, 1936; Manton, 1932; Morinaga, 1928; Morinaga and Fukushima 1930; Nagai and Sasaoka, 1930; Silmotomat 1925; Howard, 1938 a).

2) Catrheside (1934) counted the number as $n=18$. His material may be a different form. Several strains of B. napus, indigenous to Europe, Russia and Japan, examined by the author possessed without exception 19 gametic chromosomes (MORINAGA and Funushima 1930). 
several workers to analyse the complicate species relationships in this genus, with the view of giving a clue towards the general speciation problems. These attempts have been carried out along the following ways of approach: (1) Analysis of the morphological differences of somatic chromosome, with special reference to the relation existing between the nucleolus and SAT-chromosomes (CATCHESIDE (1934) on B. napus and B. rapa; Alam (1936) on B. campestris, B. trilocularis and B. juucea; RICHHARIA (1937a,b) on B. oleracea, B. pekinensis, B. rapa and B. chinensis); (2) Study of "secondary association" of chromosomes in meiosis (CATCHESIDE (1934, 1937) on B. rapa, B. oleracea, and 'B. napus' ; AlAM (1936) on $B$. campestris and $B$. trilocularis; RICHHARIA (1937a, b) on B. chinensis, B. rapa, and B. pekinensis; HAGA (1938a) on B. nigra, B. juncea, and B. oleracea; SIKKA (1940) on B. monensis, B. sinapistrum, and B. nigra.); (3) Genome-analysis of species, which is achieved by the studies of interspecific and intergeneric hybridizations. Studies on this line will be dealt with below in details; (4) The study of the haploid mutantation (MorinaGA and Fukushima, 1933, on the haploid $B$. Napella) ; (5) Geno-systematic investigations on cultivated species (SINSKAIA, 1927, 1928); (6) Studies of genetic behaviours of characteristics, especially that of incompatibility, revealing the nature of the secondarily balanced polyploid (DETJEN, 1927, and KAKIZAKI, 1930, on the sterility in $B$. oleracea; also Cf. LAWRENCE, 1930); (7) The serological examination of species through precipitin reactions (FuKushima and MaruYaMa, 1929).

In Brassica, as in other genera like Triticum, Nicotiana, Gossypium, etc., investigations on the chromosome conjugation in interspecific and intergeneric hybrids are considered to be the most significant and fruitful way to study the complex problems of species formation in that genus. The artificial interspecific hybridization in Brassica would be traced back to 1834, when HerBerT (quoted by Focke, 1881) succeeded in obtaining the $\mathrm{F}_{1} B$. napus $\times$ $B$. rapa. Since then the interspecific hybridizations of various combinations have been produced by several workers. It was, however,not until 1928 that any thorough cytogenetic studies were made on the interspecific hybrids of Brassica, and the credit of doing so for the first time must be given to Morinaga (1928, 1929a, b, c ; $1931,1933,1934 \mathrm{a}, \mathrm{b})$. His work, which was followed by those of SASAOKA (1930), U (1934a,b; 1935) and KARPECHENKO (1937a), has 
shown that the species with higher chromosome numbers (i.e., species in group VI, VII and VIII in Table 1) can be taken as allopolyploids (amphidiploids), of which chromosome complexes are composed of two genomes each found respectively in the species with lower chromsome numbers (i.e., species in group I, II and III in Table 1).

The intergeneric crossing between Raphanis sativus and Brassica oleracea was succeeded in $1826^{\circ}$ for the first time by SAGERET (quoted by GÄRTNER, 1849), and the attempt was followed later by several investigators. As more recent workers on this line, including some other kinds of combination of species, the names of Grawatr (1914), Baur (1922) and Moldenhauer (1924). have to be mentioned. Though their studies have no direct bearing on the genome-analysis in Brassica species, it is considered to be very fruitful in confirming indirectly the results obtained from the interspecific hybrids. KARPECHENKo's later worlss (1927a, b; $1928,1929 \mathrm{a}, \mathrm{b})$ on this intergeneric hybrid, Raphanus sativus $\times$ Brassica oleracea, and that on the amphidiploid, 'Raphanobrassica' originated in the progeny of the cross above mentioned, made a valuable contribution to genetics, as it showed for the first time the fruitful course of new species (or genus) formation through amphidiploidy. Further he has tried several crossings between 'Raphanobrassica' and various Brassica species, including artificially produced tetraploid $B$. oleracea, and produced some hexaand octogenomic hybrids (KARPECHENKO, 1929a, b; 1937b, KARPECHENKo and SHCHAVINSKaIA, 1929). Thus he has succeeded in giving another source of evidence for the analysis of Brassica species, and made clear, further, some essential natures and significances of the amphidiploidy itself. In succession to KARPECHENKO's investigation, cytogenetical studies on the intergeneric hybrids between Raphanus and Brassica, of the same parental combination or others, have been worked out by several authors; PIECH and MoldENHAUER (1927), Terasawa and SHimotomai (1928), Fukushima (1929), TERASAWA (1932a,b), MORINAGA (1933), U (1935), RICHHARIA (1937a) and U, Midusima and SArTô (1937) are some of the examples.

Since 1926 the author has been engaged in cytogenetic studies of the intergeneric hybrid between Raphanus and Brassica. Various kinds of the $F_{1}$ hybrids as well as their successive generations were investigated with special interest in the structure and behaviour 
of the occasional polyploid derivatives. In the present paper the results of investigations on the various kinds of $F_{1}$ plants raised during 1927-1938 are presented, and the derivatives of those hybrids will be described in this series successively. Preliminary report on some of those $F_{1}$ plants was made in 1929 (Fukushima, 1929).

\section{Materials}

The author has made crosses between several horticultural varieties of Japanese radish, Raphanus sativus $\mathrm{L}$. (R. sativus $\mathrm{L}$. var. acanthiformis MAKINO, $R$. acanthiformis MOREL) and several species and varieties of Brassica. The $\mathrm{F}_{1}$ hybrids hitherto investigated by the author are as follows (Table 2):

\section{Table 2.}

\section{Di-genome hybrids}

(i) Raphanus sativus $\mathrm{L}$. $(\mathrm{n}=9) \times$ Brassica oleracea $\mathrm{L} .(\mathrm{n}=9)$ and its reciprocal. "RR" "cc"

(Parental combination) (Experiment No.) ( $F_{1}$ Nótation)

(1) R.s. "An escape" $\times$ B.o. var. capitata L. "Succession" $27 / 28 \mathrm{~F}_{1}(101) \mathrm{F}_{1} \mathrm{~A}$

(2) R.s. "Syōgoin" $\times$ B.o. var. capitata L. "Succession" $37 / 38 \mathrm{~F}_{1}(29) \quad \mathrm{F}_{1} \mathrm{H}$

(3) R.s. "Miyasigé-Naga" $\times$ B.o. var. capitata L. "Sadaya" $37 / 38 F_{1}(34) \quad F_{1} I$

(4) R.s. "Miyasigé-Maru" $\times$ B.o. var. capitata L. "Succession" $37 / 38 F_{1}(37) F_{1} J$

(5) R.s. "Harumati" $\times$ B.o. var. caulorapa DC. (Kohl-rabi) $\quad 29 / 30 \mathrm{~F}_{1}(2) \quad \mathrm{F}_{1} \mathrm{D}$

(6) R.s. "Harumati" $\times$ B.o. var. caulorapa DC. (Kohl-rabi) $35 / 36 \mathrm{~F}_{1}(1) \quad \mathrm{F}_{1} \mathrm{G}$

(7) B.o. var. capitata L. "Succession" $\times$ R.s. (not identified) $37 / 38 F_{1}(24) \quad F_{1} K$

(ii) Raphanus sativus L. $(\mathrm{n}=9) \times$ Brassica alboglabra BAILEY $(\mathrm{n}=9)$ "RR" "cc"

(8) R.s. "Harumati" $\times$ B. alboglabra BALLEY $30 / 31 \mathrm{~F}_{1}(21,22$ and 23$) \quad \mathrm{F}_{1} \mathrm{E}$

\section{Tri-genome hybrids}

(i) Brassica carinata BRAUN ( $\mathrm{n}=17) \times$ Raphanus sativus $\mathrm{L} .(\mathrm{n}=9)$ "bbcc" "RR"

(9) "B. carinata $\times$ R.s. " Harumati" $31 / 32 \mathrm{~F}_{1}(24,25$ and 27$) \quad \mathrm{F}_{1} \mathrm{~F}$

(ii) Brassica cernua Hemst. $(\mathrm{n}=18)$, Brassica juncea Coss. $(\mathrm{n}=18) \times$ Raphanus sativus $\mathrm{L} .(\mathrm{n}=9)$, "aabb" "aabb" "RR"

(10) B. cernua $\times$ R.s. "Minowasé" $26 / 27 \mathrm{~F}_{1}(28) \quad \mathrm{F}_{1} \mathrm{~B}$

(11) B. juncea $\times$ R.s. "An escape" $26 / 27 F_{1}(11) \quad F_{1} C$ 
The seeds of the parental species and varieties used were kindly provided by Prof. MoRINAGA of the Plant-Breeding Laboratory, Kyüsyū Imperial University. The chromosome numbers and the genomic constitutions of those Brassica species were already determined by Morinaga ( $C f$. Morinaga, 1934). The number of chromosomes in those Brassica species was reascertained by the author, and it was also confirmed by him that those Japanese radishes having nine chromosomes in haploid did not show any irregularities in their meiotic processes.

The $F_{1}$ plants were raised during $1926-1938$ by the author on the Experimental Farm of the Institute of Agronomy of the Kyüsyu Imperial University. The seeds were sown usually in Septernber, and the young plants were transplanted in the Farm in November. All of the $F_{1}$ plants were highly sterile, though the degree of sterility was still variable in each case. Some $F_{1}$ plants produced a few seeds under open-pollination, while others produced no seeds at all even under the artificial pollination. Back-crossings were also tried in some $F_{1}$ plants with or without success. Investigations on the $F_{2}$, $\mathrm{F}_{3}$, and still later offsprings, and also on the hybrids between the $F_{1}$ and the pollens from various sources including some polyploid ones, were carried out when obtainable. Results of the latter studies will be dealt with in a near future.

\section{Cytological Technique}

Meiosis of $\mathrm{F}_{1}$ 's A, B, C, D, E, F and G (Cf. Table 2) was examined chiefly on the permanent preparations. In those cases, the flower buds in a proper stage of growth were fixed with either Bouin's or Flemming's weak solution, and both the fixatives gave quite satisfactory results. Fixed materials were embedded in paraffin after they had passed through a finely graded series of alcohol and chloroform, and the sections were cut $c a .10 \mu$ thick. For staining the Heidenhain's iron-alum-haematoxylin method was followed. For the plants, $\mathrm{F}_{1}$ 's H, I, J and $\mathrm{K}$, meiosis was examined invariably with aceto-carmine smear preparations of the materials, which had been fixed in Carnoy's solution and preserved in alcohol.

All figures were drawn on the table or on a lower level with the help of a camera lucida under Zeiss apochromatic objectives, $x$ 
90 or $\times 120$, and compensation oculars, $K \times 20$ or $K \times 30$, thus the projection magnification of those figures was not the same throughout. For the taking of photomicrographs Zeiss' equipments were also conveniently used. All the drawings were reduced to onehalf or two-thirds in reproduction.

\section{OBSERVATIONS}

\section{Part I. Di-genome $\mathrm{F}_{\mathrm{l}}$ Hybirds}

(i) Raphanus sativus $(\mathrm{n}=9) \times$ Brassica oleracea $(\mathrm{n}=9)$ and its reciprocal "RR" "cc"

\begin{tabular}{|c|c|c|c|}
\hline (Notation) & (Parental combinaton) & (Exp. No.) & $\begin{array}{l}\text { Number of } \\
F_{1} \text { plant }\end{array}$ \\
\hline$F_{1} \mathrm{~A}$ & R.s. "An escape" $\times$ B.o. capitata "Succession" & $27 / 28 \mathrm{~F}_{1}(101)$ & 1 \\
\hline $\mathrm{F}_{1} \mathrm{H}$ & R.s." Syōgoin" $\times$ B.o. capitata "Succession" & $37 / 38 F_{1}(20)$ & 1 \\
\hline$F_{1} I$ & R.s. "Miyasigé-Naga" $\times$ B.o. capitata "Sadaya" & $37 / 38 \mathrm{~F}_{1}(34)$ & 1 \\
\hline$F_{1} \mathrm{~J}$ & $\begin{array}{r}\text { R.s. "Miyasigé-Maru" } \times \text { B.a. capitata " Succes- } \\
\text { sion" }\end{array}$ & $37 / 38 F_{1}(37)$ & 2 \\
\hline$F_{1} \mathrm{D}$ & R.s. "Harumati" $\times$ B.o. caulorapa (Kohl-rabi) & $29 / 30 F_{1}(2)$ & 2 \\
\hline$F_{1} G$ & R.s. "Harumati" $\times$ B.o. caulorapa $($ Kohl-rabi) & $37 / 36 F_{1}(1)$ & 1 \\
\hline$F_{1} \mathrm{~K}$ & B.o. capitata "Succession" $\times$ Radish" & $37 / 38 F_{1}(24)$ & 1 \\
\hline
\end{tabular}

(ii) Raphanus sativus $(\mathrm{n}=9) \times$ Brassica alboglabra $(\mathrm{n}=9$ )

$$
\text { "RR" "cc" }
$$

(8) $\mathrm{F}_{1} \mathrm{E} \quad$ R.s. "Harumati" $\times$ B. alboglabra

$$
\begin{aligned}
& 30 / 31 \mathrm{~F}_{1}(21,22 \\
& \text { and } 23)
\end{aligned}
$$

The author dealt here with $14 \mathrm{~F}_{1}$ individuals of which 8 were raised from 6 different crossings of Raphanus sativus $\times$ Brassica oleracea, and one from its reciprocal mating $\left(F_{1} K\right)$, while the remaining 5 indivuduals were from the crossing of $R$. sativus $\times B$. alboglabra. All the varieties of Japanese radish and $B$. oleracea used in these crossings have 9 chromosomes in haploid and show regular meiotic behaviours. The above mentioned hybrids between Raphanus and B. alboglabra were the ones achieved for the first time (Figs. 1 and 2). According to MorinaGA (1933) the genome of $B$. alboglabra is quite homologous to that of $B$. oleracea, and genomic designation "cc" was given by him to these species. It was reascertained by the author that the meiotic behaviour of

\footnotetext{
* This variety of radish was not identified.
} 
B. alboglabra used was quite regular, showing 9 bivalnt chromosomes in the heterotypic metaphase. $B$. alboglabra is a species considered to be indigenous to south-eastern Asia, and is now extensively cultivated in Thai, Indo-China, Malay, and South China regions. The strain used in this experiment was introduced to Japan several years ago through the courtesy of Dr. SINSKAIA of the Institute of Applied Botany at Leningrad. Morphologically $B$. alboglabra is somewhat like "Kale", B. oleracea var. acephala, so that it is interpreted by some authors as a variety of the latter form. B. alboglabra, however, has large white flowers, instead of yellow ones, and its blooming begins, in Japan, in late autumn or early winter, though the blooming time of all the varieties of oleracea is the early spring of the next year. For those characters that are quite unique, alboglabra would be safely considered as a form distinct from oleracea.

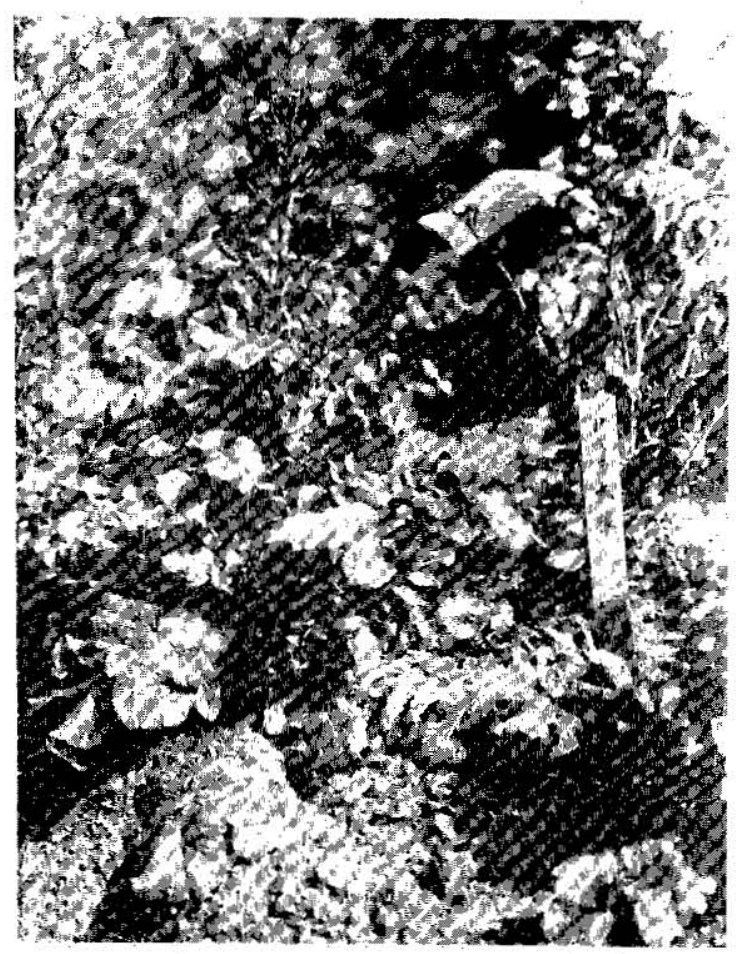

Fig. 1. Rapharus sativus L. "Harumati" $(\mathrm{n}=9)$. 
The results of the investigations with these $14 \mathrm{~F}_{1}$ plants above mentioned are presented together in the following paragraghs:

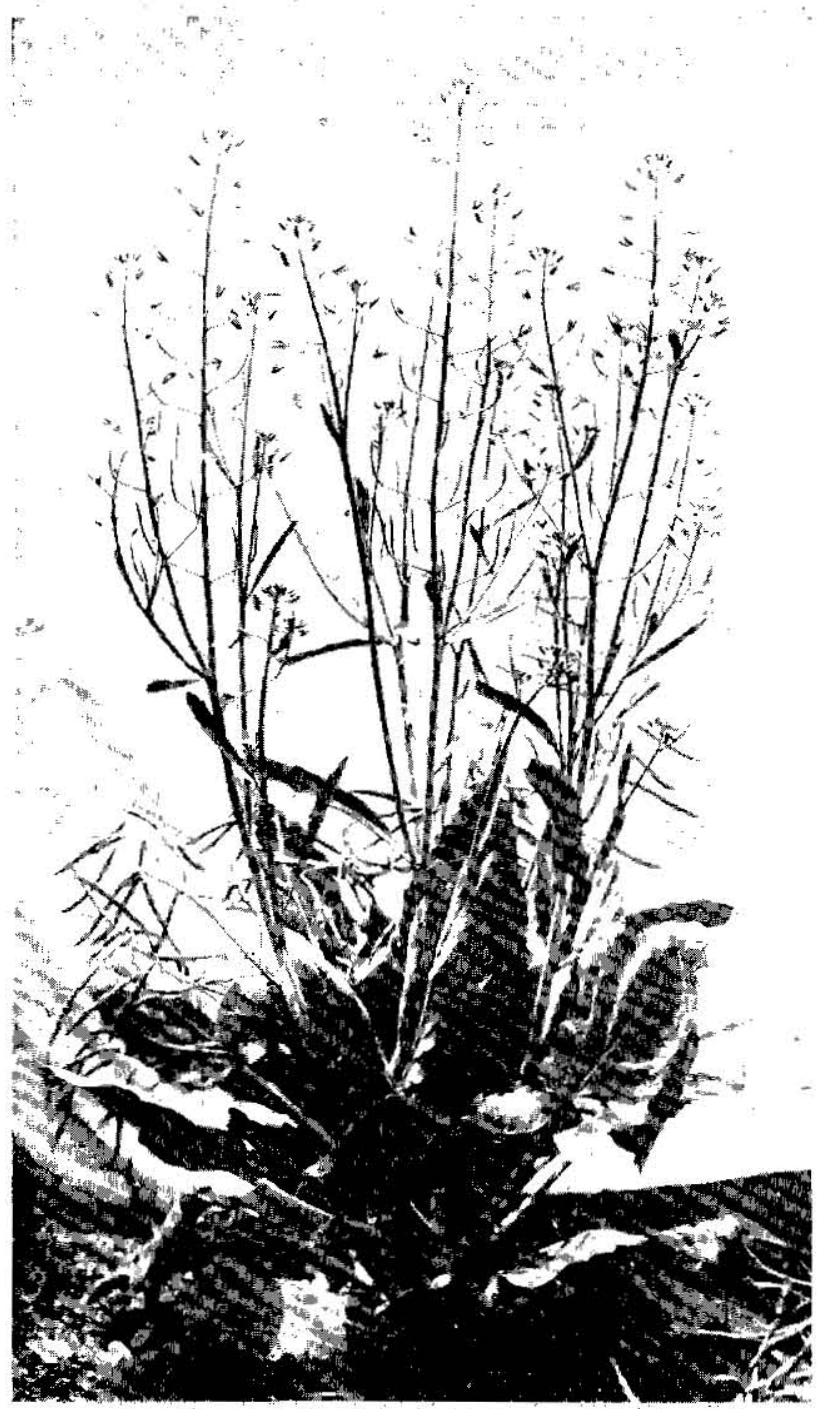

Fig. 2. B. alboglabra Bailey $(\mathrm{n}=9)$.

Origin of $\mathrm{F}_{1}$ hybrids

In 1927, the author first succeeded in the hybridization between Raphanus and B. oleracea, and thereafter it was successfully 
repeated by him in 1929, 1935 and 1937. As mentioned above, it has been generally accepted that the crossing between Raphanus and $B$. oleracea is only sucessful when the former species is taken as the maternal parent, its reciprocal mating being very difficult. Though the author had tried matings reciprocally in every occasions, he could not succeed in raising any $\mathrm{F}_{1}$ hybrid of $B$. oleracea $\times R$. sativus until 1937 , when only one $\mathrm{F}_{1}$ plant $\left(\mathrm{F}_{1} \mathrm{~K}\right)$ was obtained together with $4 \mathrm{~F}_{1}$ plants of Raphanus $\times$ B. oleracea. Another case of $B$. oleracea $\times R$. sativus was reported by U, MiduSIMA, and SAITô (1937). Such a tendency of one-sided crossability is not noticed clearly between Raphanus and other monogenomous Brassica species, especially those belonging to the 10-chromosome group, and three cases of $B$. chinensis $\times$ Raphanus (TERASAWA and Shimotomai, 1928; TerasaWa, unpublished*, Richiharia, 1937a), and one case of each Raphanus $\times$ B. rapa and Raphanus $\times$ B. campestris (RICHHARIA, 1937a; U, Midusima and SAITô, 1937) have ever been reported.

In 1922, KARPECHENKo (1924) pollinated 202 flowers of Raphanus sativus var. prol. niger with the pollens of Heart Cabbage, Kohlrabi, Savoy Cabbage and Brussels Sprouts, and raised respectively $55,33,4$, and $31 \mathrm{~F}_{1}$ plants, though only 3 out of those $123 \mathrm{~F}_{1}$ plants were ascertained of their hybrid nature cytologically. KAKIzAKI (1927) pollinated 50 and 36 flowers of Japanese radish "Miyasigé" with the pollens of Heart Cabbage and Kohl-rabi, and obtained 25 and 31 seeds respectively. He also tried in vain the reciprocal matings using 66 flowers.

Taking several varieties of each species, the author tried, in 1937, crossings of various combinations between Raphanus and $B$. oleracea, and obtained $F_{1}$ seeds in only 43 bags out of about 100 each enclosing 4-7 flowers artificially pollinated. These 43 bags covered in all 177 flowers, which produced 28 matured pods $(15.8$ per cent.) containing 29 seeds, viz., 1.04 seeds per pod, and 0.16 seeds per flower pollinated. From these 29 seeds only 4 matured $F_{1}$ plants were obtained. KaKizAKI (1927) obtained only 2 mature plants (not determined cytologically) out of 56 seeds above cited. Thus the results of the author and KAKIZAKI in Japan, and that of KARPFCHENKO in the USSR show a clear-cut contrast in raising $F_{1}$ hybirds.

The $F_{1}$ seeds obtained by the author were very small and

* Cited from U, Midusima and Sarrô (1937). 
shriveled variously. The germination power of the seeds and the growth activity of the $F_{1}$ seedlings were very weak, and only a very small percentage of the seeds collected could produce matured $F_{1}$ hybrids. No doubt, the development of $F_{1}$ embryo is checked in various stages of its completion, mainly by its ill-harmonized genotypic constitution. Such a situation is also noticeable in later stages of growth, though less in extent. As in KaKIZAKI's experiment, the author also detected a precocious germination of certain $F_{1}$ seeds in the pods when they were collected.

Hybridization between Raphanus and B. alboglabra was successful only when Raphanus was used as the maternal parent. In the spring of 1930,12 pods developed from 16 Raphanus flowers pollinated with the pollen of $B$. alboglabra. From those 12 pods $20 \mathrm{~F}_{1}$ seeds were obtained, of which 5 showed somewhat normal appearance, though smaller in size. Out of those 20 seeds sown only 5 plants grew up to maturity, showing that they were the true $F_{1}$ hybrids.

\section{Characters of $F_{1}$ hybrids}

Growth habit: As mentioned above, only a small percentage of the hybrid seeds obtained could germinate and develop into mature plants. The germination took place very slowly and ununiformly, and the seedlings produced grew up rather slowly in their earlier stages, though they showed later very vigorous growth, overgrowing finally their parent individuals. In some cases, there were produced several seedlings with chlorotic cotyledons or albinos, which died out in their very early stages of growth. With a large number of $F_{1}$ individuals, KARPECHENKO (1924) carried out thoroughly the morphological studies of Raphanus $\times$ B. oleracea hybrids, and noticed the polymorphous nature of the $F_{I}$ plants, especially in vigour. According to the vigour at the end of their first growing season, he classified the $F_{1}$ plants into three major types; dwarf stunted (I type), vigorous bush-form (II type), and vigorous form with strong stem with many branches (III type). The author's $F_{1}$ individuals, though the number was small, all belonged to the vigorous III type of KARPLCHENKO, excepting one individual of $F_{1} E$, which was a little less vigorous. The $F_{1}$ plants attained 1.5 metre or more, being much taller than their parents, 
and they had many large leaves. Though the height of plants differed with the cross conbinations, the sister plants derived from the same crossing usually attained nearly the same height.

Their strong stem produced many branches, and the branching habit, which showed various types between erect and divergent, gave much effect in the general appearance of each hybrid plant. The plants, F's A (Fig. 3), I, J (Fig. 5), $\mathrm{E}$ (Fig. 8), and $\mathrm{K}$, attained a very tall stature at the end of the growing season, and of them $F_{1}$ 's I and $\mathrm{J}$ plants had rather erect branches, developing at more or less upper portion of the main stem. $F_{1}$ $\mathrm{H}$ (Fig. 4) had rather short stem with a large number of basilar branches, and the upper part of the inflorescences on those reclined at the end of the season. $F_{1}$ 's D (Fig. 6) and $\mathrm{G}$ (Fig. 7) were rather short and their branching habit was more like that of Brassica parent than Raphanus. $F_{1}$ plants, $A, H, I, J$ and $K$, though they were derived from crosses with Heat Cab-

Fig. 3. R. sativus "An escape" $\times$ B. oleracea var capitata "Succession" $\left(\mathrm{F}_{1} \mathrm{~A}\right)$.

bages, did not develop the "heart". They remained in a rosette state throughout the growing season, and flowered in the next spring as did the Raphanus parents. Flowering time of $\mathrm{F}_{1}$ hybirds was slightly earlier or later than their Raphanus parents. With $F_{1}$ E plants, however, flowering habit of B. alboglabra predominated, 
and they bcgan to flower earlier than the Raphanus parent. Due to highly sterile nature of the hybrids, the flowering period was much prolonged, and many flowering branches were produced successively. Some $F_{1}$ hybrids, which had shown a strong tendency toward such regenerative activity, outlived the hot summer season and flowered again in the next season. In rare cases some survived even that season, under the field conditions. KaKIZAKI's two $F_{1}$ individuals showed also vigorous growth habit as in the present cases. The author did not ascertain any differences between the reciprocal hybrids raised.

Stems: Raphanus has a hairy and hollow stem, while the stems of both $B$. oleracea and $B$. alboglabra are glabrous with waxy efflorescence, developing normal blocked pith. The stems of the $\mathbf{F}_{1}$ hybrids have normal pith and are glabrous with more or less waxy efflorescence. $F_{1} D$ (Fig. 6) and $G$ plants developed inflated stem, though in less degree than those of the Kohl-rabi. About onehalf of the $F_{1}$ individuals between Raphanus and Kohlrabi, which were obtained by KARPECHENKo (1924), also showed a more or

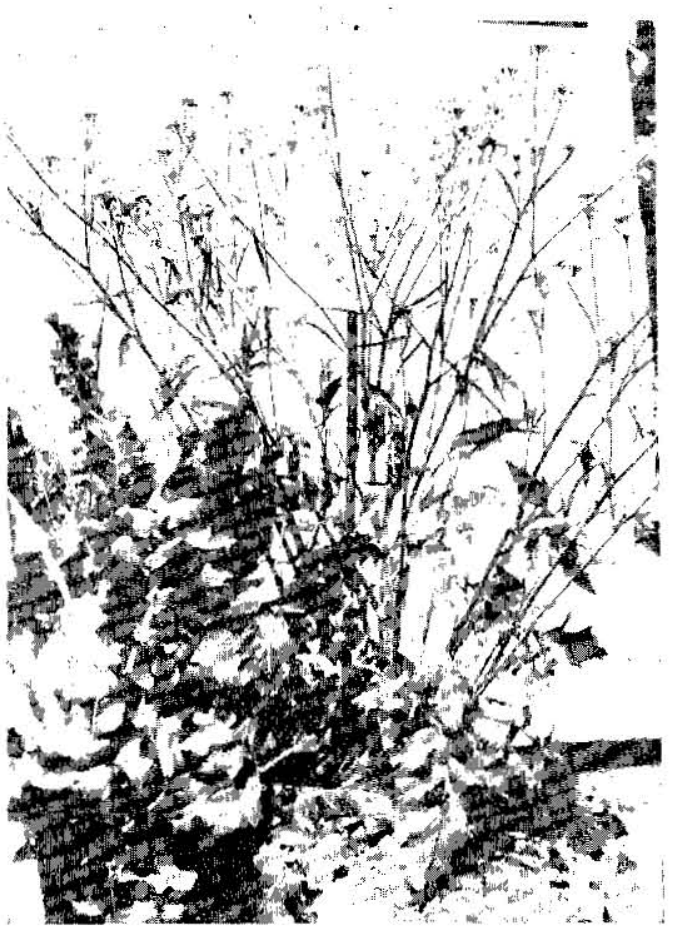

Fig. 4. R. sativus "Syōgoin" $\times$ B. oleracea var. capitata "Succession" $\left(\mathrm{F}_{1} \mathrm{H}\right)$.

less inflated stem. $F_{1}$ stems showed a tendency of producing branches more profusely.

Roots: The roots of the $F_{1}$ hybrids, Raphanus $\times$ B. oleracea, usually remained slender like those of Brassica parent, though in $\mathrm{F}_{1}$ 's $\mathrm{K}, \mathrm{D}$ and $\mathrm{G}$ plants a slight thickening of root was noticed. The root of the $\mathrm{F}_{1}$ 's, Raphanus $\times$ B. alboglabra, was quite similar to that of $B$. alboglabra. KARPECHENKo (1924) has reported a con- 
spicuous outgrowth of roots in a large number of his $F$ : hybrids, but such abnormal roots were not encountered at all by the author and KAKIZAKI (1927).

Leaves: Radish has thin, coarse and hairy leaves, regularly parted in sections with conspicuously serrated margin. While

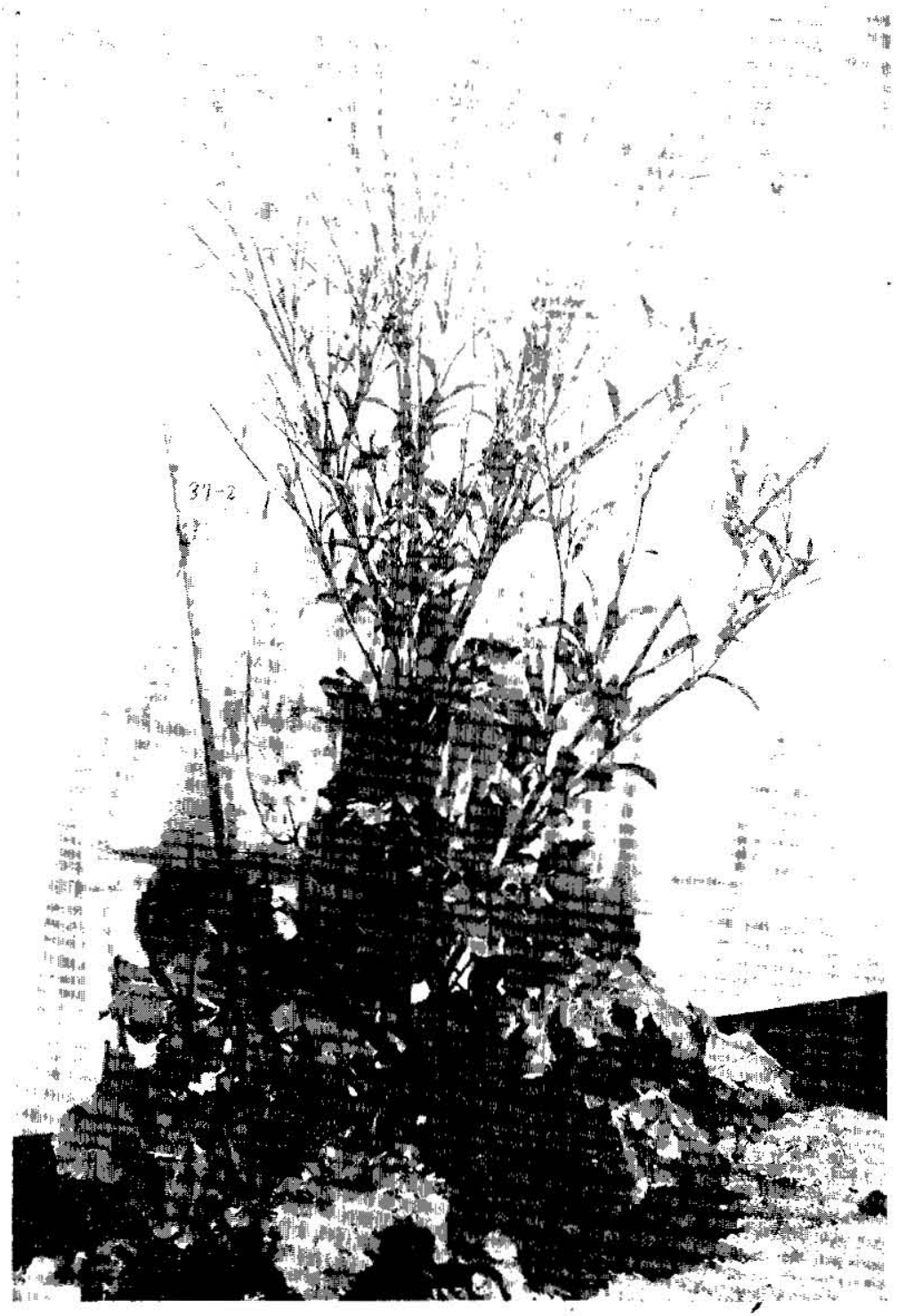

Fig. 5. R. sativus "Miyasigé-Maru" $\times$ B. oleracea var. cabitata "Succession" $\left(\mathrm{F}_{1} \mathrm{~J}-2\right)$. 
leaves of cabbages are more fleshy and glabrous with waxy efflorescence, their colour being deeper green. Cabbage leaves with or without petioles take much variable shapes. Leaves of $B$. albo-

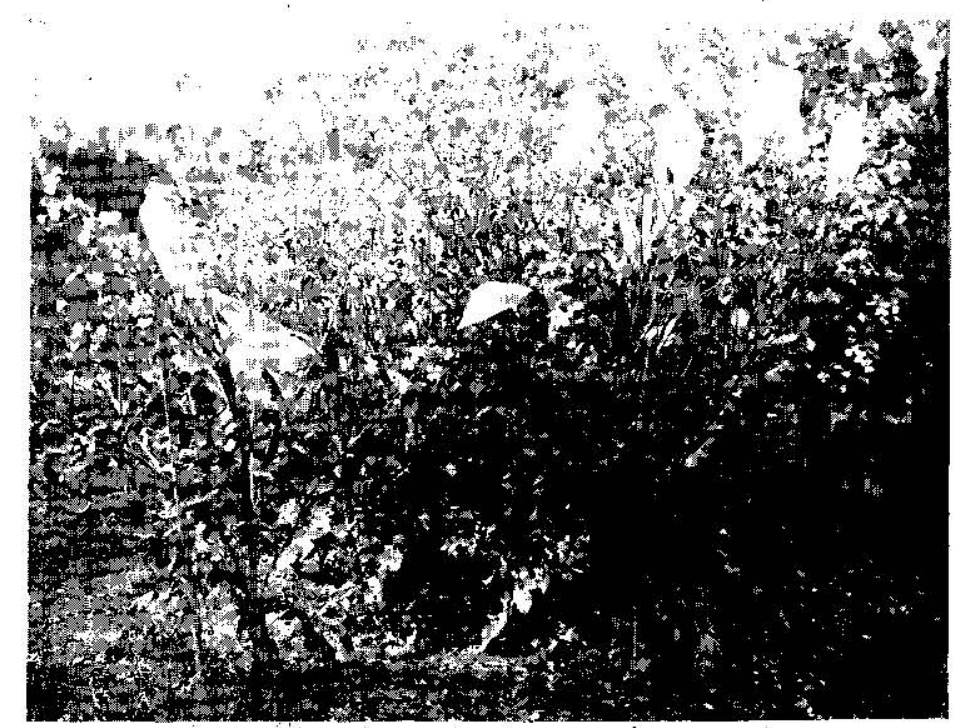

Fig. 6. R. sativus "Harumati" $\times$ B. oleracea var. caulorapa "Kohl-rabi" $\left(F_{1} D.\right)$, in the right. Plant in the left having a thickened root is a radish of parental strain.

glabra, being glabrous and glaucous, have oval shaped blade with irregularly serrated margin, and have conspicuous long stalk sometimes auricled at the base of the blade. $F_{1}$ leaves show intermediate characters of the parents (Figs. 9-12). In general, the $F_{1}$ leaves and the cross section of the $F_{1}$ petioles are much more like radish in shape, while in glaucous green colour, pubescence, fleshiness, and waxy efflorescence, the hybrid leaves resemble much more those of the cabbage parent. The hybrids produce more numerous leaves which are very large in size. KARP'ECHENKo (1924) observed in his $F_{1}$ hybrids every combination of two leaf characters, i.e., waxy efflorescence and pubescence. In the author's experiments, the sister plants from the same cross took a quite uniform appearance, though some $F_{1}$ plants showed minor deviation in several characters from the typical intermediate form. Thus $F_{1}$ A (Fig. 9), being less glabrous, is covered slightly with waxy efflorescence, and its lower leaves take more or less erect position, and $F_{1} \mathrm{H}$ produces rather small, 
thin, light green, non-waxy leaves, apex of which tapering to a point, instead of being obtuse. On the other hand, $F_{1} G$ (Fig. 11) has more or less thin leaves with very slight pubescene, while the

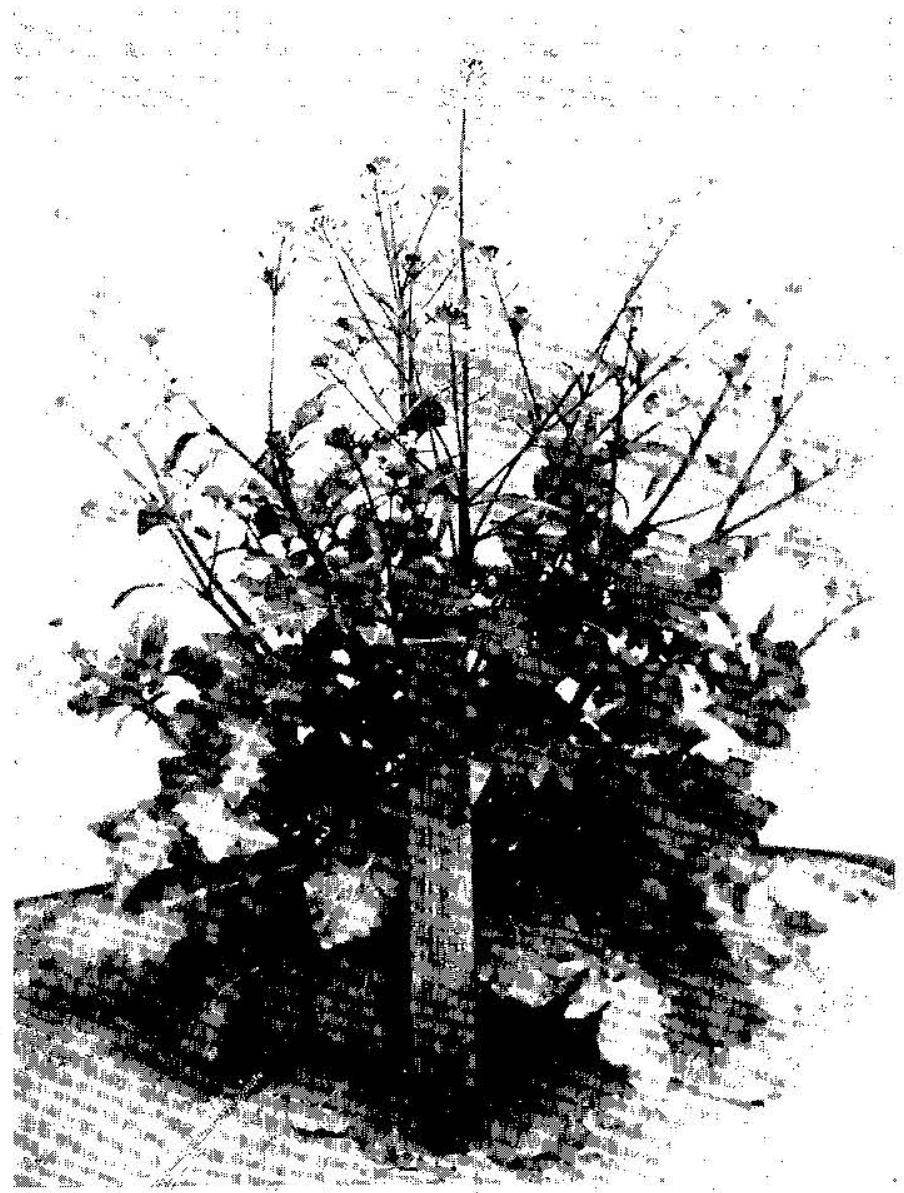

Fig. 7. R. sativus "Harumati" $\times$ B. olevacea var. caulorapa "Kohl-rabi" $\left(F_{1}, G\right)$.

leaves of $F_{1} E$ (Fig. 12) are rather thin and of a slightly light green colour.

Flowers: The $\mathrm{F}_{1}$ inflorescence belongs rather to the cabbage type and in young stage its top protrudes as the cabbage inflorescence does, though the peduncles are shorter than those of the cabbage. The flower cluster of Raphanis, cabbage and B. alboglabra usually consists each of 20-40 flowers, while the $F_{1}$ inflorescence sets one 
hundred or more flowers densely along its very long axis (Figs. 1618). On each $F_{1}$ cluster from seven to ten flowers open on the same day, and owing to the highly sterile nature of the hybrid they do not wither out so soon as the parent flowers. The calyx of Raphanus flower is pubescent, while that of hybrids is glabrous as in Brassica parents. Its form in the bud as well as the bloom.

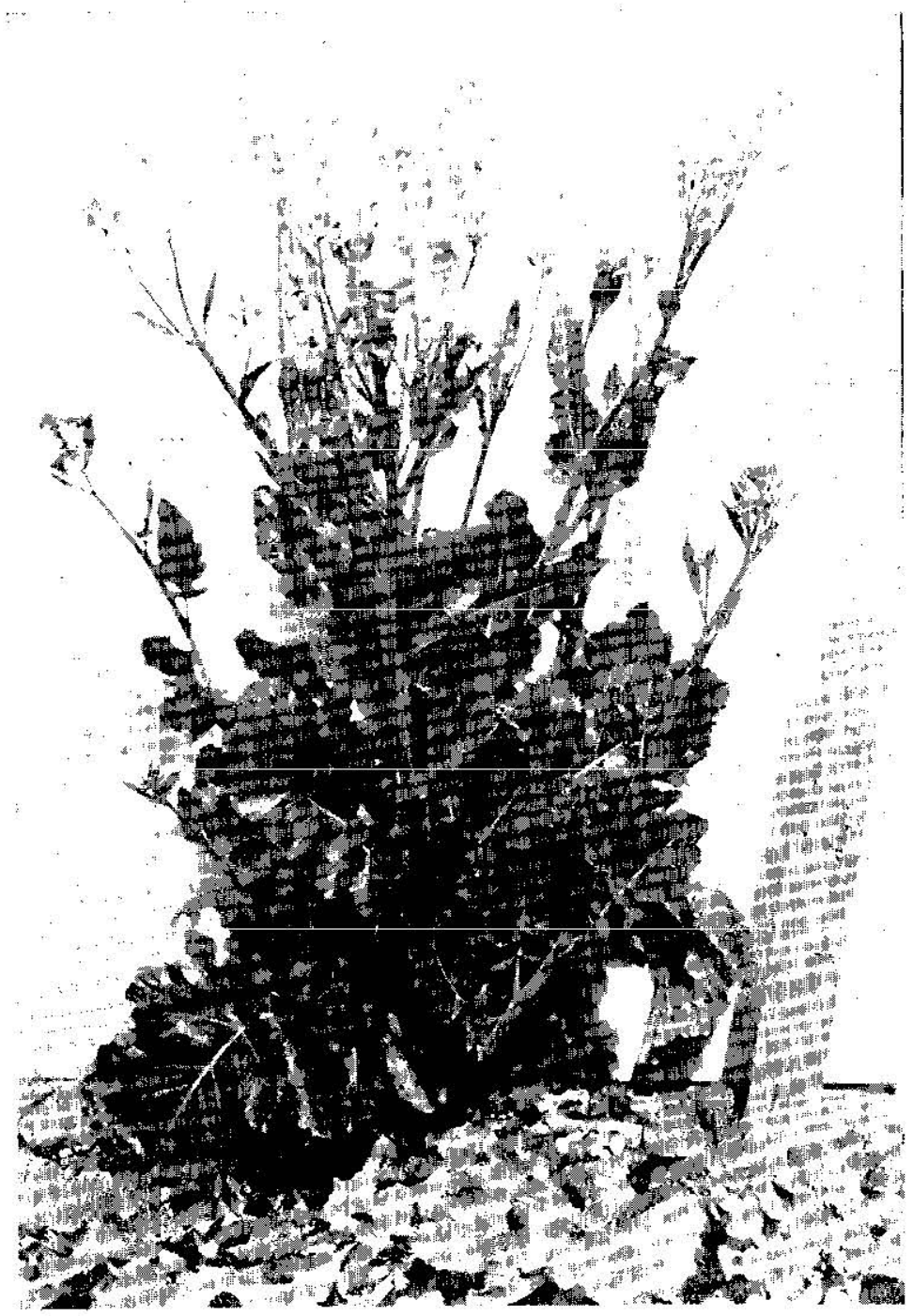

Fig 8. R. sativts "Harumati" $\times$ B. alboglabra $\left(\mathrm{F}_{1} \mathrm{E}\right)$. 
ing stage assumes the Brassica type, and its length is inferior to that of the claw of petals. Unlike either of the parental types, the $F_{1}$ calyx does not assume a divergent position even in full anthesis. The hybrid petals take intermediate shape and are rather smaller in size than those of the parents (Figs. 9 and 13), excepting $F_{1} \mathrm{E}$ plants, in which larger size of B. alboglabra is found predominating. The ground colour of the petals is usually pure white, showing no purple shade as found in Raphanus, though $\mathrm{F}_{1} \mathrm{E}$ hybrids produced exceptionally as in $B$. alboglabra a slight purple shade at the apex of the petals in bud. Nervures of hybrid petals are rather incon-
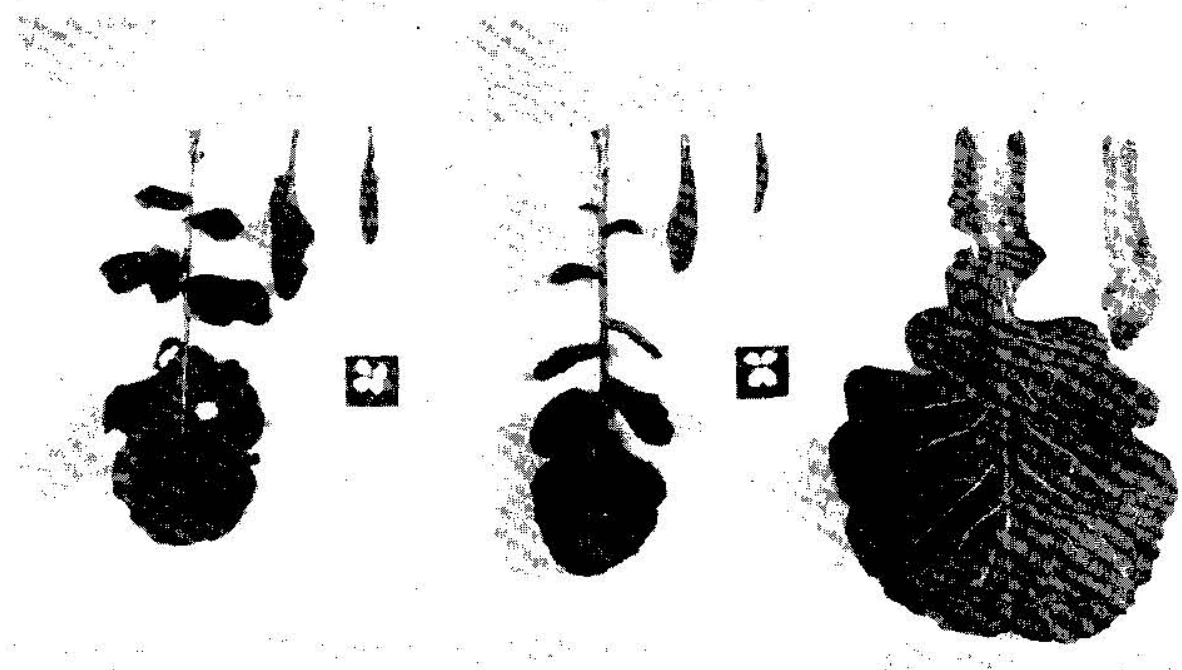

Fig. 9. Leaves and flowers of $R$. sativus "An escape", $\mathrm{F}_{1} \mathrm{~A}$, and $B$. oleracea "Succession", from left to right.

spicuous, making a clear contrast with those purple ones in Raphanus. As a rare case, however, petal nervures of $F_{1} G$ plants assume yellowish green colour as in cabbage and B. alboglabra. Generally speaking, the stamens of the $F_{1}$ hybrids develop poorly and small anthers produced are non-dehiscent at blooming. The dehiscence of anther-sacs, however, occurred in some rare cases, where much larger percentage of viable pollen grains is found. Some Brassica parents, e.g., B. alboglabra and Kohl-rabi, have a conspicuous red-purple dot at the tip of the anther, while no 
radish varieties have any such colouring, and this peculiar character predominates in the $F_{1}$ hybrids.

The ovary of the hybrids shows a very characteristic ap-
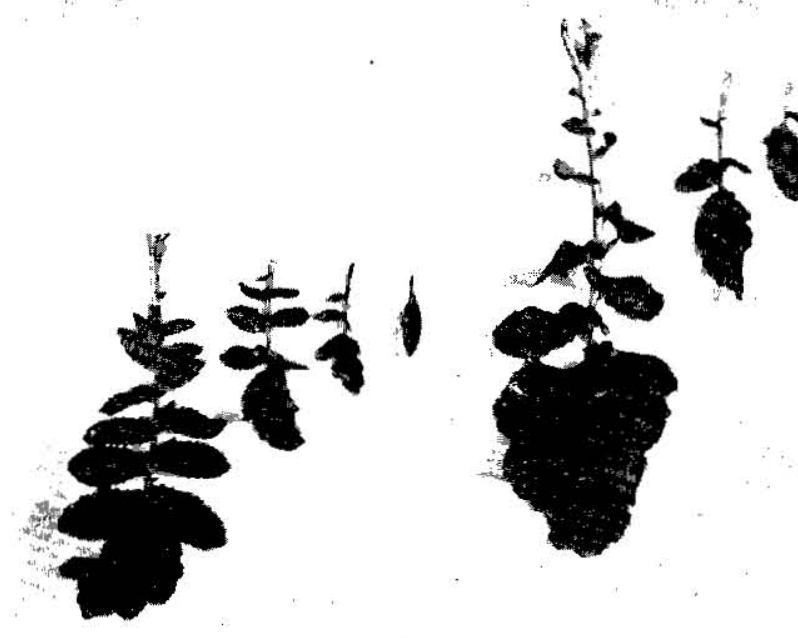

Fig. 10. Leaves of $R$. sativus "Harumati", $F_{1} D$, and $B$. oleracea "Kohl-rabi", from left to right.

pearance, consisting of two different parts, valvate and non-dehiscent, which have been developed equally well in one body (Fig. 14). In the radish ovary, the length of valvate part covers only $c a .3 .5$ per cent. of the whole length, in contrast to 83-86 per cent. for the Brassica parents. Percentage lengths of valvate parts to the total length of the ovary are $22.2,32.5$ and 35.0 per cent. respectively for $F_{1}$ 's $D, G$ and $E$. Eight to twelve ovules are found in one radish ovary, and 30-45 ovules in Brassica. Each hybrid ovary contains about 10 ovules. A large number of ovaries of the $F_{1}$ hybrids fell off soon after blooming, leaving only a few which develop into pods. Parthenocarpic development of ovaries to some degree was always observed in the $F_{1}$ hybrids.

Pods: The lower part of the hybrid pod is distinctly twocelled as in the cabbage pod, with longitudinal partition membrane in it, but the upper part is quite like the radish pod. filled up 
with spongy mesocarp and is non-dehiscent in nature. Anthocyanin pigment on the pod of $B$. alboglabra appears also in the $F_{1}$ plants. Matured pods present variable shapes according to the

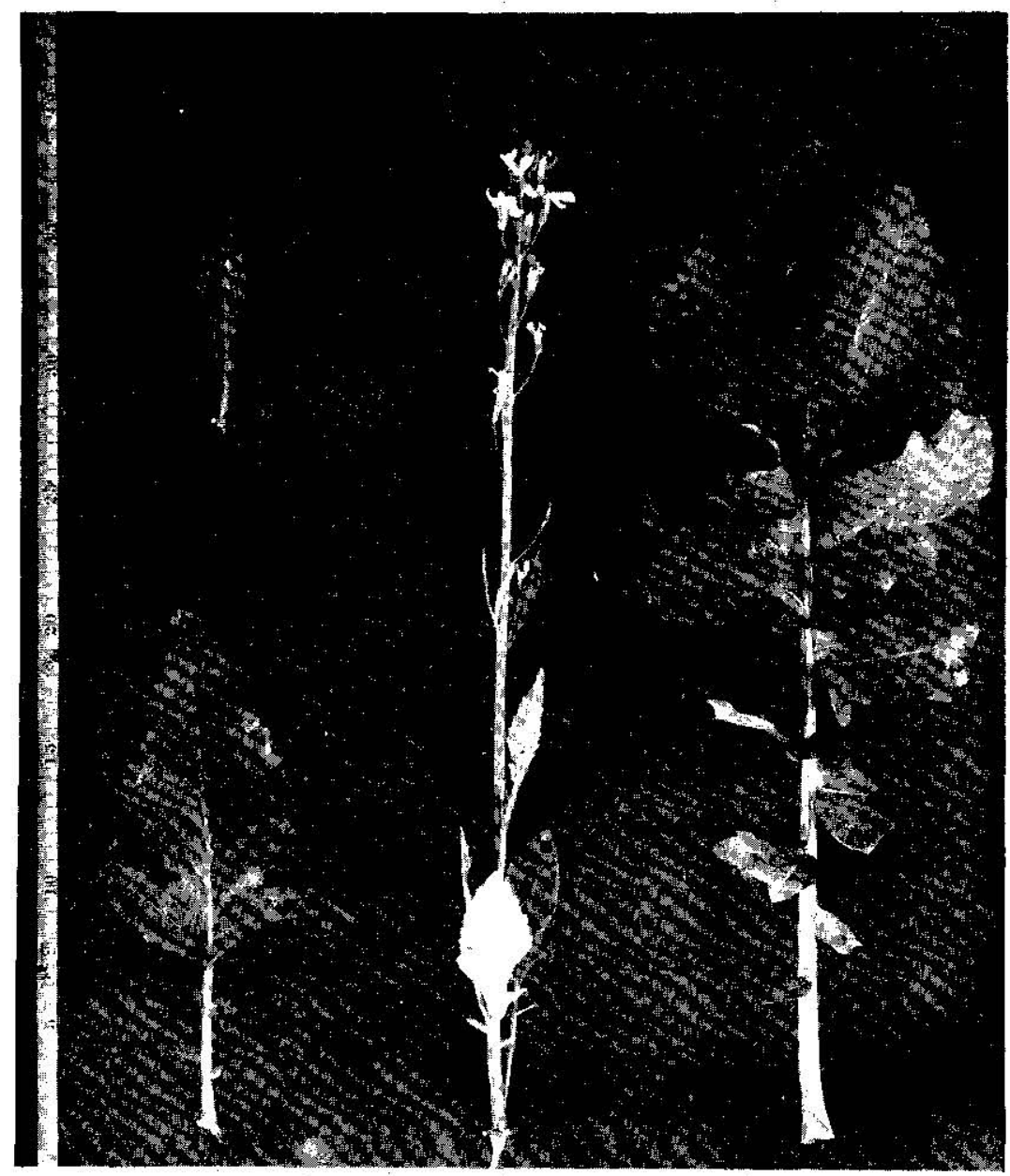

Fig. 11. Leaves and inflorescence of $R$. sativus "Harumati" $\times$ B. alboglabra "Kohl-rabi" ( $F, G)$.

number of seeds set in each pod and also to the position of the seed matured. Fig. 15 shows matured pods of various shapes in $F_{1}$ D plants. Matured pods of radish show a strong tendency to take the direction parallel to gravity, notwithstanding the direction of branches on which they stand. In Brassica species, how- 
ever, the pod-axis takes a definite angle relative to the branch. The former situation prevails in the $F_{1}$ hybrids, though much less in its extent.

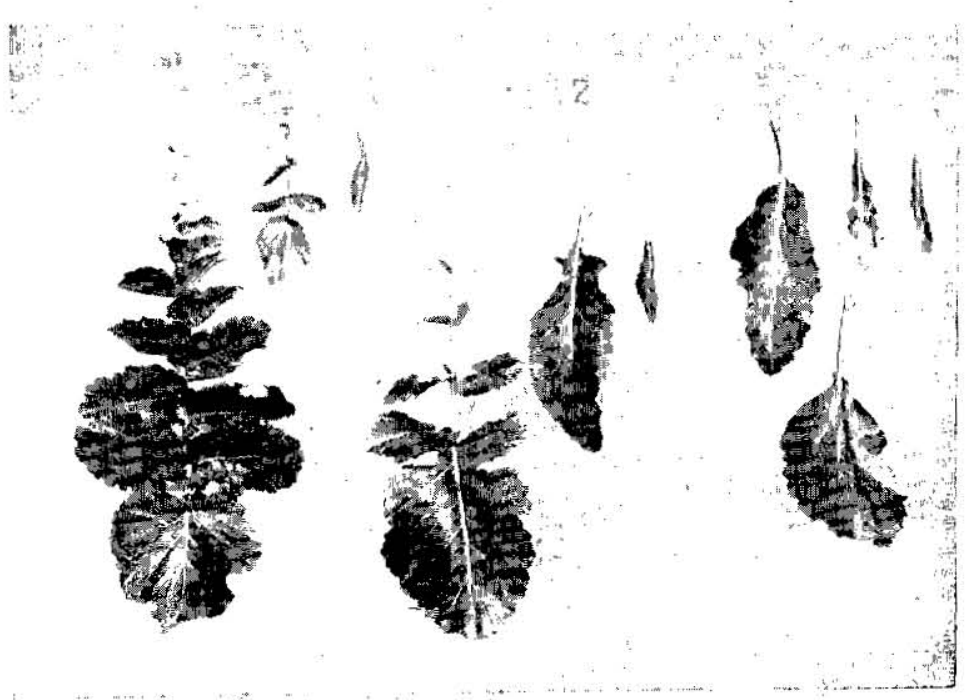

Fig. 12. Leaves of R. sativus "Harumati", $\mathrm{F}_{1} \mathrm{E}$, and B. alboglabra, from left to right.
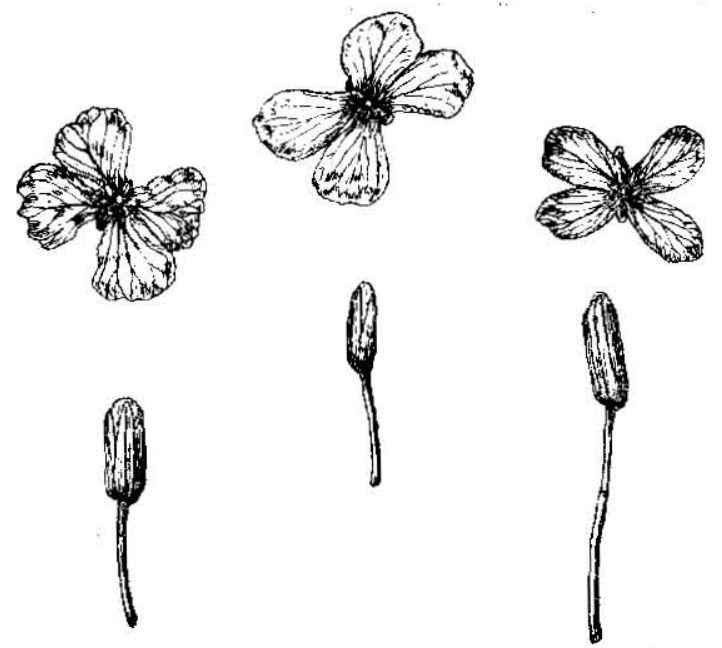

Fig. 13. Flowers in full bloom and in their bud stage. From left to right; $R$. sativus, $\mathrm{F}_{1}, \mathrm{D}$ and B. oleracea. $\times 1$. 

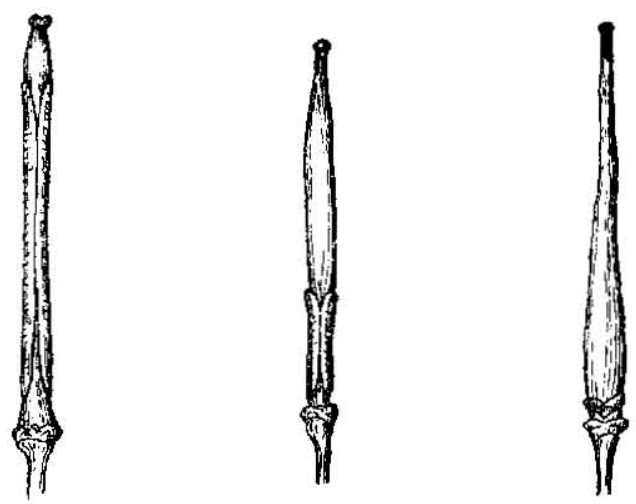

Fig. 14. Ovaries at full anthesis from left to right; $B$. oleracea, $\mathrm{F}, \mathrm{D}$, and R. sativus. $\times 2$.
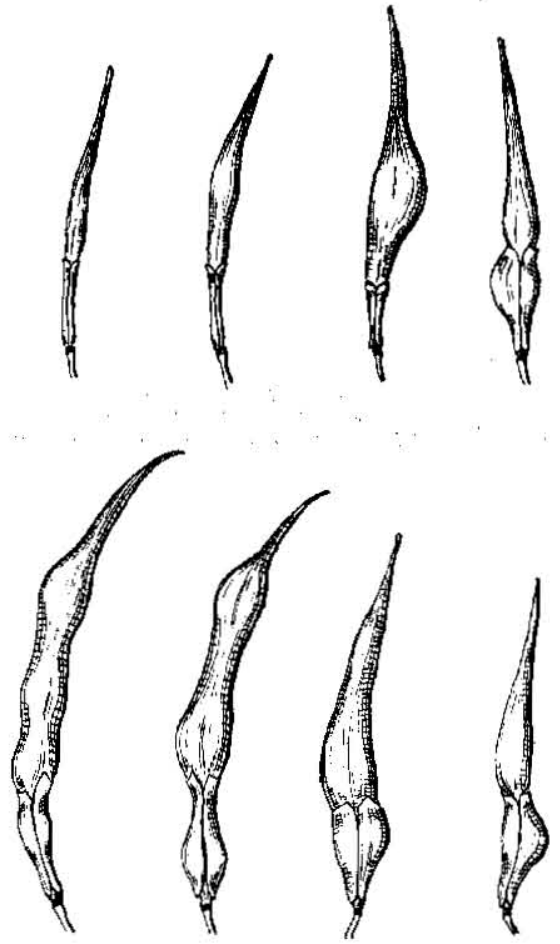

Fig. 15. Different shapes of matured pods of $R$. sativus $\times$ B. oleracea $\left(\mathrm{F}_{1} \mathrm{D}\right), \times 1$. 


\section{Fertility of $F_{1}$ hybrids and the results of breeding experiments}

$F_{1}$ hybrids show, as a rule, very high degree of sterility, although some ovaries show parthenocarpic growing to some extent. $\mathrm{F}_{1}$ 's $\mathrm{A}, \mathrm{I}, \mathrm{J}$ and $\mathrm{K}$ were completely sterile, producing no seed at all even under open pollination. F1's D (Fig. 16), H (Fig. 17), G and E (Fig. 18) produced a few seeds and their later generations could be traced. The author carried out extensive artificial cross-pollinations on $F_{1}$ 's $I$ and $J$ with the pollens of various sources, i.e., pollens from $2 \mathrm{n}$-radish, $2 \mathrm{n}$-cabbage, $4 \mathrm{n}$-radish, $4 \mathrm{n}-$ B. alboglabra, $4 \mathrm{n}$ -

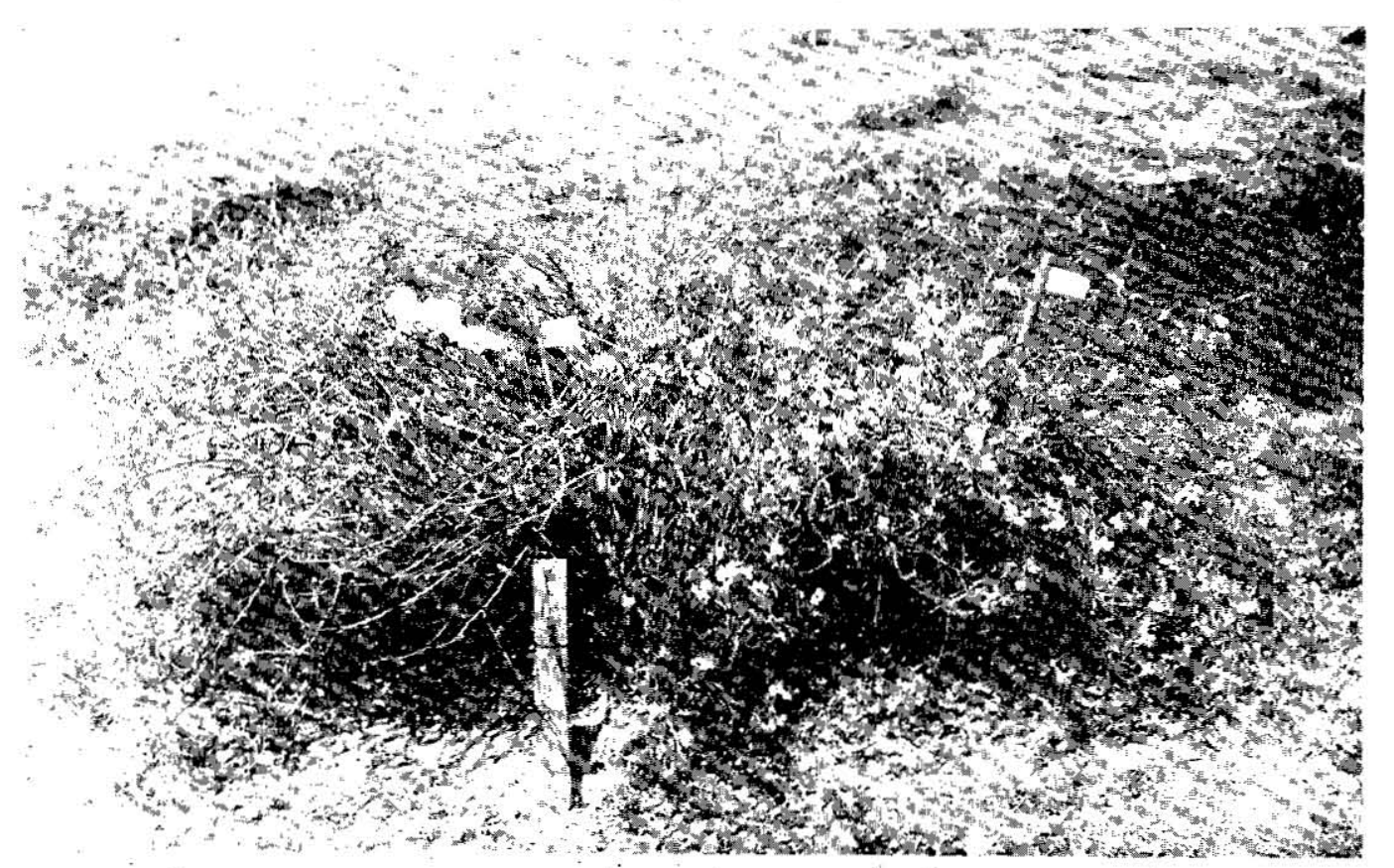

Fig. 16. R. sativus "Harumati" $\times$ B. oleracea "Kohl-rabi" $\left(F_{1} D\right)$.

B. pekinensis and an allopolyploid (amphidiploid) Raphanus-Brassica, but did not succeed in obtaining any viable seed. On the other hand, 112 flowers of $F_{1} H$ produced 36 pods (32.14 per cent. set) under natural conditions. Average length of matured pods then raised under open pollination reached $3.26 \mathrm{~cm}$. Since some of those matured pods were very small and contained no seed, average number of seeds obtained in one pod was only 0.83 , in a marked contrast with the status in Raphanus, of which ten 
varieties produced 3.1-6.0 seeds per pod, or 4.3 in an average, in the same season. While about 50 flowers of $F_{1} H$ hybrid pollinated with cabbage or radish did not produce any seed at all, though in

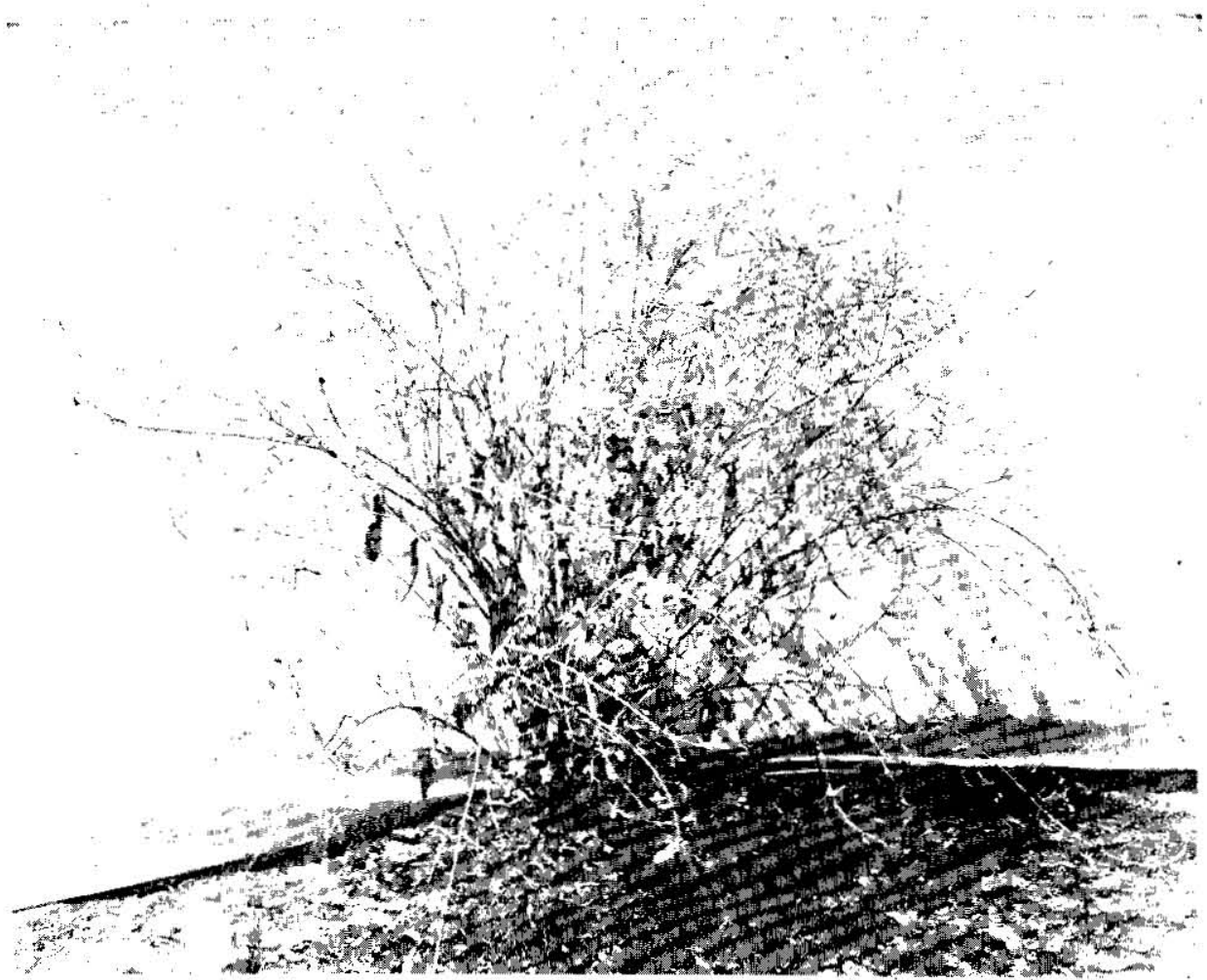

Fig. 17. R. satious "Syōgoin" $\times$ B. oleracea "Succession" $\left(\mathrm{F}_{1}\right.$ H).

the following two crossings positive results were obtained; (i) 26 flowers pollinated with an allopolyploid Raphamis-Brassica, 37/38 $\mathrm{F}_{1}-6,2 \mathrm{n}=43$, produced 6 seeds in 6 matured pods; (ii) 32 flowers pollinated with $4 \mathrm{n}$ radish plant, $37 / 38 \mathrm{~T}_{4}-336$, produced 4 seeds in 9 matured pods. One of the two $F_{1} D$ plants, $29 / 30 F_{1}$ (2)-3 (Fig. 16), was again completely sterile, while the other one, $29 / 30 \mathrm{~F}_{1}(2)-2$, showed partial fertility producing 137 matured pods out of 1862 flowers examined (7.36 per cent. set). From 203 flowers of $F_{1} G$ plant the author also obtained 71 pods ( 35.0 per cent. set), the average length of which being $2.98 \mathrm{~cm}$. Average numbers of seeds contained were respectively $0.7,0.6$ and 0.3 for their long, medium and short 
pods. A very slight partial fertility was also noticed rather uniformly in 5 sister plants of $\mathrm{F}_{1} \mathrm{E}$ hybrid (Fig. 18), producing only a few $F_{2}$ seeds. As mentioned elsewhere, $F_{1}$ 's I, J and $\mathrm{K}$ overlived

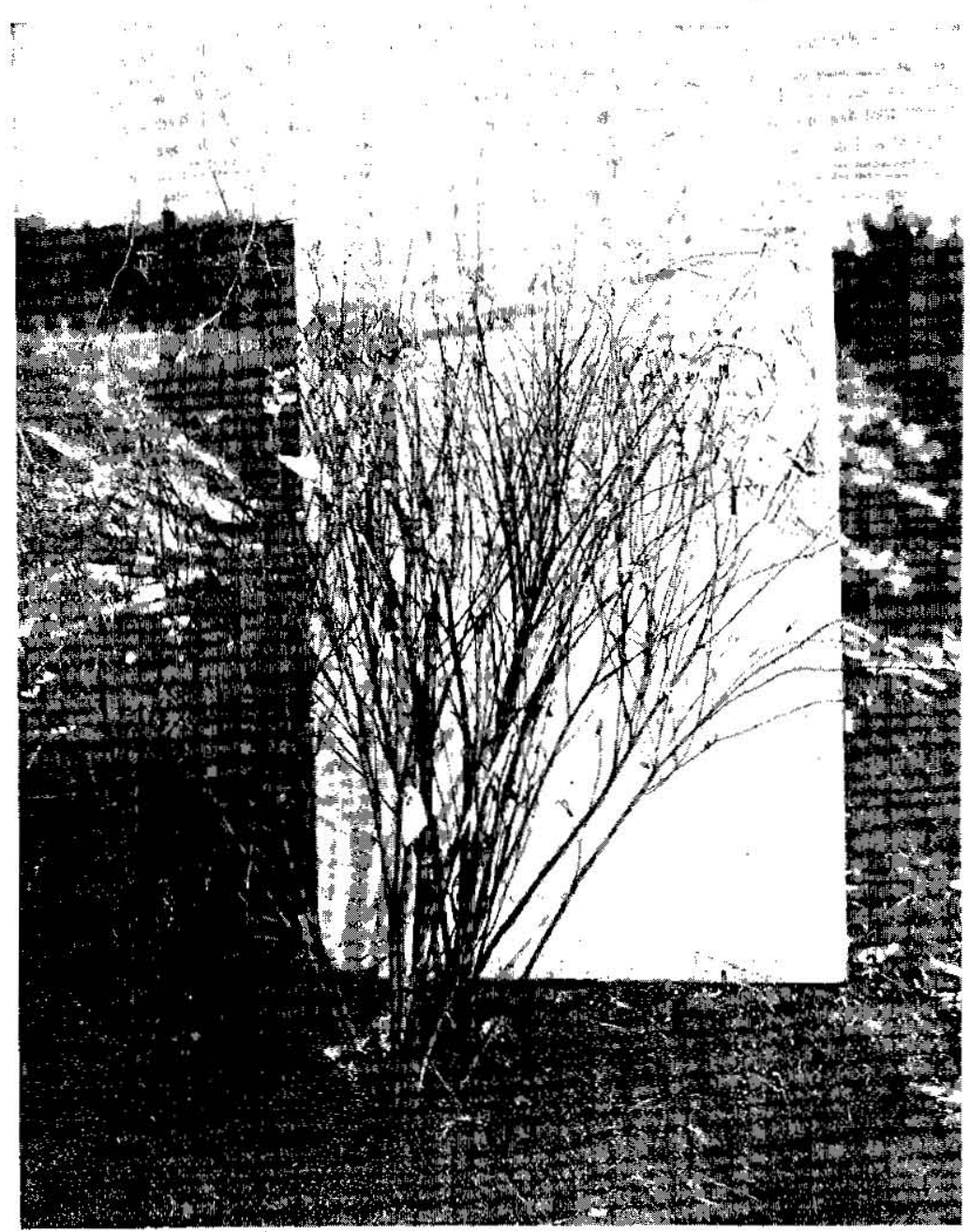

Fig. 18. R. satimus "Harumati" $\times$ B. alboglabra $\left(\mathrm{F}_{1} \mathrm{E}\right)$.

the second year of their sowing and showed again vigorous growth and blooming in the following season, showing no different status in both their morphologic and physiologic behaviours. KARPECHENKO (1927) reported that his $123 \mathrm{~F}_{1}$ hybrids were fully sterile 
at the end of the first growing season, although some individuals remained in a vegetative condition. In the second season, however, he obtained 19 partially fertile plants out of 90 plants, which grew up from preserved stumps of the former year. The fertility grades of his $\mathrm{F}_{1}$ hybrids were quite variable, for he could collect 189 seeds from the most fertile plant, as against only one or two from the least fertile one. Generally speaking, the fertility in the $F_{1}$ hybrids treated by the author was very low, and complete sterility was met with in several cases. When partially fertile, its grades are clearly variable with individuals, even within the sister plants of the same crosses. A similar phenomenon was always noticed by several workers (KARPECHENKO, 1S24; RICIHARIA, 1937a; KAKIZAKI, 1927).

The author obtained several $F_{2}$ seeds from some $F_{1}$ hybrids as described above, and the results of studies on the later generations of such hybrids will be dealt with in future papers of this series.

\section{Cytology of $\mathrm{F}_{1}$ hybrids}

Cytological investigations have been carried out with all the hybrid plants raised, and the results obtained will be summarized in this place with special reference to some abnormal features encountered. Meiosis in $\mathbf{F}_{1} \mathbf{A}$ hybrid has been reported already by the author (FukUshima, 1929).

\section{(1) Somatic chromosomes.}

Somatic chromomes are counted and examined in the root-tip cells of $F_{1} A$ and also in the ovary tissues of $F_{1} D$. No detailed morphological studies on the somatic chromosomes, however, have been entertained in this occasion. Thus the number of chromosomes of the $F_{1}$ hybrids is usually determined at the meiotic phases. All the $F_{1}$ hybrids contain exclusively 18 chromosomes, the sum of 9 gametic chromosomes of each parental species.

(2) Microsporogenesis.

Roughly speaking, the course of meiosis is carried through similarly in the hybrids above described, though minor peculiar procedures or irregularities are naturally unavoidable for those of 
different origins. Throughout the following investigations, special attentions were given to the association of chromosomes at the heterotypic nuclear division.

Prophase: In the resting nucleus of the hybrids there appear pro-chromosomes as in the parental species. Owing to a very small size of the nucleus, detailed study of chromosomes in zygotene or in early diplotene stage is practically impossible. Thus the author's attentions were concentrated chiefly on the nucleus in diakinesis or in heterotypic metaphase. No special irregularities are met with in the early prophase, excepting the protrusion of nuclear substances into cytoplasm, which occurred rather frequently in $F_{1} \mathrm{E}$ hybrids (Figs. 19-22). In a large number of late prophasic cells nuclei are protruding a part or parts, while in other cells the protrusion products of various appearances, one large and a few small accessory nuclei, usually $1-4$ in number, or two nuclei of somewhat equal size are observed (Fig. 21). The protrusion of a part of the nucleus seems to occur first in the premeiotic resting nucleus resulting in the production of two or more nuclei

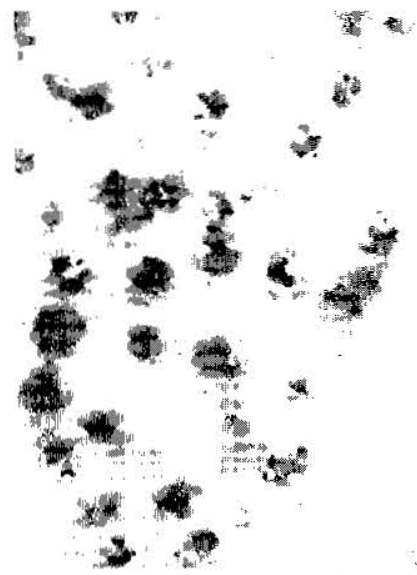

Fig. 19. PMCs in meiotic prophase, showing nuclear protrusion $(\mathrm{F}, \mathrm{E})$. in one PMC. Protruded nuclei, at a glance, somewhat resemble those in cytomixis, but the behaviour of these nuclei in later division stages clarifies that the situation is quite different. The author did not notice the occurrence of cytomixis in the $F_{1}$ hybrids.

Diakinesis: In diakinetic nuclei, there appear one or two nucleoli, two in the majority of cases, and a corresponding number of chromosomes, according to the degree of chromosome associations. Diakinesis was examined in several $F_{1}$ hybrids, i.e., $F_{1}$ 's A, I, D and E. No statistical examination of chromosome association was carried out for this stage of meiosis. Bivalent chromosomes in this stage, however, are clearly discriminated from the univalent ones. A diakinetic nucleus in $F_{1} D$ (Fig. 23), contains 18 univalent chromosomes, showing no association of any chromosomes. Satellite-like bodies, which usually appear in the materials 

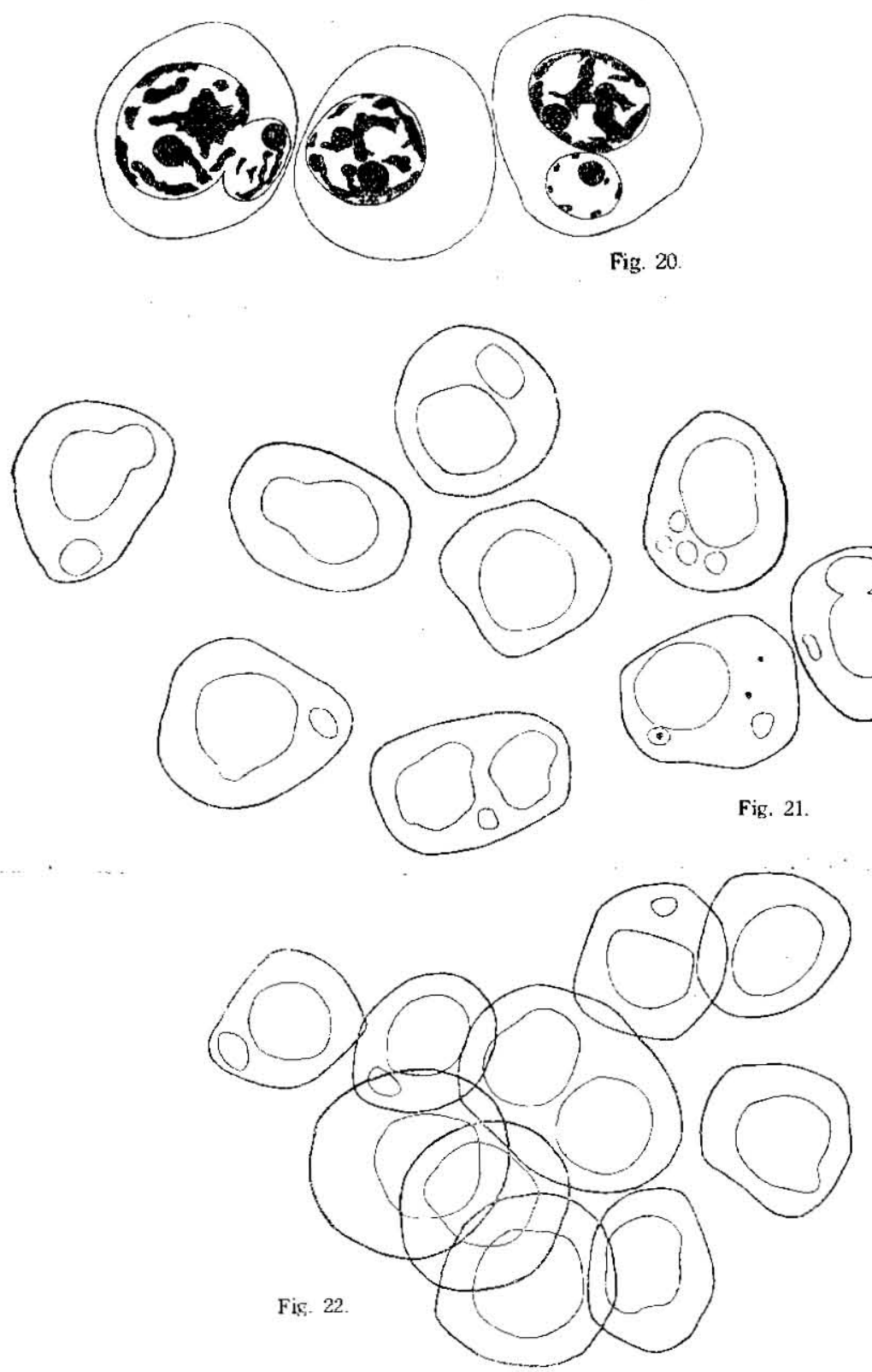

Figs. 20-22. Various appearances of PMCs in meiotic prophase, showing nuclear protrusion or containing protrusion products of various kinds. Fig. 22 shows several tetraploid PMCs produced through certain premeiotic irregularity $\left(F_{1} E\right)$. 
fixed with Bouin's solution and cut in paraffin, can be noticed in the figure. The number and size of such bodies vary with the nucleus, and they remain until the heterotypic anaphase, though much less in number. In $F_{1} E$ material, the author also observed such satellite-like bodies. Fig. 24 represents an abnormal PMC found in $\mathrm{F}_{1} \mathrm{E}$, containing two diakinetic nuclei which are considered to have resulted by the process of nuclear protrusion.

Heterotypic division: The diakinetic nucleus then passes into the prometaphase, losing the nuclear membrane thereby, and the - chromosomes coming into a close assemblage in the centre of the nucleus (third contraction), then again the chromosomes disperse, but now on the equatorial plane. As mentioned above, the chromosome association occurs in variable degrees with the nucleus, also showing different kind of association procedure for each $\mathrm{F}_{1}$ hybrid. In the PMCs of $\mathrm{F}_{1} \mathrm{~A}$ examined, 18 univalent chromosomes are counted exclusively in the heterotypic metaphse, showing no true bivalents at all. Such non-association of chromosomes also prevails in $F_{1} D$ and $F_{1} E$. Though a few I-M plates of $F_{1} D$ with 17 chromosomes were observed, the author could not prove positively any case of true gemini formation in that hybrid. Thus in these three kinds of $F_{1}$ hybrids, the mode of chromosome association seems to be quite similar, making usually no true association of chromosomes. Figs. 25 and 26 represent PMCs of $F_{1}$ D, containing respectively 18 univalent metaphasic chromosomes. In Fig. 27 one univalent chromosome in the equatorial region shows splitting, two sateliite-like bodies being also detectable. In Figs. 28 and 29, a side and a polar views of $\mathrm{I}-\mathrm{M}$ cells of $\mathrm{F}_{1} \mathrm{E}$, one chromosome is found respectively out of the spindle region. KARPECHENKo's (1924, $1927 \mathrm{a}, \mathrm{b}$; 1928) $\mathrm{F}_{1}$ hybrids in none chromosomal association behaved quite similarly to the present three $F_{1}$ hybrids.

In the other $F_{1}$ hybrids raised by the author, i.e., $F_{1} H, F_{1} I$, $F_{1} J, F_{1} K$ and $F_{1} G, 6$ plants altogether, association of chromosomes is noticed usually, though the number of associated chromosomes varies. The occurrence of chromosome pairing in the $F_{1}$, Raphanus sativus $\times$ Brassica oleracea, is first made known by RichHARIA (1937a) with his Cambridge materials. In the same year, U, Midusima and SAITô (1937), in Japan, also reported the occurrence of 1-3 bivalent chromosomes at $\mathrm{I}-\mathrm{M}$ in their $\mathrm{F}_{1}$ hybrid, Brassica oleracea "Kale" $\times$ Raphanus sativus "Syögoin". RichHARIA (1937a) 


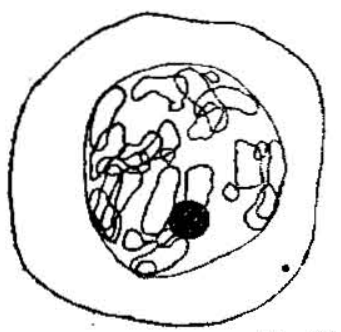

Fig. 23

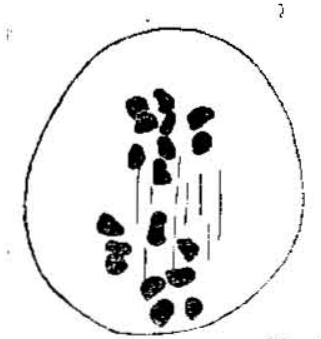

Fig. 26.

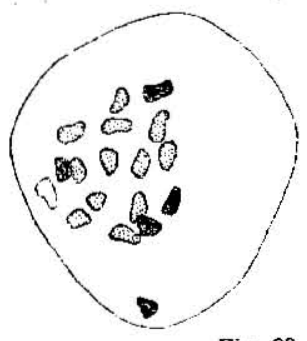

Fig. 29.

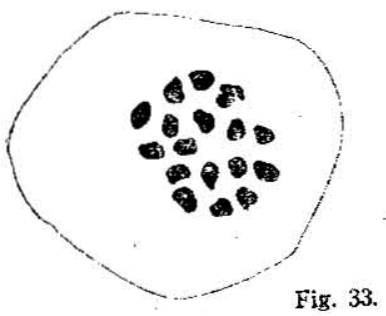

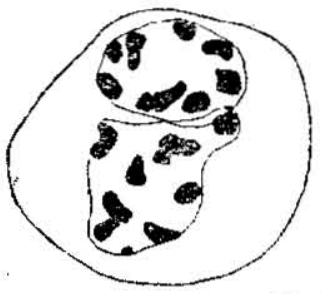

Fig. 24.

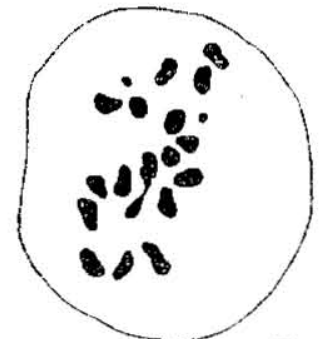

Fig. 27

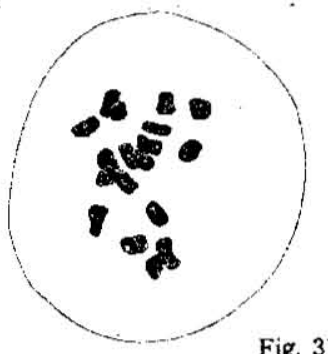

Fig. 31

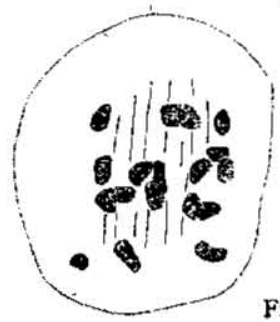

Fig. 34

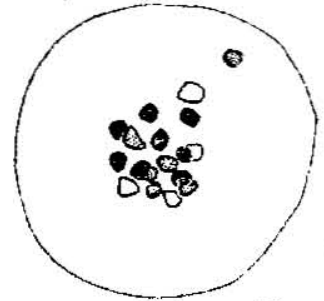

Fig. 25.

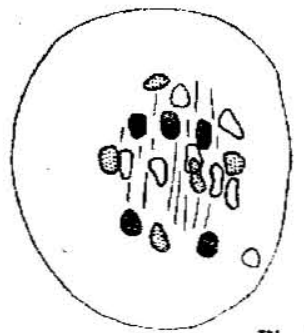

Fig. 28.

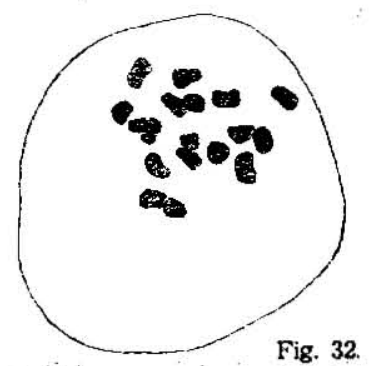

Fig. 32.

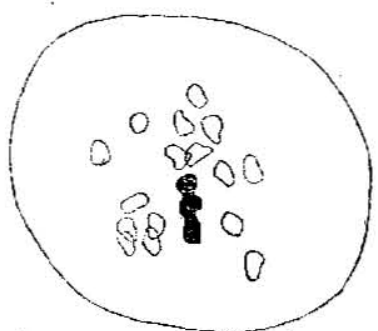

Fig. 35 .

Figs. 23-29, 31-35. Meiotic division of PMCs in $\mathrm{F}_{1}$ hybrids, $R$. sativis $\times B$. oleracea, and $R$. sativus $\times B$. alboglabra. Fig. 23, A PMC in diakinesis, showing 18 univalents and a few satellite-like bodies $\left(F_{1} D\right)$. Fig. 24 , An abnormal PMC containing 2 diakinetic nuclei which are considered to have been derived by the process of nuclear protrusion $\left(F_{1} E\right)$. Fig. 25, I-Metaphase (polar view), 18 univalents $\left(F_{1} D\right)$. Fig. 26, I-Metaphase (side view), 18 univalents $\left(F_{1} D\right)$. Fig. 27, I-Metaphase (side view), 18 univalents, one in equatorial region showing splitting, 2 satellite-like bodies being detectable ( $\left.F_{1} D\right)$. Figs. 28 and 29, I-Metaphase (side and polar views), 18 univalents $\left(\mathrm{F}_{1} \mathrm{E}\right)$. Figs. 31-33, I-Metaphase, 18 univalents. Univalents in Fig. 33 take somewhat regular arrangement on the equatorial plane $\left(\mathrm{F}_{1} \mathrm{G}\right)$. Fig. 34 , I-Metaphase (side view), 18 univalents $\left(\mathrm{F}_{1} \mathrm{E}\right)$. Fig. 35, I-Metaphase, 1 bivalent and 16 univalents $\left(F_{1} G\right)$. 
also examined $F_{1}$ PMCs in a late diplotene stage and observed variable amount of bivalent chromosomes, six being the maximum number. The whole data obtained by him in $6 F_{1}$ plants, $R$. sativus $x$ $B$. oleracea "Brussels Sprouts", at the I-M and at a late diplotene, will be referred to in the following Table 3 .

Table 3. Frequency of bivalents in $F_{1}$ hybrids, $R$. sativus $\times$ B. oleracea, at a late diplotene (a) and I-Metaphase (from RichHARIA's Table XI; 1937a).

\begin{tabular}{lccccccccccc}
\hline Hybrid No. & \multicolumn{1}{c}{ Number of bivalents } & \multicolumn{4}{c}{$\begin{array}{c}\text { Total number } \\
\text { of PMCs }\end{array}$} \\
& 0 & 1 & 2 & 3 & 4 & 5 & 6 & 7 & 8 & 9 & \\
$1-U N$ (a) & 3 & 3 & 2 & 8 & 10 & 4 & 2 & 0 & 0 & 0 & 32 \\
$1-U N$ & 2 & 2 & 2 & 5 & 8 & 6 & 1 & 1 & 0 & 0 & 27 \\
$7-3$ & 1 & 2 & 2 & 3 & 7 & 2 & 6 & 2 & 1 & 0 & 26 \\
$10-9$ & 2 & 3 & 4 & 6 & 9 & 2 & 2 & 0 & 0 & 0 & 28 \\
$10-14$ & 1 & 1 & 1 & 5 & 6 & 6 & 8 & 6 & 4 & 3 & 41 \\
$11-11$ & 0 & 1 & 2 & 6 & 3 & 1 & 4 & 5 & 3 & 0 & 25 \\
$11-12$ (a) & 1 & 3 & 5 & 7 & 3 & 3 & 1 & 0 & 0 & 0 & 23 \\
$11-12$ & 1 & 1 & 5 & 3 & 2 & 3 & 1 & 3 & 5 & 2 & 26 \\
\hline
\end{tabular}

As it is shown in Table 3, RICHHARIA observed a slighly larger number of bivalent chromosomes in the I-M than in a late diplotene stage, and in the former stage the number amounted in certain PMCs even to 9. Discrepancy in the numbers of bivalents in the two stages was attributed by him to a deep staining of the metaphasic chromosomes, in which circumstances the pairs of secondarily associated univalents might have been easily mistaken for true bivalents. Thus his results obtained in a late diplotene seem to be more reliable than those in the I-Metaphase. For convenience' sake the data of U, et al. (1937) is also repeated in Table 4.

Table 4. Frequency of bivalents in $\mathrm{F}_{1}$ hybrid, B. oleracea $\times$ $R$. sativus (from Table 1 in U, Midusima and SAITô, 1937).

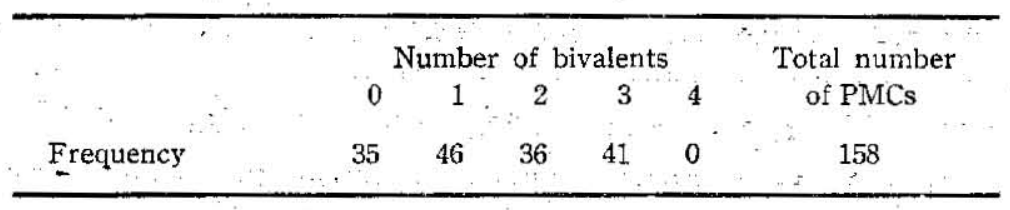


The author examined the chromosome valencies exclusively in the I-Metaphase, but he did not encounter with such a difficult situation as pointed out by RICHHARIA. The true associated bivalent chromosomes can be more or less easily determined in their side views. Statistical data of the chromosome valencies in the I-Metaphase are represented in Table 5 and Fig. 30. All of the figures used in the statistical survey are taken from PMCs which contain the total number of chromosomes contributed by the parents. Such circumstances will be easily apprehended by the examination of the following table and the representative metaphasic figures presented.

As is clearly seen in the Table 5 , the number of bivalent chromosomes is very variable, reaching to 6 in extreme. The maximum numbers of bivalents in each kind of hybrids are; 3 in $F_{I}$ $\mathrm{G}, 4$ in $\mathrm{F}_{1} \mathrm{I}, 5$ in $\mathrm{F}_{1} \mathrm{H}$ and $\mathrm{F}_{1} \mathrm{~K}$, and 6 in $\mathrm{F}_{1} \mathrm{~J}$ respectively. The average number of bivalents per one PMC varies from 1.45 to 3.58 . The author here represents the data for the two sister individuals, $F_{1} J-1$ and $F_{1} J-2$. The materials were collected from these plants respectively on two different dates. Some differences in degrees of association could be noticed in this way between the two sister plants and also between the PMCs collected on different dates. The grades of chromosome associations somewhat differ even in the same individual at different dates of observation. On the other hand, two $F_{1}$ plants of the same parental combination, raised in different years, showed different degrees in chromosome associations. $F_{1} G$ plant is a quite similar hybrid as $F_{1} D$ plant. In the latter hybrid, the author can find no true bivalent chromosome, while in the former hybrid 1-3 bivalent chromosomes are encountered in 73 per cent. of its PCMs. Trivalent chromosomes are observable in very rare occasions (Cf. Table 5). So far as the author's examination goes, trivalent chromosome occurred only in two PMCs out of 223 examined in $\mathrm{F}_{1} \mathrm{H}$ (Fig. 46), in one PMC out of 101 in $F_{1} I$ (Fig. 47), and in two PMCs out of 110 in $F_{1} K$ (Figs. 48 and 49). No. trivalent chromosome has been ascertained in other $F_{1}$ plants.

Figs. 27, 29 and 31-34 show PMC in the I-Metaphase, each containing 18 univalent chromosomes. Most of the univalents usually appear scattered at random in the sphere of spindle. In Figs. 29 and 33 , however, a large number of univalents take a somewhat 
Table 5. Frequency of PMCs with various degrees of chromosome association in I-Metaphase.

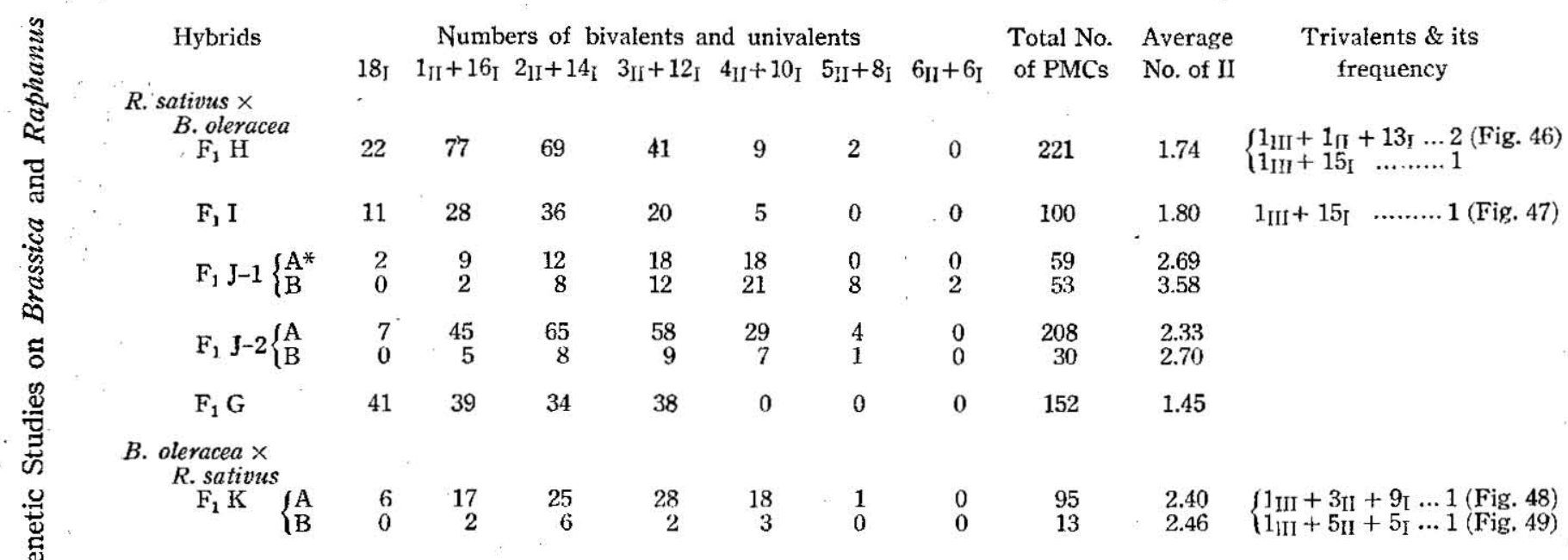

* A, B denotes that the materials examined are collected at different dates. 
regul ar configuration on the equator. On the other hand, the author observed, not infrequently, a few chromosomes situated away from the sphere of spindle (Fig. 29). Fig. 27 shows two satellite-like

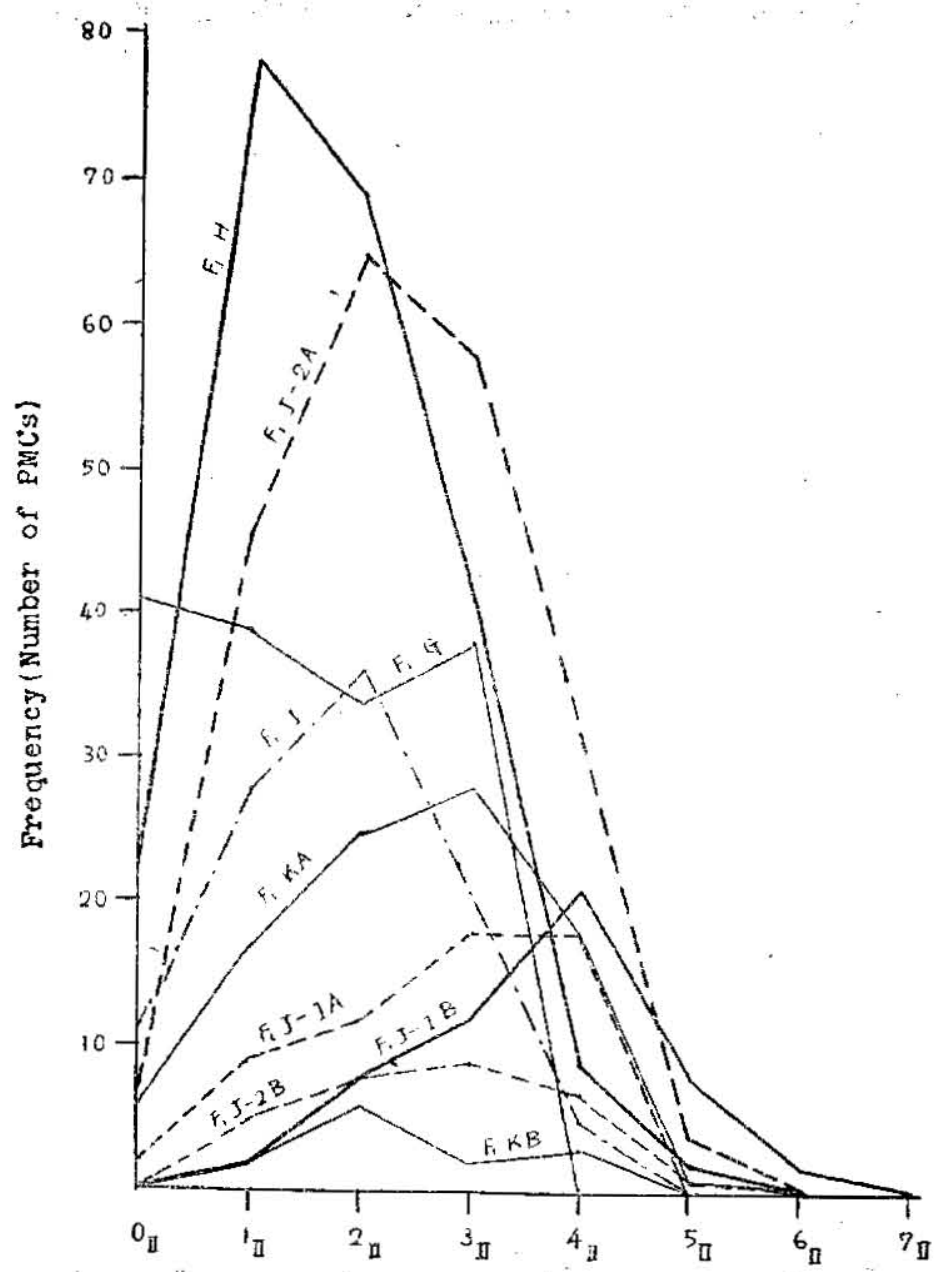

Fig. 30. Frequency polygons of the number of bivalent chromosomes per nucleus in I-Metaphase (abscissae) of various $\mathrm{F}_{1}$ hybrids, $R$. sativus $\times$ $B$. oleracea and $B$. oleracea $\times R$. sativus, depicted from data in Table 5 .

bodies with no observable connecting thread, and one split univalent chromsome. Figures 35-45 show the general appearance of PMC with some bivalent chromosomes. Figs. 35-37 show each respectively a PMC with one bivalent and 16 univalent chromosomes, 


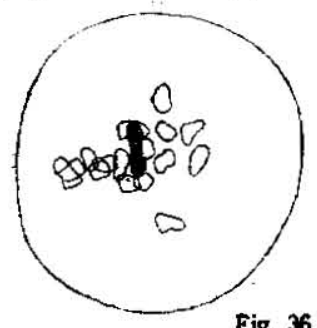

Fig. 36

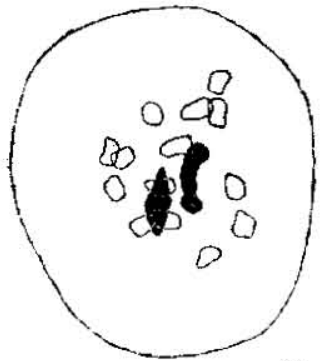

Fig 39

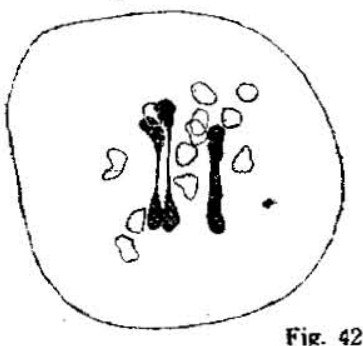

Fig. 42

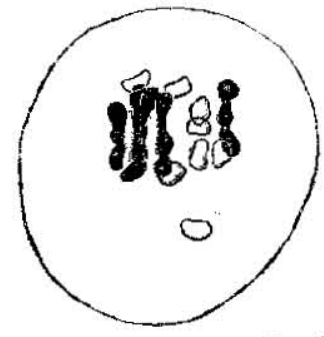

Fig. 45
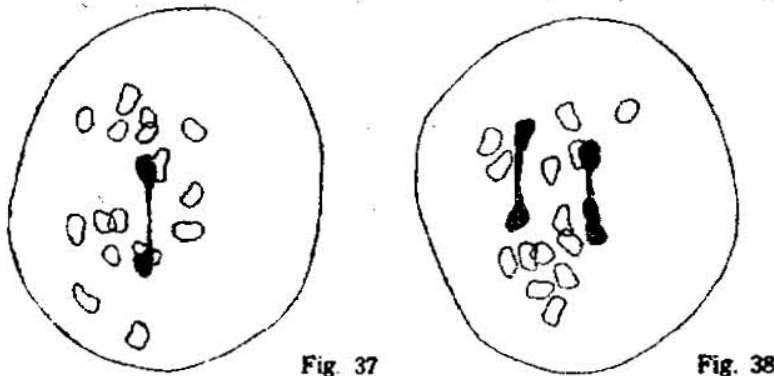

Fig. 38.
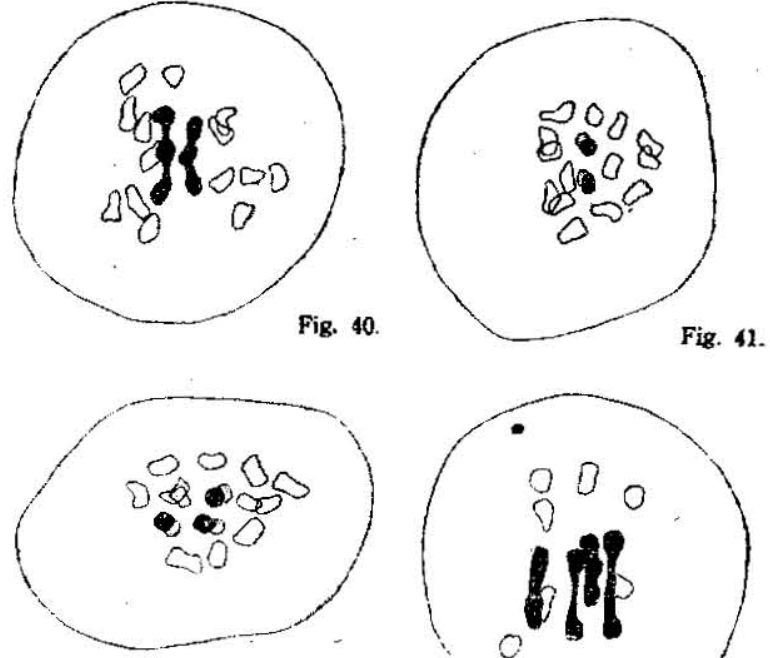

Fig. 43

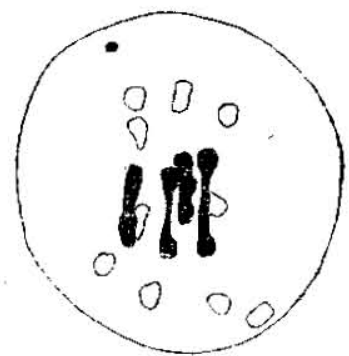

Fig. 44.
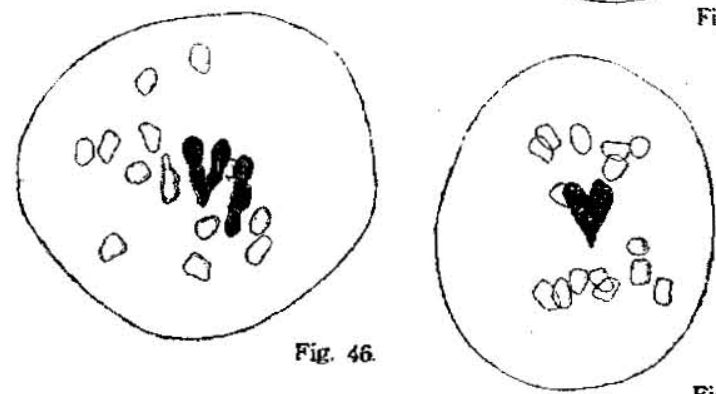

Fig. 47

*Figs. 36-47. Meiotic division of PMCs in $\mathrm{F}_{1}$ hybrids, $R$. sativus $\times B$. oleracea. Figs. 36 and 37, I-Metaphase, $I$ bivalent and 16 univalents $\left(F_{1} G\right)$. Fig. 38-41, I-Metaphase, 2 bivalents and 14 univalents on each spindle. PMC in Fig. 41 in polar view (Figs. 38 and 39 from $F_{1} H$, and Figs. 40 and 41 from $F_{1} G$ ). Figs. 42 and 43, I-Metaphase, 3 bivalents and 12 univalents on each spindle (side and polar views) ( $\left.F_{1} G\right)$. Fig. 44, I-Metaphase, 4 bivalents and 10 univalents $\left(F_{1} H\right)$. Fig. 45, I-Metaphase, 5 bivalents and 8 univalents $\left(F_{1} H\right)$. Fig. 46, I-Metaphase, showing $1_{I I I}+1_{I I}+13_{I}$ configuration $\left(F_{1}\right.$ H). Fig. 47, I-Metaphase, showing $1_{I I I}+15$ configuration $\left(F_{1} I\right)$. 
while Figs. 38-41 show 2 bivalents and 14 univalents, the last figure being in polar and others in side views. PMCs in Figs. 42 and 43 contain $3_{\mathrm{II}}+12_{\mathrm{I}}$ chromosomes, and Fig. 44 shows $4_{\mathrm{II}}+10_{\mathrm{I}}$ and Fig. 45 shows $5_{\text {II }}+8$ i chromosomes.

In the mid-metaphase, bivalent chromosomes orientate regularly on the centre of equatorial plate, while the univalent ones usually take random positions freely in the spindle sphere. Each bivalent chromosome has one or two chiasmata, not more than two, and takes somewhat ordinary shape as in the parental types. RICHHARIA (1927a) analyzed the mode of chiasma frequencies in diakinesis stage and reported that the $F_{1}$ showed only one or two chiasmata per one bivalent, while the parental types, $R$. sativis and $B$. oleracea (Brussels Sprouts), showed one, two or three chiasmata per one bivalent, and that the occurrence of bivalents with three chiasmata was 13.1 and 11.1 per cent. for these parental types respectively.

Terminalization of chiasmata in most of the pairs of $F_{I}$ hybrids is complete, resulting in rod or ring bivalents at I-Metaphase, the former being met with more frequently as shown in the figures. According to RICHHARIA (1937a), terminalization coefficient was 1.0 for the $\mathrm{F}_{1}$, while those for Raphanus and Brassica parents were respectively 0.88 and 0.87 .

Some irregularities are met with in this stage of meiosis. The tripolar spindle appears in very rare occasions instead of ordinary bipolar one. Fig. 50 shows such a PMC in $F_{1} I$, where $1_{I I}+16_{I}$ chromosomes and one satellite-like body are clearly discernible. In $F_{1} E$, in which no association of chromosomes occurs, frequently appear abnomal PMCs with two spindles (Figs. 51 and 52). These figures are considered, no doubt, to have been derived from abnormal prophasic nuclei mentioned elsewhere on this $F_{1} E$ hybrid. Two spindles in one PMC always differ in size, and the number of chromosomes found on each spindle also varies with spnidles. The total number of chromosomes found in such a PMC are, however, always 18, or the somatic number of the hybrid. Sister nuclei in such a PMC usually get into division process simultaneously, but in some cells larger nucleus forestalls the smaller accessory one in division processes (Figs. 53 and 54). There are still rarer cases, where a smaller accessory nucleus or nuclei, without showing any sign of division, remain intact throughout the meiosis.

In the I-Anaphase the bivalent chromosome first disjoins and 


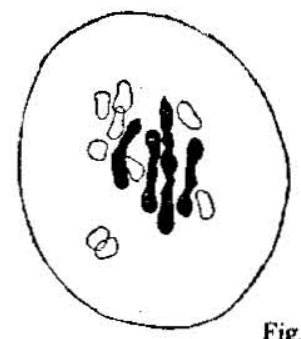

Fig. 48 .

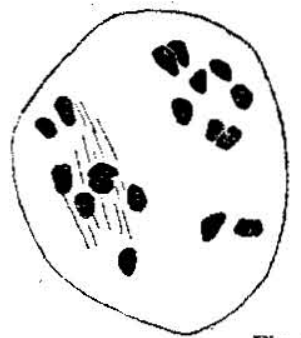

Fig. 51.

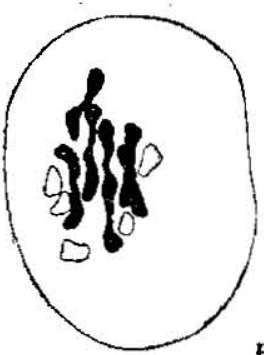

Fig. 49

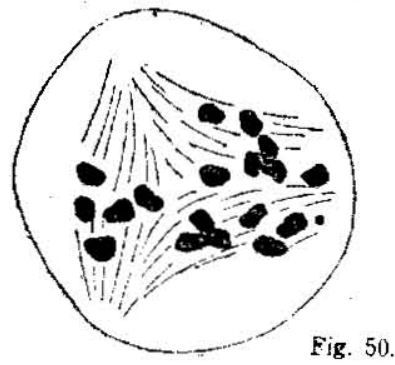

Fig. 50 .
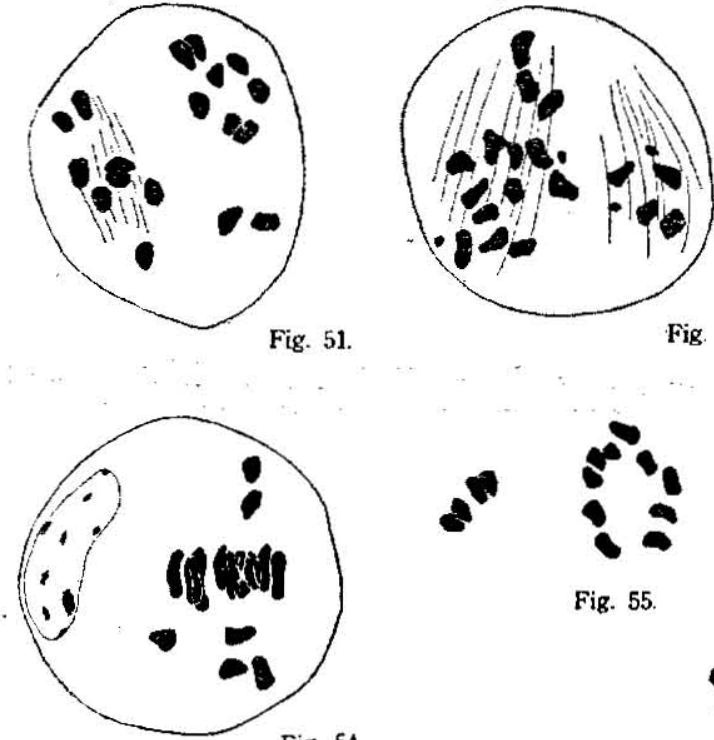

Fig. 52 .

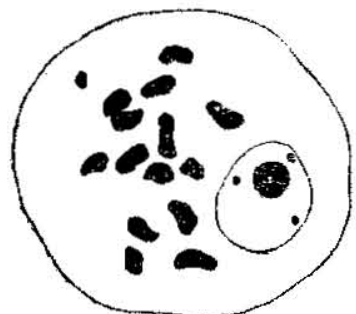

Fig. 53.

Fig. 54.

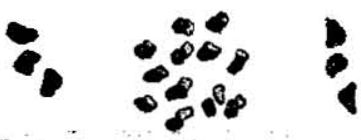

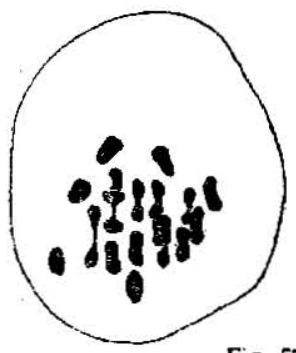

Fig. 57

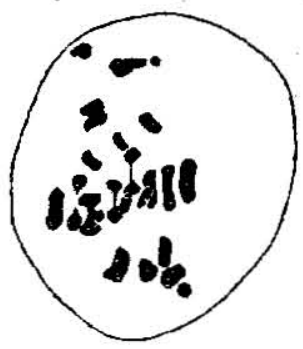

Fig. 58.

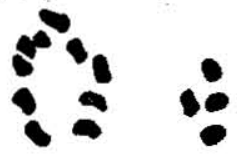

Fig. 55.

Fig. 56 .

Fig. 59.

Figs. 48-59. Meiotic division of PMCs in $\mathrm{F}_{1}$ hybrids, $R$. sativus $\times B$. oleracea, B. oleracea $\times$ $R$. sativus and $R$. sativus $\times B$. alboglabra. Fig. 48, I-Metaphase showing $1_{11 I}+3_{1 \mathrm{I}}+9_{\mathrm{I}}$ configuration $\left(\mathrm{F}_{1} \mathrm{~K}\right)$. Fig. 49, I-Metaphase showing $1_{\mathrm{III}}+5_{\mathrm{I}}+5_{\mathrm{I}}$ configuration $\left(\mathrm{F}_{1} \mathrm{~K}\right)$. Fig. 50, I-Metaphase. $1_{\text {II }}+16_{\text {I }}$ chromosomes and one satellite-like body on a tripolar spindle (F, I). Figs. 51 and 52, Abnormal PMCs at I-Metaphase, each containing two minor spindles of unequal size. Satellite-like bodies are discernible in Fig. $52\left(F_{1} E\right)$. Figs. 53 and 54, Abnormal PMCs at I-Metaphase, each containing one additive micronucleus still in prophase $\left(F_{1} E\right)$. Figs. 55 and 56, I-Anaphase. Chromosomes are depicted at 3 consecutive foci (polar view). Univalents on the equatorial region (middle focus) in Fig. 56 take rather regular arrangement, showing splitting, and those in Fig. 55 take a circular position $\left(F_{1} G\right)$. Figs. 57-59, I-Anaphase (side view), showing intact lagging univalents and split ones (PMCs in Figs. 57 and 58 are depicted from $F_{1} E$, and that in Fig. 59 from $F_{1} G$ ). 
their halves proceed toward the poles. Univalent chromosomes found scattered on the sphere of spindle show, in turn, somewhat complicated behaviours. Univalent ones which are situated nearer to the equatorial region, move toward the equator and some of them first take more or less a regular orientation, and then their splitting follows. The splitting occurs in the univalent chromosomes only on the equator or its vicinity, and the split halves of some of those chromosomes move to their respective poles, while the other univalents move toward either one of the poles without being separated into halves. The author considers such a different behaviour of univalent chromosomes to be mainly due to the difference in their position on the spindle. Univalent chromosome lying rather at a remote position from the equator, moves intact to a pole nearer to it. Some of the split halves and intact univalents often lag behind without taking part in the formation of the daughter nuclei. The chromosomes excluded in this manner out of the daughter nucleus remain in the cytoplasm as simple inclusions or accessory micronuclei. Figs. 55 and 56, depicted from two PMCs at the I-Anaphase, show the chromosomes in their polar views at three consecutive foci. The upper and lower foci show the groups of the disjoined halves and the intact univalents, and on the middle focus are the univalents on the equatorial region. In Fig. 56, the univalents, split already, take rather a regular arrangement on the equator, while the univalents in Fig. 55 assume a circular arrangement, showing that their central region has been occupied formerly by the bivalent chromosomes. Figs. 57-60 are depicted from the PMCs in I-Anaphase in their side views. The number of lagging intact univalents as well as that of split ones varies much with the cells. In extreme cases, about 12 univalents are observed near the equator. The number of such lagging chromosomes found in the I-Anaphase may correspond roughly to the number of chromosomes which have moved more or less toward the equator. Moreover, most of the univalent chromosomes which have reached the equator or its very proximity show their splitting at this stage. When the I-Anaphase is of a short duration, or the stage is passed through rapidly, this movement of the univalents is cut short to such an extent, that a smaller number of split univalents are produced in turn. If the duration is long enough, there may take place a complete splitting in a large number of univalent chromosomes, and their halves will reach op- 


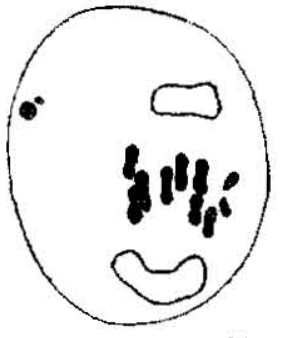

Fig. 60

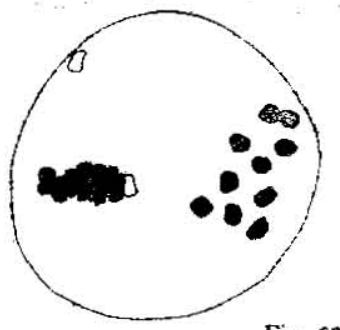

Fig. 63.

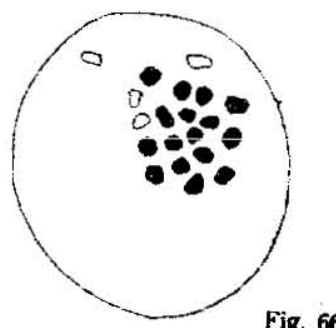

Fip. 66.

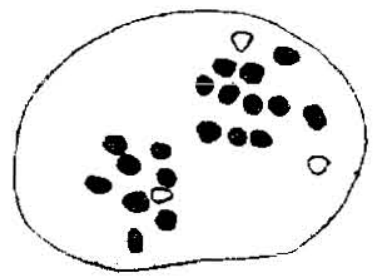

Fig. 69.
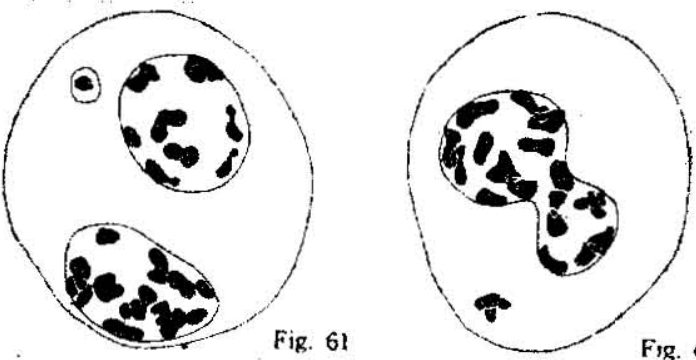

Fig. 62

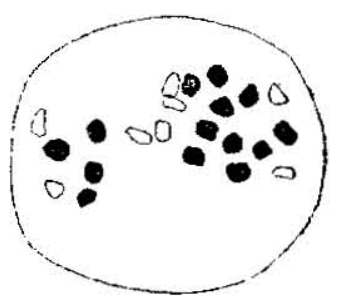

Fig. 64

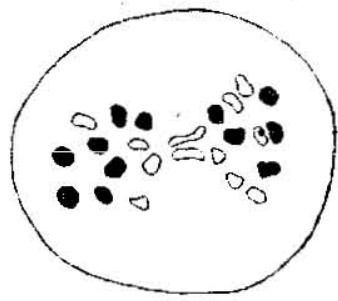

Fig. 67

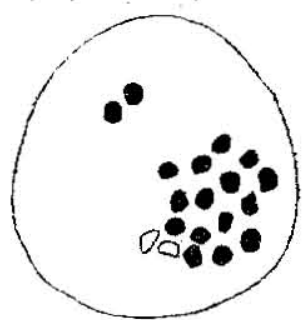

Fig 65.

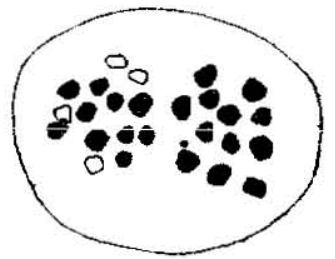

Fig. 18.

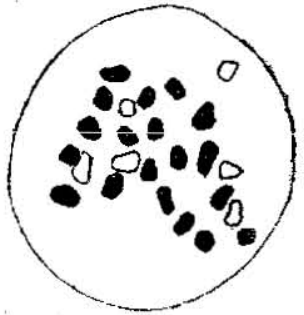

Fig. 71.

Figs. 60-71. Meiotic division of PMCs in $F_{1}$ hybrids, $R$, sativus $\times$ B. oleracea. Fig. 60, IAnaphase (side view), showing intact lagging univalents $(F, D)$. Fig. 61, Interphase. Two large nuclei, one of them contsisting of 8 diads and 5 monads, and the other 4 diads and 4 monads, and one small accessory one $\left(F_{1} D\right)$. Fig. 62, Interphase. A restitution nucleus in dumb-bell shape and 2 univalents in cytoplasm (F, D). Figs. 63-64, II-Metaphase. Each PMC containing 2 plates. Diad chromosomes are drawn in solid black and monad ones in profile $\left(F_{1} H\right)$. Figs. 65-67, II-Metaphase. Each contains one plate. Chromosomes represented in solid black are diad ones and those in profile are monad ones (Fig. 65 from $F_{1} H$, and Figs. 66 and 67 from $F_{1}$ G). Figs. 68-71, II-Metaphase. Various kinds of metaphasic plates. All the chromosomes in these figures are drawn without. discrimination of their nature, and chromosomes shown in profile are situated more or less distantly from the equatorial plane of the spindle $\left(F_{1} D\right)$. 
posite poles to give rise to daughter nuclei. When the duration of anaphase is short, and the nuclear formation begins precociously, splitting of univalents occurs only in some limited extent, and a large number of chromosomes will remain out of the daughter nuclei, producing, in turn, the interphasic PMCs with many supernumerary micronuclei. Between these two extremes, there may exist naturally many intermediate division procedures, resulting in various kinds of PMCs at interphasic stage. When the I-Anaphase proceeds much more slowly accompanied by a rather earlier formation of nuclear membrane, the restitution nuclei will result in the telophase. The frequency of occurrence of such restitution nuclei is somewhat variable with the hybrid individuals examined, and it also varies, clearly with the anthers as well as flowers even in one and the same hybrid individual. Fig. 61 represents an interphasic cell with two large nuclei and one small accessory one. One of the former two nuclei contains 8 diad- and 5 monad-chromosomes, and the other one 4 diad- and 4 monad-chromosomes, and it is made clear that at least 5 univalent chromosomes have divided at I-Anaphase in this PMC. Fig. 62 shows a restitution nucleus in somewhat dum-bell shape. Such restitution nucleus rarely contains the whole chromosome complements as it usually excludes some of those out of the nucleus. Thus in a large majority of such cells appear a few additional micronuclei. The author obtained a statistical data with the interphasic PMCs in one flower of $F_{1}$ I hybrid. One hundred and eighty-two cells out of 241 showed more or less regular course of I-division and resulted in 137 cells containing only two nuclei of similar size, and 45 cells with two large and one or more accessory nuclei; while in the remaining 59 cells restitution occurred, of which 18 cells containing no accessory micronuclei, 37 cells with one, and remaining 4 cells with two or three respectively. Such frequency of restitution will also be made known by the examination of PMCs at their sporad stage. In $F_{1} A$, which shows no chromosome association, the author has already reported on the peculiar mode of its Idivision, viz., their univalent chromosomes receive severe obstacle early in I-Anaphase and 2-6 nuclei of manifold sizes result in one cell, which soon degenerates without setting in the homotypic division processes (See Fig. 3 in Fukushima, 1929).

Homotypic division: Chromosomes do not disappear in the 
interphase and soon the II-division sets in. In the II-Metaphase, all the diad chromosomes arrange themselves on the equator and divide regularly, while the monad ones behave somewhat like the univalent chromosomes in the I-Metaphase. In the II-Anaphase monad chromosomes, however, do not divide again, though some of them show splitting, and either move toward a pole or lag behind. Thus a few micronuclei are produced after the second division. Figs. 63 and 64 show PMCs in II-Metaphase resulted through the usual course of I-division. Fig. 63 shows two plates, one, in side view, with 8 diad chromosomes and 1 monad one, and the other with 8 diad chromosomes, and one diad and one monad are found far out of the plates. The cell in Fig. 64 contains two plates, $10 \mathrm{~d}+6 \mathrm{~m}^{*}$ and $4 \mathrm{~d}+2 \mathrm{~m}$. Fig. 65 shows a large plate with $15 \mathrm{~d}+2 \mathrm{~m}$ and a very small one with only $2 \mathrm{~d}$. Figs. 66 and 67 show similar cells in II-Metaphase containing only one plate respectively. As represented in these five figures, nature of each chronosomes, diad (depicted in solid black) or monad (depicted in outlines), has been made clear rather easily by careful examination upon the shape and position of each chromosome. Figs. $68-76$ will suffice to show various kinds of PMCs in IIMetaphase, though the chromosomes are depicted in these cases without discrimination of their nature, showing some ones scattered out of the equator only differently in outlines. Figs. 75 and 76 show PMCs containing three homotypic spindles. As will be known from these figures, number of chromosomes on each spindle is quite variable. Some univalent chromosomes divide at the Idivision, so the total number of chromosomes per one PMC usually becomes to surpass 18 in this stage. Most of the PMCs with one large spindle are considered to have been caused by the restitution. The number of chromosomes on such large spindles also varies to some extent, and the spindles in Figs. $70-73$ contain respectively $20,25,24$, and 22 chromosomes. A PMC in side view, containing an exceptionally large number of monad chromosomes is shown in Fig. 74. Chromosome plates on these large spindles are usually somewhat irregular in shape, and the chromosomes themselves take more or less irregulr orientation on the spindles. Perhaps such situations have resulted from the facts

\footnotetext{
* By the abbreviations $\mathrm{d}$ and in are represented diad- and monad-chromo.
} somes respectively. 
that the restitution nuclei take more or less irregular shapes in interphase, and that a much longer time is required for such a
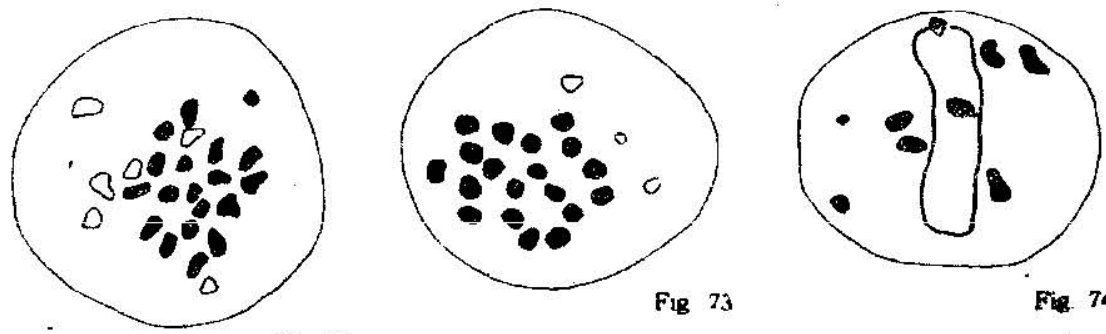

Fig 72

Fig 73

Fire. 74

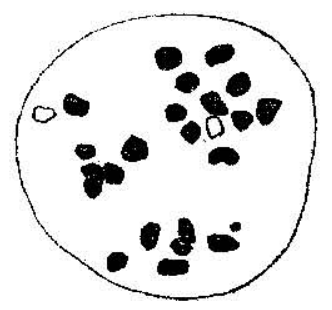

Fig. 75

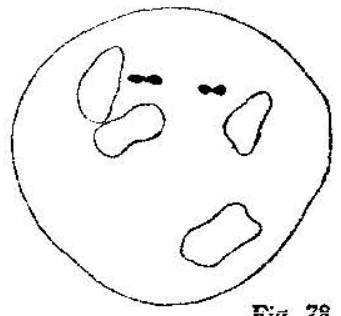

Fì, 28

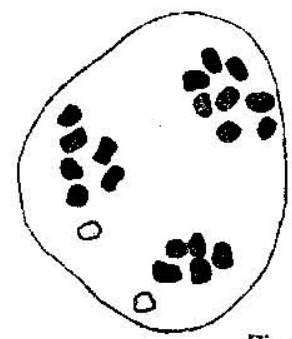

Fig. 76.

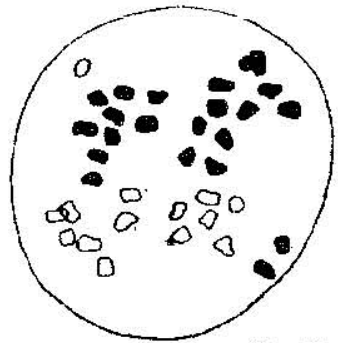

Fig. 77

Figs, 72-79. Meiotic division of PMCs in $F_{1}$ hybrids, $R$. sativus $\times B$. oleracea and $R$. sativus $\times B$. alboglabra. Figs. 72-74, II-Metaphase. Various kinds of metaphasic plates, quite similar ones as Figs. 68-71. For explanations see the latter figures $\left(F_{1} D\right)$. Figs. 75 and $76, \mathrm{I}$-Metaphase. Each with 3 homotypic spindles $\left(F_{1} E\right)$. Fig. 77, II-Anaphase. 36 chromosomes, twice the somatic number, are clearly discernible ( $F_{2}$ H). Figs. 78 and 79, II-Anaphase. Several lagging chromosomes, some of them showing split $\left(F_{1} I\right)$.

large number of chromosomes to take a regular arrangement on the equator. The author also met with another type of the large homotypic plates which are considered to have been derived from 
the fusion of two spindles at the II-Metaphase. Fig. 77 shows a PMC in II-Anaphase, in which all the 36 chromosomes, or twice the somatic number, are clearly discernible. Anaphasic spindles in Figs. 78 and 79 have several laggards, some of them showing split. The positive data toward the occurrence of second division of monad chromosomes have not been obtained so far on these $F_{1}$ hybrids, though it seems likely to occur in certain rare cases ( $C f$. FukUSHIMA, 1929). After the second nuclear division soon follows cytokinesis by invagination, and the sporads are produced.

Sporads: Various kinds of sporads, i.e., diads, triads, tetrads, pentads and other polyads, are usually produced in these $F_{1}$ hybrids. Thus the regular tetrad formation is rather of a less frequent occurrence in the hybrids. Fig. 80, depicted from one

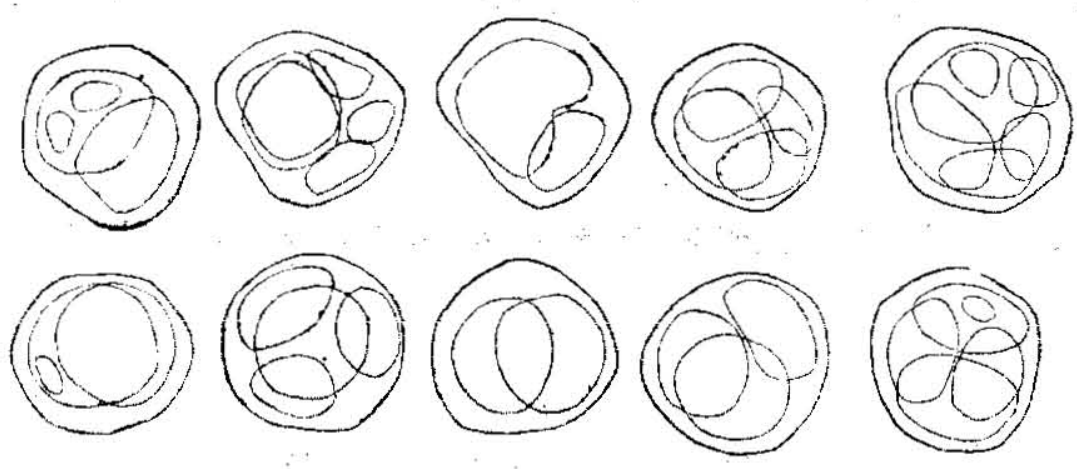

Fig. 80

Fig. 80. PMCs in sporads stage of $R$. sativus $\times$ B. oleracea $\left(\mathrm{F}_{1} \mathrm{G}\right)$. Diads, tetrads, and their various derivative types, depicted from an anther-locule.

anther-locule, shows representative figures of sporads. Fig. 81 is a photomicrograph of a part of anther-locule in this stage. Frequency of each kind of sporads, of course, much varies from anther to anther and from flower to flower. Extent of diad formation, which has a direct bearing to the viable gamete formation in the present hybrids, also shows much variation with the plants. Table 6 is compiled from the statistic data obtained from five $F_{1}$ plants, including four different crossings.

Data on each preparation slide show frequency distribution of various types of sporads in a single anther-locule examined. 
Table 6 . The frequencies of sporads of different types in $F_{1}$ hybrids, Raphanus sativus $\times$ Brassica oleracea.

Types of sporads 2 .

\begin{tabular}{|c|c|c|c|c|c|c|c|c|c|c|c|c|c|c|}
\hline \multirow{5}{*}{$\begin{array}{c}\text { Hybrids } \\
F_{1} \mathrm{H}\end{array}$} & \multirow[t]{2}{*}{$\begin{array}{l}\text { Experiment } \\
\text { No. of } \\
\text { slides }\end{array}$} & \multicolumn{5}{|c|}{$\begin{array}{c}\text { I } \\
\text { (Diads and their allied types) }\end{array}$} & \multicolumn{6}{|c|}{$\begin{array}{c}\text { II } \\
\text { (Tetrads and their allied types) }\end{array}$} & \multirow[t]{2}{*}{$\begin{array}{l}\text { I+II } \\
\text { Total number } \\
\text { of sporads }\end{array}$} & \multirow[t]{2}{*}{$\%$ of } \\
\hline & & (6) & (5) & (4) & (3), & (2) & (4) & (5) & (6) & (7) & (8) & (9) & & \\
\hline & 4995 & - & - & 5 & 1 & 8 & 64 & 36 & 40 & 6 & 2 & - & 163 & 8.6 \\
\hline & $6351-B$ & - & 5 & 9 & 16 & 16 & 116 & 37 & 6 & 1 & - & - & 206 & 22.3 \\
\hline & 6351-D & - & 1 & 5 & 3 & 2 & 44 & 38 & 26 & 4 & 2 & - & 125 & 8.8 \\
\hline$F_{1} I$ & 6364 & - & - & 13 & 11 & 15 & 93 & 43 & 16 & 1 & - & - & 192 & 20.3 \\
\hline & 6365 & - & 4 & 4 & 6 & 4 & 48 & 58 & 36 & 7 & 1 & 1 & 169 & 10.7 \\
\hline & 5474-A & 2 & 4 & 8 & 10 & 9 & 99 & 81 & 31 & 5 & 2 & - & 251 & 13.3 \\
\hline & $5474-\mathrm{B}$ & - & - & 6 & 8 & 4 & 76 & 81 & 47 & 9 & 1 & - & 232 & 7.8 \\
\hline$F_{1} \mathrm{~J}-1$ & 6354 & - & I & 13 & 46 & 46 & 73 & 19 & 3 & - & - & - & 201 & 52.7 \\
\hline & 6355-A & - & 6 & 16 & 22 & 27 & 64 & 23 & 6 & 2 & - & - & 166 & 42.8 \\
\hline & 6356-A & - & 13 & 19 & 39 & 24 & 63 & 46 & 6 & 2 & - & - & 212 & 44.8 \\
\hline & $6356-\mathrm{B}$ & 1 & 4 & 21 & 35 & 43 & 65 & 37 & $\angle$ & 2 & 1 & - & 211 & 49.3 \\
\hline & $6366-\mathrm{D}$ & 1 & 2 & 11 & 33 & 64 & 79 & 11 & I & - & - & - & 202 & 55.0 \\
\hline & 6408-A & - & - & 15 & 25 & 60 & 58 & 16 & 1 & 1 & - & - & 176 & 56.8 \\
\hline $\mathrm{F}_{1} \mathrm{~J}-2$ & $6358-\mathrm{C}$ & - & - & 8 & 42 & 113 & 27 & 2 & - & - & - & - & 192 & 84.9 \\
\hline & $6358-F$ & - & 1 & 14 & 33 & 88 & 31 & 9 & 2 & - & - & - & 178 & 76.4 \\
\hline$F_{1} G$ & 10783-A & & & 210 & & & & & & & & & 294 & 71.4 \\
\hline & 10783-B & & & 171 & & & & & & & & $!$ & 217 & 80.7 \\
\hline & $10780-\mathrm{C}$ & & & 124 & & & & & & & & & $252 \ldots$ & 48.1 \\
\hline & $10780-\mathrm{D}$ & & & 97 & & & & & & & & & 228 & 42.6 \\
\hline
\end{tabular}

1) Remarks are given in the text.

2) Sporads are classified in two major categories, I and II, and respective types denoted as (2), (3), (4), etc., show diads, triads, tetrads, and so on, and other polyads belonging in each category. 
Materials on the slides of different experiment numbers were collected at different dates, excepting the materials for Nos. 6354 and 6355 , which were collected on the same day. Different slides in the same experiment number were obtained from different flowers. Table 6 clearly shows that there exist more or less definite differences in the tendency of formation among those five plants examined. The percentage values of diads show a very wide range of variation among them, their extreme values being 7.8 and 84.7 per cent. respectively. The frequency occurrence of diad cells varies, moreover, even within the same individual, though much less in extent. $\quad F_{1} \mathrm{H}$ and $F_{1} I$ give smaller values, 8.6-22.3 per cent. in the former and 7.8-20.3 per cent. in the latter, while $\mathrm{F}_{1}$ 's J-1 and J-2 give far larger values of 42.8-56.8 per cent. and 76.4-84.9 per cent. respectively. $F_{1} \mathrm{G}$ plant gives rather large but much variable values of $42.6-80.7$ per cent. The results above mentioned point to the fact that the process of diad formation differs not only with the plants but also with the flowers of the same individual.

Pollen grains: Some of the hybrid microspores grow up to mature pollen grains, but a large number of them die out at various stages of their growth. The meiotic procedures above described show that the genomic constitution of each gamete is very variable and that the chance is very rare for the genome of Brassica or Raphanus, or for those two, to be recovered completely in one gamete. The viability of $F_{1}$ gametes is, no doubt, considered to have been governed by the degree of recovery of parental genome or genomes in their chromosome constitutions, and actually the anther-locules show various degrees in their pollen grain development. The number of matured grains in one locule is, as a rule, so small that the anther-sacs hardly dehisce at the blooming time. Fig. 82 shows various types of microspores in one locule. Figs. 83 and 84 show the young pollen grains, of which larger ones are thought to have more or less diploid number of chromosomes. Some irregular courses of pollen development mentioned below have been noticed generally in all the hybrids treated.

The author observed sometimes or rather frequently in $F_{1} E$ plants that the cytokinesis after the second nuclear division did not proceed to its completion. Such PMCs carry on growth, thickening normally their cell walls, but without being divided 


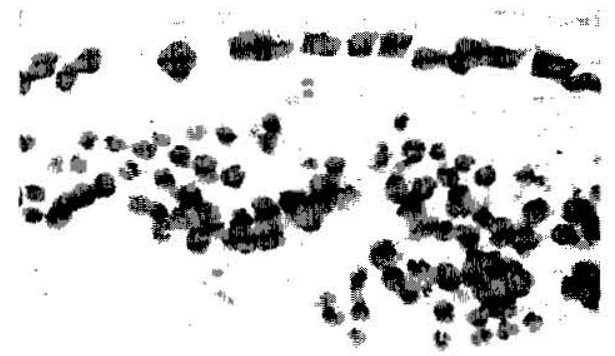

and $=0$

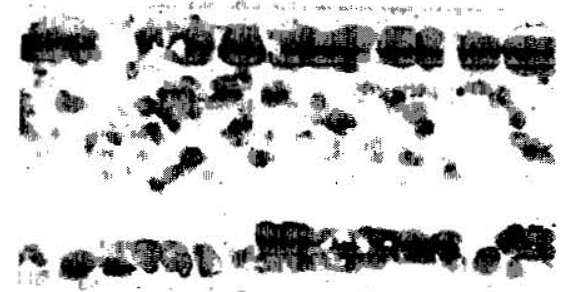

Fig. 81

Fig. 82

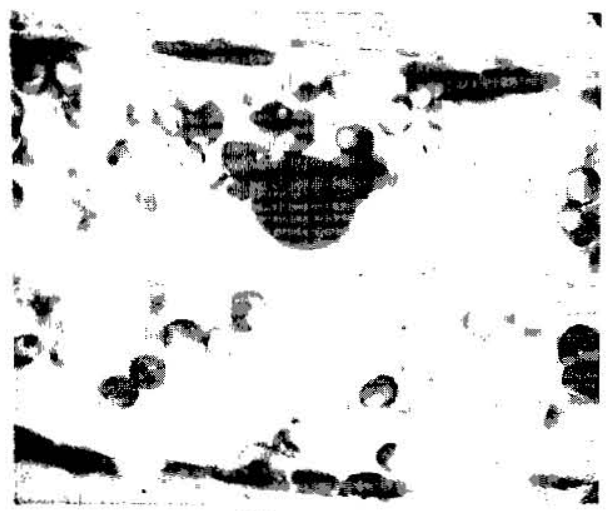

Fig. 83


Fig. 84

t.

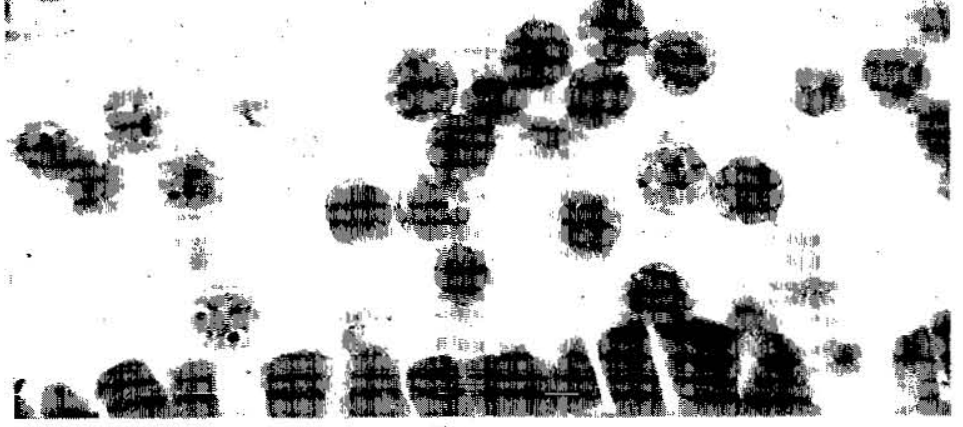

Fig. $8 \bar{s}$

Fig. 81, PMCs in sporads stage of $R$. sativus $\times B$. oleracea $(F, D)$. Fig. 82, Various types of microspores in an anther-locule of $R$. sativus $\times B$. oleracea $\left(F_{1}\right.$ D). Figs. 83 and 84 , Young pollen grains of $k$. sativus $\times$ $B$. oleracea $\left(\mathrm{F}_{1} \mathrm{D}\right)$, of which larger ones are considered to have nearly diploid number of chromosomes recovered. Fig. 85, Abnormal spores of $R$. sativus $\times B$. alboglabra $\left(F_{1} E\right)$ in some growth stage. These spores take nearly uniform size and show that the cytokinesis has stopped shortly before its completion. 
into microspores. All these pollen grains take more or less irregular outlines, though they are nearly uniform in size. Some of these grains, no doubt, grow up to maturity. Fig. 85 shows

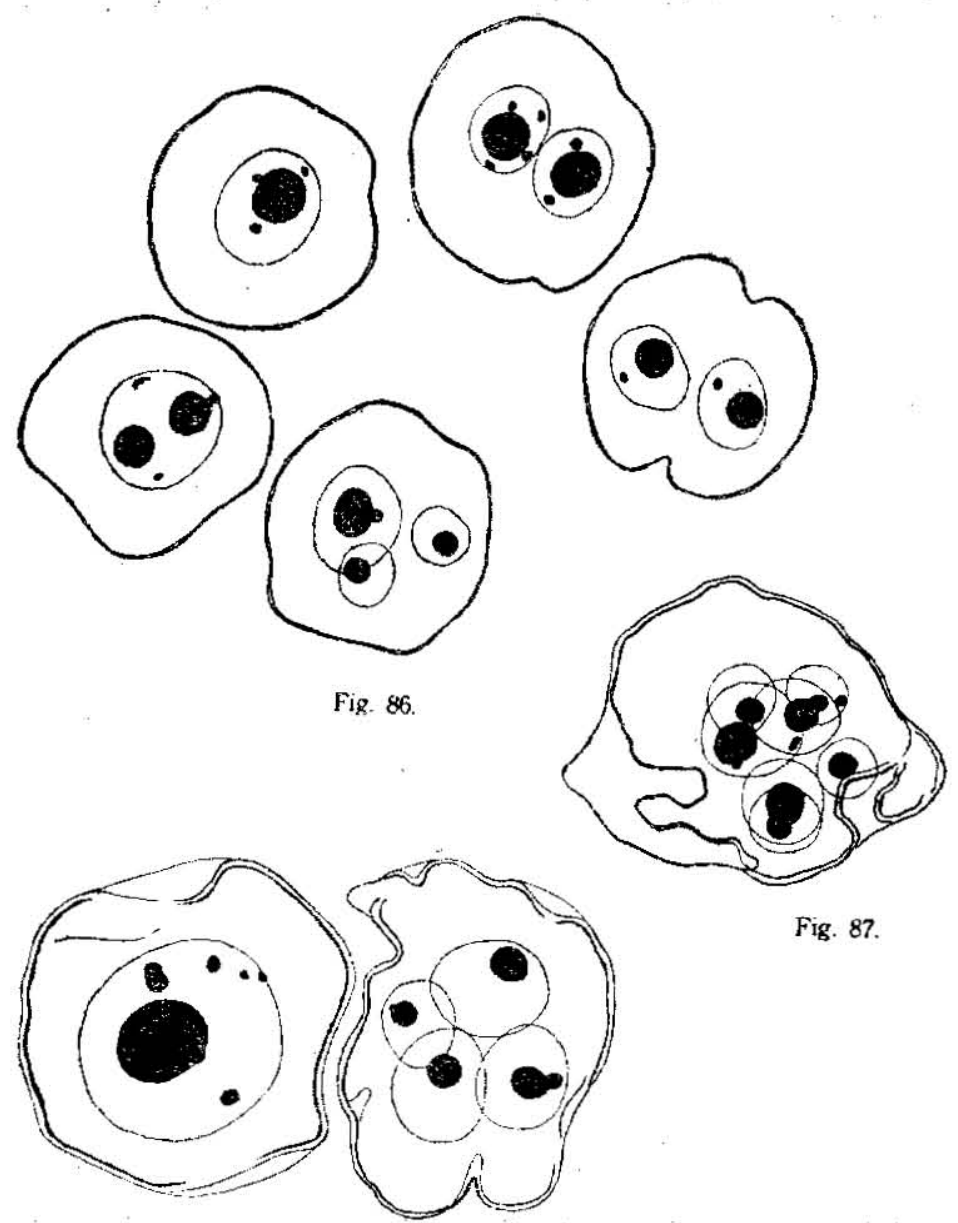

Fig. 88.

Fig. 86. Abnormal monad spores of $R$. sativus $\times B$. alboglabra in some stage of their growth. One, two or three nuclei are contained respectively (F $F_{1}$ E). Figs. 87 and 88 , Abnormal monad spores of $R$. sativus $\times B$. alboglabra in still later stage of their growth $\left(F_{1} E\right)$.

such abnormal spores, each of which containing several nuclei of various sizes. In such spore fusion of nuclei may occur. Thus Fig. 86 represents three young spores with one, two, or three 
nuclei. Figs. 87 and 88 show spores in still later stages of their growth. When a single large nucleus appears in such spore, it may contain 36 chromosomes, or twice the somatic number of the hybrid, or slightly less than 36 , if a few chromosomes become easily excluded from the nucleus. Large spore nuclei with more than 36 chromosomes may also be produced, as it is not improbable that a few univalent chromosomes become to divide twice on the meiosis in these $F_{1}$ hybrids. Such monad spores containing the didiploid number of chromosomes are also produced, not infrequently, through another course. PMCs grow up to pollen grains without undergoing meiotic divisions. Fig. 89 shows young microspores produced through such an irregular course. Here is no spore containing micronuclei in addition to one large didiploid nucleus. Fig. 90 shows two anther-locules in a still later stage. These anther-locules are filled up with a large number of young grains of similar size, which, no doubt, contain exactly 36 chromosomes. Degeneration occurs also in some of these monad spores in the course of their growing. The irregularities above described occur commonly with all the $F_{1}$ plants studied, though such ones are met with a little more frequently in both $F_{1} E$ and $F_{1} D$ plants.

Other irregularities observed: (i) All the PMCs in one anther-locule proceed, as a rule, at a uniform pace in meiosis, but in rare occasions there occur anther-locules, in which PMCs appear at several different stages of meiosis. For example, the author met with one locule in $F_{1} \mathrm{D}$ plant, in which PMCs appeared in successive stages from diakinesis to sporads.

(ii) The author observed the occurrence of giant PMCs in a group among normal diploid ones. Quite similar cases have been alrcady reported by the author in Brassica japonica (Funusuman, 1931). Giant cells occur in groups, and their original cells are considered to have been produced during the premeiotic divisions. These giant PMCs are usually of $4 \mathrm{n}$ or $8 \mathrm{n}$ in nature. Fig. 91 shows giant cells of $8 \mathrm{n}$ type in prophase and Fig. 92 shows $4 \mathrm{n}$ cells in diakinesis. In both cases those are mingled among normal diploid ones. Division processes in the giant cells are somewhat in advanced or retarded phases than in adjacent diploid cells. In Fig. 22, one of the giant cells contains two nuclei. Figs. 83 and 84 show some large spores thus produced. In such $4 \mathrm{n}$ PMCs, 


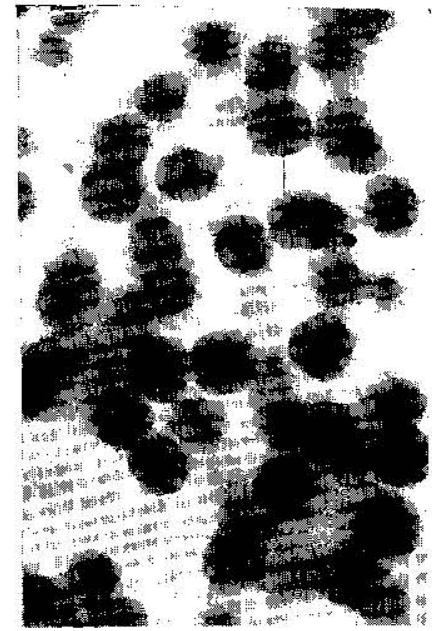

Fig. 89

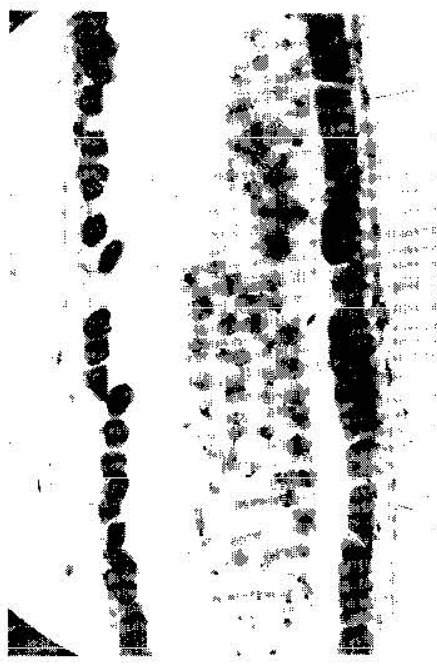

Fig. 91

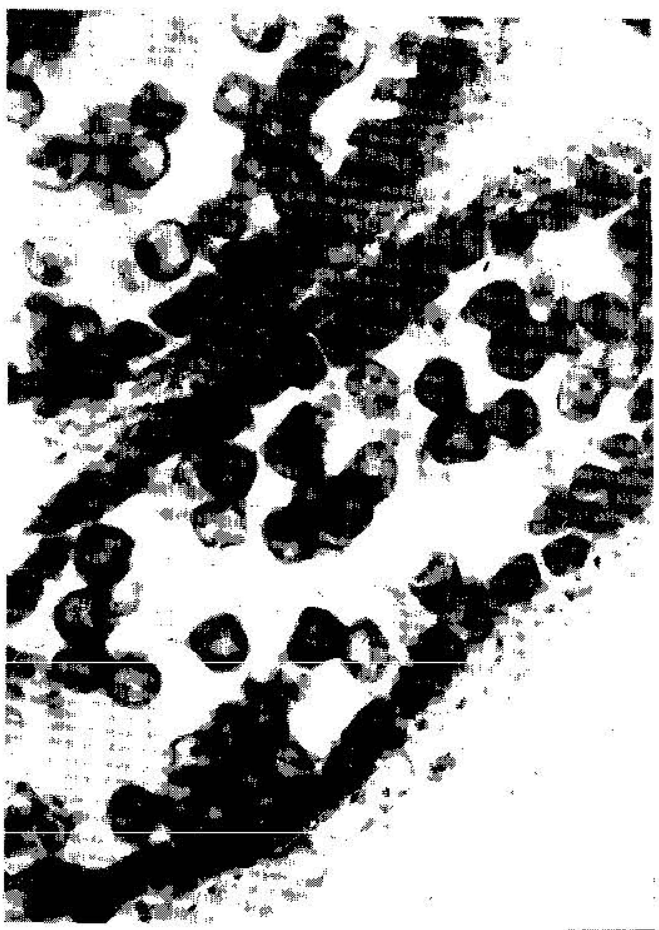

Fig. 90

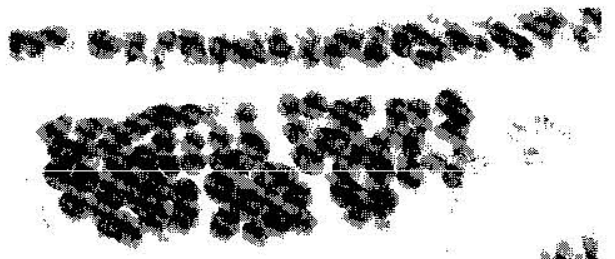

4

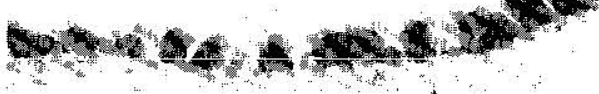

Fig. 92

Fig. 89. Young abnormal monad spores, which are considered to have been directly grown up from PMCs without undergoing meiosis ( $F_{1} E$ ). Fig. 90 , Two anther-locules of $R$. sativus $\times$ B. oleracea $\left(F_{1} D\right)$, containing young monad pollen grains only, which are considered to have been produced without undergoing meiosis. Fig. 91, A part of anther-locule of $R$. sativus $\times B$. oleracea $\left(\mathrm{F}_{1} \mathrm{D}\right)$. One $8 \mathrm{n}$ giant $\mathrm{PMC}$, in prophase, Iying among ordinary $2 \mathrm{n}$ PMCs. Fig. 92, A part of anther-locule of $R$. sativus $\times$ B. alboglabra $\left(\mathrm{F}_{1} \mathrm{E}\right)$. Group of $4 \mathrm{n}$ giant $\mathrm{PMCs}$, in diakinesis, together with normal $2 \mathrm{n}$ PMCs in prophase. 
bivalent chromosomes may be expected exclusively in the heterotypic division, as each chromosome has its homologous partner. The author actually observed 18 bivalent chromosomes in certain $\mathrm{F}_{1}$ E PMCs in the diakinesis as well as in the I-Metaphase. So it is well to expect that the meiosis in these polyploid cells, especially in the tetraploid ones, may proceed quite regularly as in the diploid balanced species, resulting in the formation of $2 n$ pollen grains. Thus, in these $F_{I}$ hybrids, there is still another course of producing polyploid gametes besides the processes above mentioned.

(iii) Plasmodium-like cells or tissues were noticed rarely in some anther-locules of $\mathrm{F}_{1} \mathrm{~A}$ and $\mathrm{F}_{1} \mathrm{D}$ hybrids. It is considered that this irregularity has a more or less intimate bearing on the irregularity described in (ii).

(3) Megasporogenesis and female gametophyte formation

The megasporogenesis of $\mathrm{F}_{1}, R$. sativus $\times B$. oleracea, was first examined by KARPECHENKO (1924) to certain extents, and he reported, in 1928, that in spite of a great number of preparations examined by him, he was not able to elucidate the process of divisions in EMC. The only one I-Metaphasic figure encountered by him showed 9 bivalent chromosomes, and he considered that degeneration set in in most of the EMCs soon after their meiotic prophase. From his results of cytological studies on $F_{2}$ hybrids, KARPECHENKo (1928) described "male and female gametes must be equal in their chromosome complex, and it is probable that the processes of their formation are also in most cases identical."

The author has studied the megasporogenesis in $\mathrm{F}_{1} \mathrm{D}$ hybrid in some details and was convinced that the processes of meiosis in EMC is quite similar as in PMCs. Following figures will suffice to show some of the general features of division processes. Fig. 93 shows EMC in diakinesis, and 18 univalent chromosomes are distinguished there. In most of the EMCs in the I-Metaphase 18 univalent chromosomes are seen, some of which have satellitelike bodies as Fig. 94 shows. Fig. 95 represents two cells in the II-division; in the upper cell 15 chromosomes are counted, and the lower cell (in the chalazal position) contains a nucleus and three chromosomes in the cytoplasm. Cytokinesis follows each nuclear 
division, and four cells, as a rule, are produced at the end of meiosis. One of these four cells, or the one lying at the chalazal end, usually divides further and embryo-sac formation starts in a

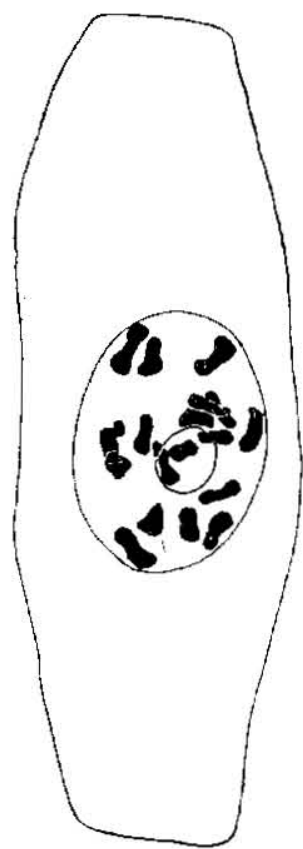

Fig. 93

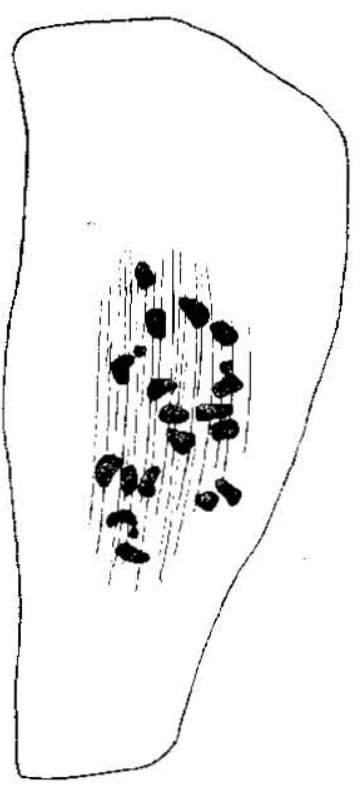

Fig. 94

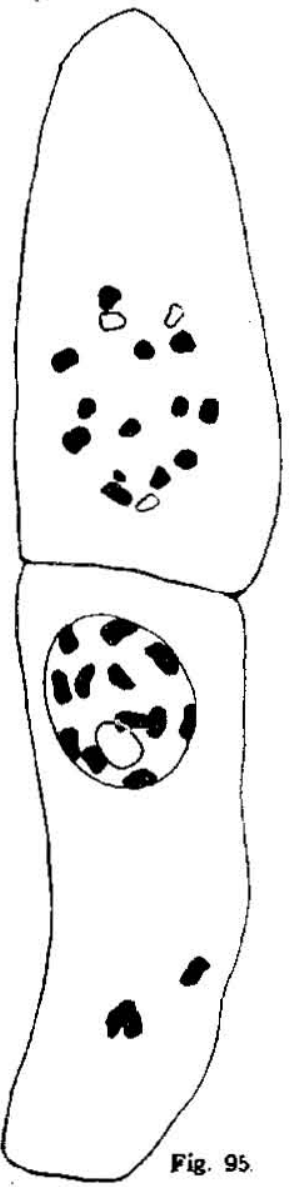

Figs. 93-95. Meiotic division of EMCs in $F_{1}$ hybrid, $R$. sativus $\times \dot{B}$. oleracea $\left(F_{1}\right.$ D). Fig. 93, Diakinesis. 18 univalents are distinguished. Fig. 94, I-Metaphase (side view). 18 univalents, some with satellite-like bodies. Fig. 95, II-division. Homotypic plate of upper cell contains 15 chromosomes, and the lower cell (in chalazal position) contains an interphasic nucleus and 3 chromosomes in cytoplasm.

quite usual manner. Mature embryo-sacs are found, however, but in a few ovules, and in a large number of ovules various degrees of degeneration processes have been observed. 
The mature embryo-sac assumes a typical appearance and contains in it two synergids, three antipodals, one egg-cell and two pole nuclei, and in the antipodal cells degeneration process has already commenced before fertilization. The formation of such mature embryo-sacs is considered to have occurred only in a small percentage of the ovules produced, and this situation may also be duely understood from the fer-

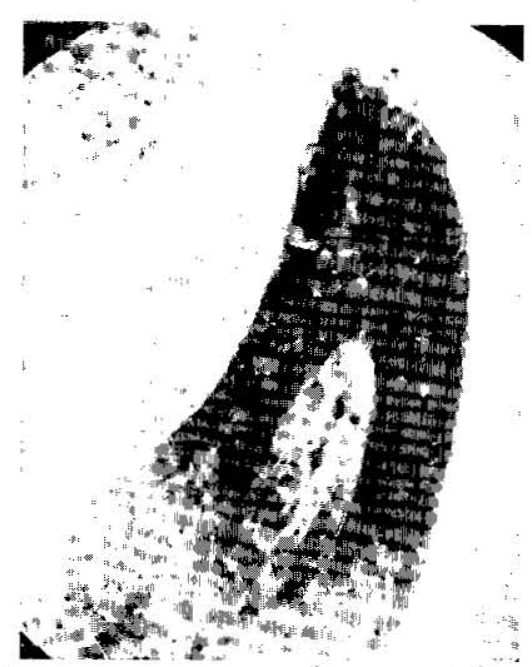

Fig. 96. A part of an ovule of $R$. sativus $\times B$. oleracea, enfolding a degenerated EMC $\left(\begin{array}{ll}F_{1} & D\end{array}\right)$. tility behaviour of the hybrids. In general, degeneration occurs at various stages of megasporogenesis as well as of the female gametophyte development. Some EMCs also degenerate without undergoing meiosis. Fig. 96 shows such an ovule with a degenerated EMC. In some ovules, EMC degenerates during meiosis without completing it, while in others, embryo-sac formation stops shortly before its completion. Fig. 97 shows an ovule, in which degeneration has occurred in a later stage of the sac formation.

After fertilization, the embryo, though very rarely, develops normally, and the division of endosperm nucleus begins simultaneously. Fig. 98 shows such a normal embryo and a large number of endosperm nuclei. The author also observed several young embryos undergoing degeneration. Fig. 99 shows such a degenerated young embryo besides many scattered endosperm nuclei already produced in the locule. Of many ovules examined, the author noticed the following abnormalities, which may have some bearing on the hybrid nature of the plant. One ovule contained one additional EMC, far apart from the other (Fig. 100). If both of those EMCs develop into viable gametophytes, a twin seed will naturally be the result. In several ovules, abnormal cell-aggregates or tissues, some ones taking an appearance like embryo-sac, are observed deposited in various parts of the nucellar tissues. Typical 


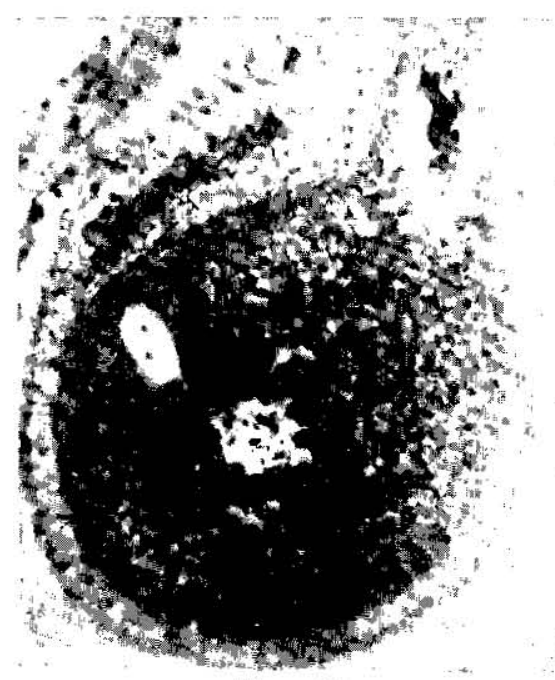

Fig. 97

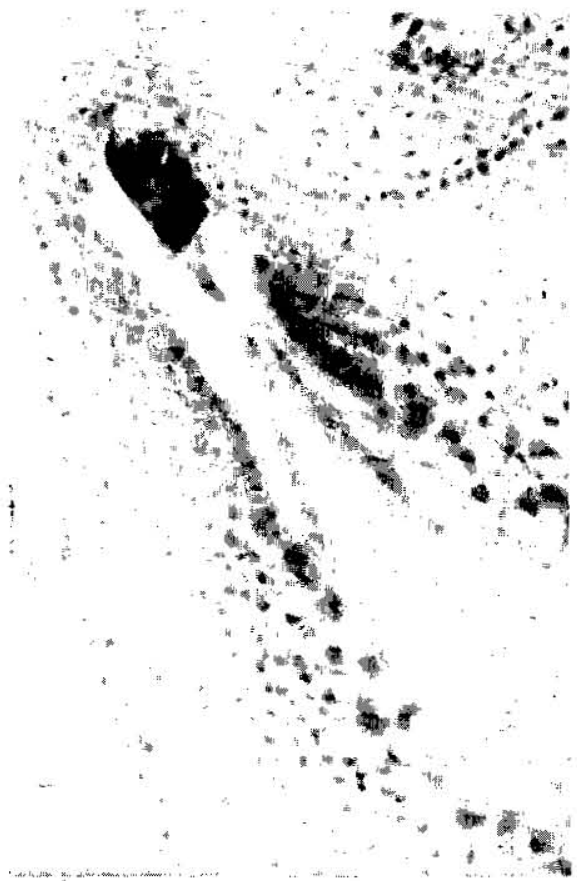

Fig. 99

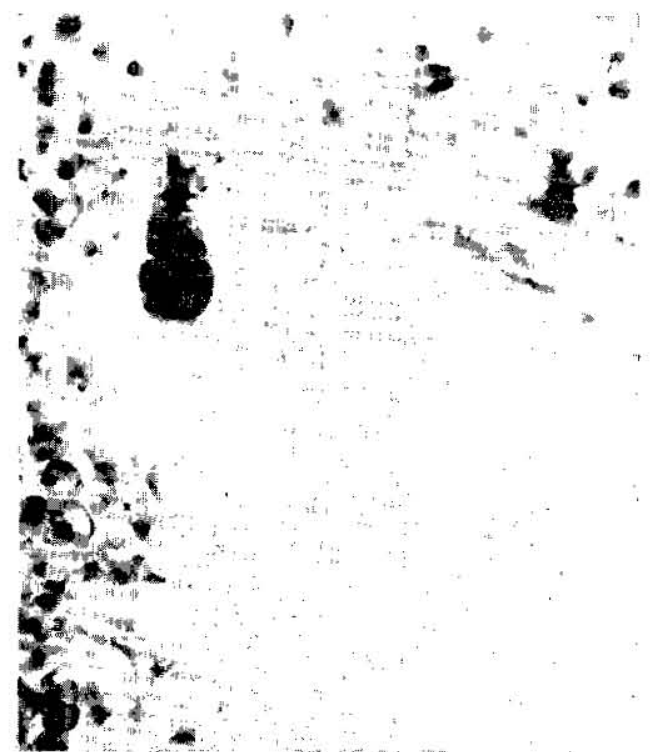

Fig. 98

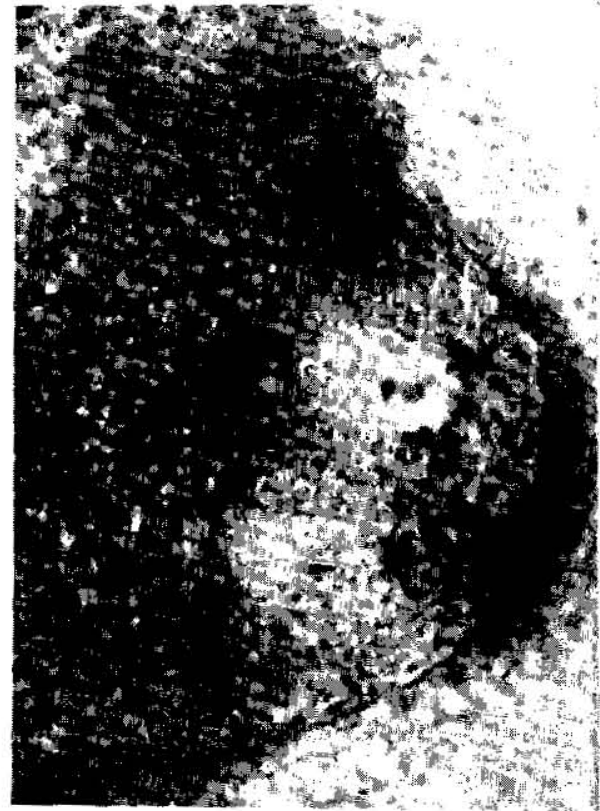

Fig. 100

Fig. 97. An ovule of $R$. sativus $\times$ B. oleracea, showing degeneration occurred in a later stage of sac-formation. A sac-like apparatus is enfolded in the nucellar tissue $\left(F_{1}\right.$ D). Fig. 98, A normal embryo growing in $F_{1}$ ovule of $R$. sutivus $\times$ $B$, olevacea. Endosperm nuclei are also scattered in the locule $\left(F_{1} D\right)$. Fig. 99, A part of $F_{1}$ ovule, $R$. sativus $\times B$. oleracea, containg embryo already degenerated at its very young stage of growth $\left(F_{1} D\right)$. Fig. 100, Abnormal ovule of R. sativus $\times B$. oleracea, containing one additional EMC $(\mathrm{F}, \mathrm{D})$. 


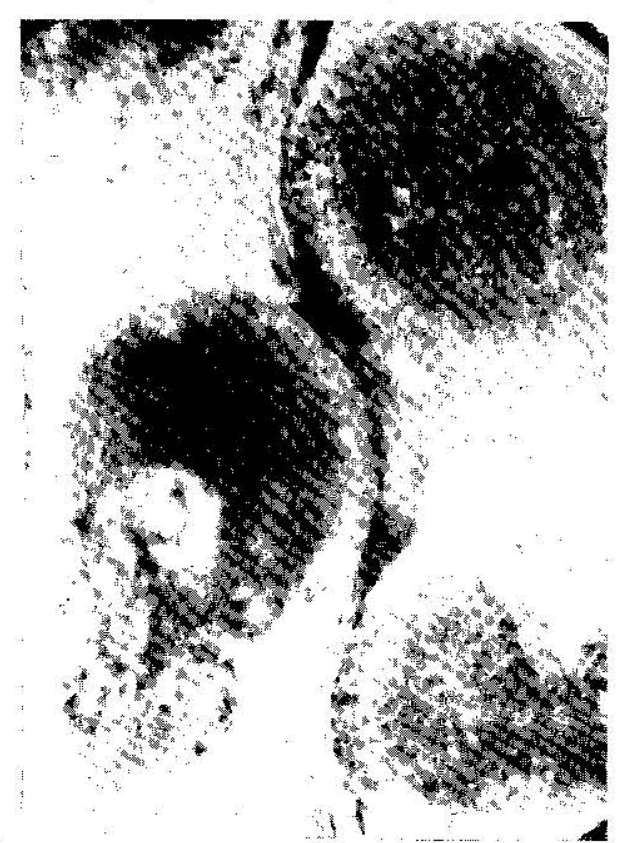

Fig. 101

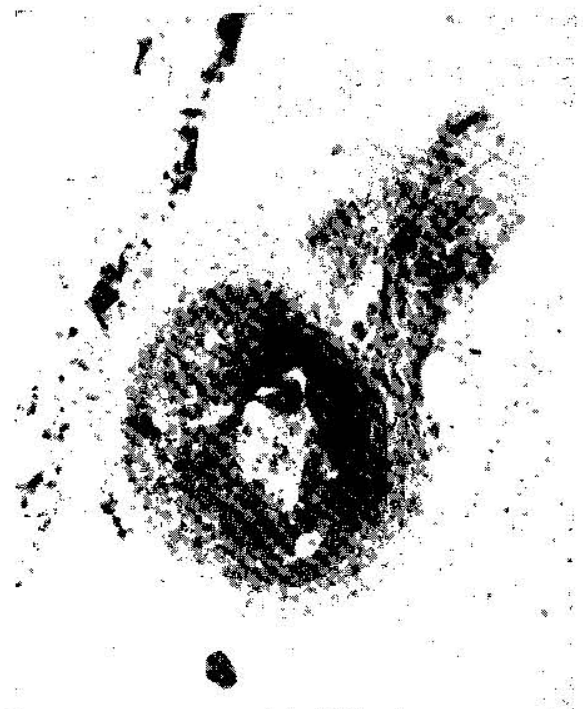

Fig. 103

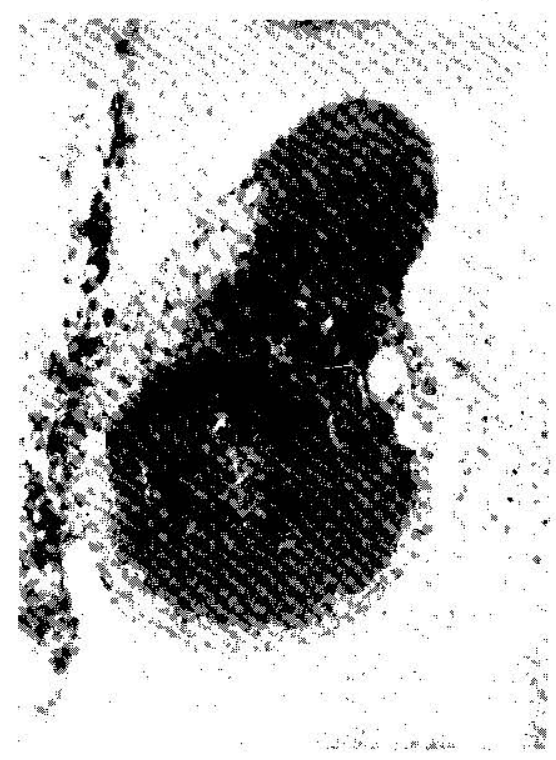

Fig. 102

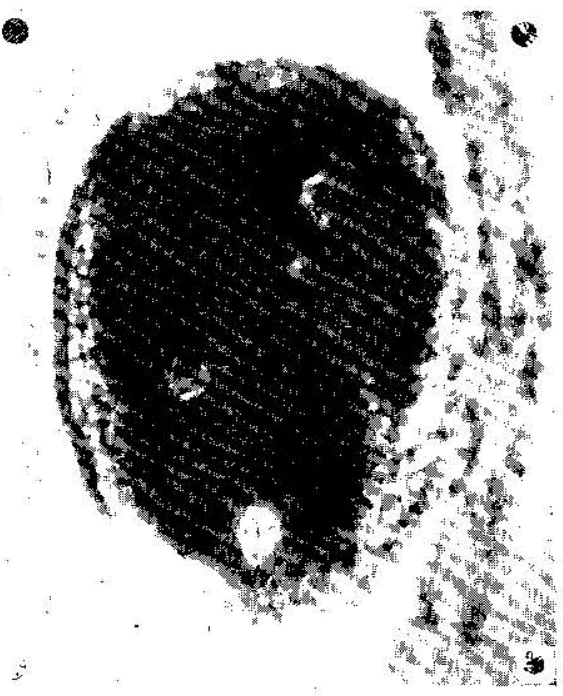

Fig. 104

Figs. 101-104. Abnormal ovules of $R$. sativus $\times$ B. oleracea $\left(F_{1}, D\right)$. These hybrid ovules show abnormal sac-like apparatuses of complex and variable appearances, deposited in various parts of the nucellar tissues. 
examples of these abnormal apparatuses of complex and variable form are represented by Figs. 97, 101-104. Such apparatuses are not encountered so far in the parental Raphanus species, and the origin and mechanism of their formation are entirely unknown at the present. "In rare occasions, the author found in an ovule a group of two or three EMCs in meiotic prophase, instead of normal single EMC. No future destiny of these ovules could be ascertained.

\section{Part II. Tri-genome $\mathbf{F}_{1}$ hybrids}

The author treats in this part the tri-genome $\mathrm{F}_{1}$ hybrids, $\mathrm{F}_{1} \mathrm{~F}$, $F_{1} B$ and $F_{1} C$, and reference to them has already been made on page 285. The parental Brassica species studied, i.e., B. carinata, $B$. cermu $a$ and $B$. juncea, are all secondarily balanced amphidiploids having respectively the genome constitutions of "bbcc," "aabb" and "aabb." The chromosomes and their behaviours in meiosis have been reexamined by the author for all parental species or strains used in his experiment. These amphidiploid species show quite regular meiotic behaviours as in other balanced diploid species. Two species, other than B. carinata ("Abyssinian mustard"), are widely cultivated in Japan. The cytology of two of these crossings, $F_{1} B$ and $F_{1} C$ hybrids, has already been briefly reported in 1929 by the author (Fukushima, 1929).

(i) $F_{1} F$, Brassica carinata $(\mathrm{n}=17)$ " bbcc" $\times$ Rathanus sativus $(\mathrm{n}=9)$ " $\mathrm{RR}$ " "Abyssinian mustard" "Harumati"

Crossings between $B$. carinata (Fig, 105) and $R$. sativus (Fig. 1) have been achieved by several authors, and the meiosis in the $F_{1}$ hybrid has been partly examined (MokINAGA, 1933; U, 1935; RiCHHARIA, 1937a, c ; and KARPECHENKO, 1937a).

\section{Origin of $F_{1}$ hybrids}

In 1931, the author pollinated 25 flowers of $B$. carinata with pollens of a Japanese strain of radish, "Harumati," and obtained 7 more or less developed pods containing 13 seeds in all. From these 13 seeds but three true matured $F_{1}$ plants could be obtained in the next spring. These three individuals are $31 / 32 \mathrm{~F}_{1}$ (24)-33 (Fig. 107), 31/32 $\mathrm{F}_{1}$ (25)-34, and $31 / 32 \mathrm{~F}_{1}$ (27)-43 (Fig. 106). A large number of reciprocal matings, however, were all in vain. Prof. MoRINAGA (1933) has referred to the same materials in connection with his other interspecific Brassica hybrids. 


\section{Characters of $\mathbf{F}_{1}$ hybrids}

Generally speaking, the character of $B$. carinata, a parent with the larger chromosome number, predominates in the $F_{1}$ hybrids, as is usually the case in such interspecific hybrids.

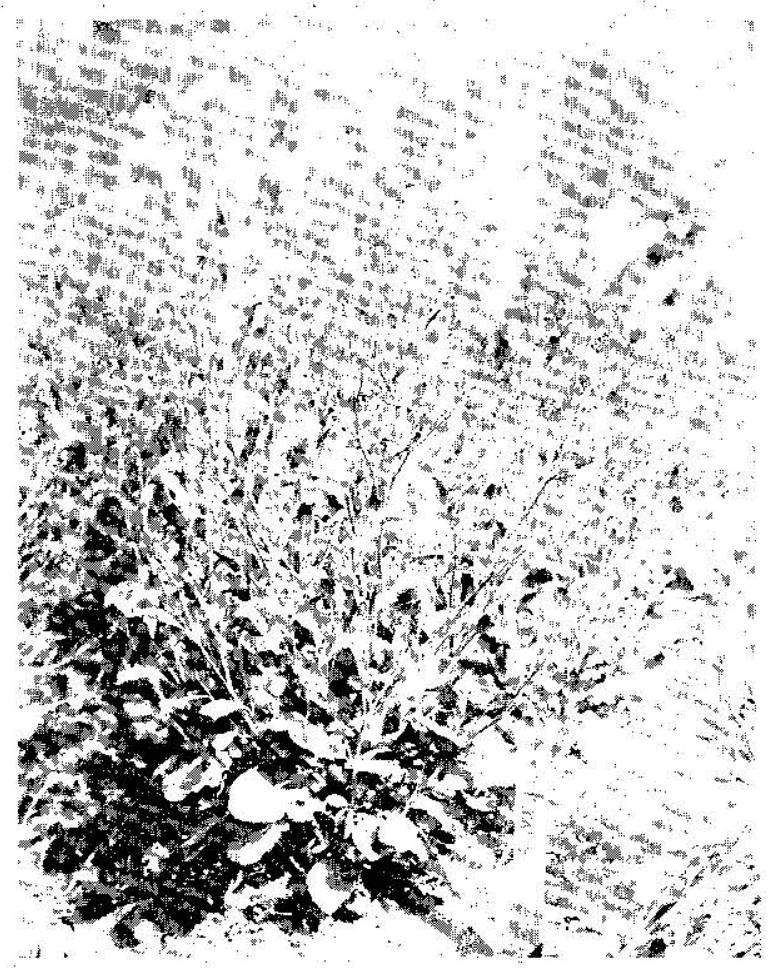

Fig. 105. B. carinata Braun $(\mathrm{n}=17)$.

Growth habit: The nature of seeds and their germination procedures in the present hybrid are quite similar to those exhibited by the hybrids treated in Part I. Three hybrid seedlings grew up rather slowly, but they showed very vigorous growth in the later stages. Sister plants were quite similar in growth habit and rather resembled $B$. carinata in general appearance.

The plants gave rise to many side branches, which ended in flower clusters as in $B$. carinata, and were covered with large leaves. Flowering began slightly later than their parents did, its duration being much prolonged because of the highly sterile nature of the hybrids. 


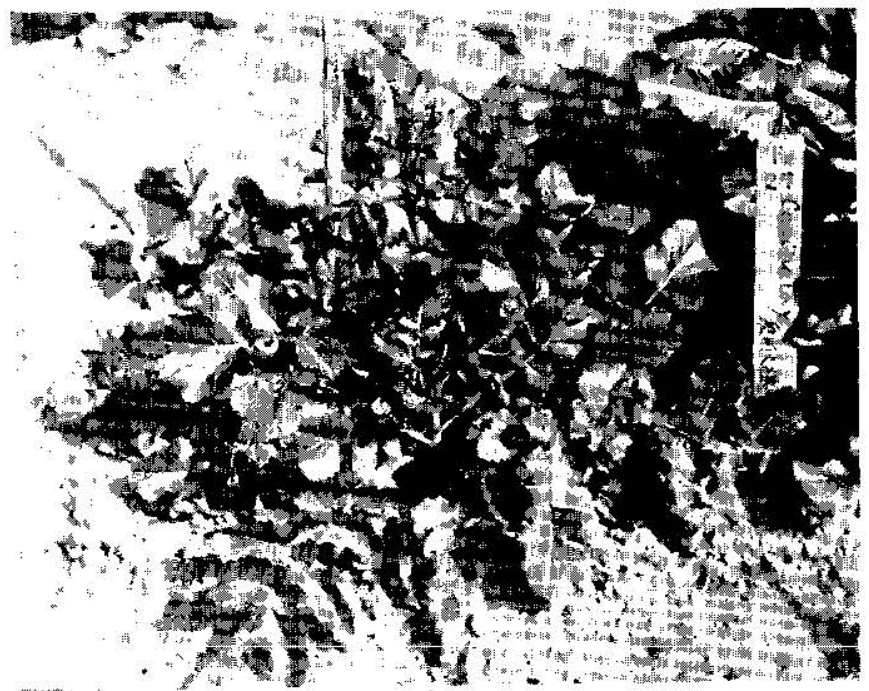

Fig. 106

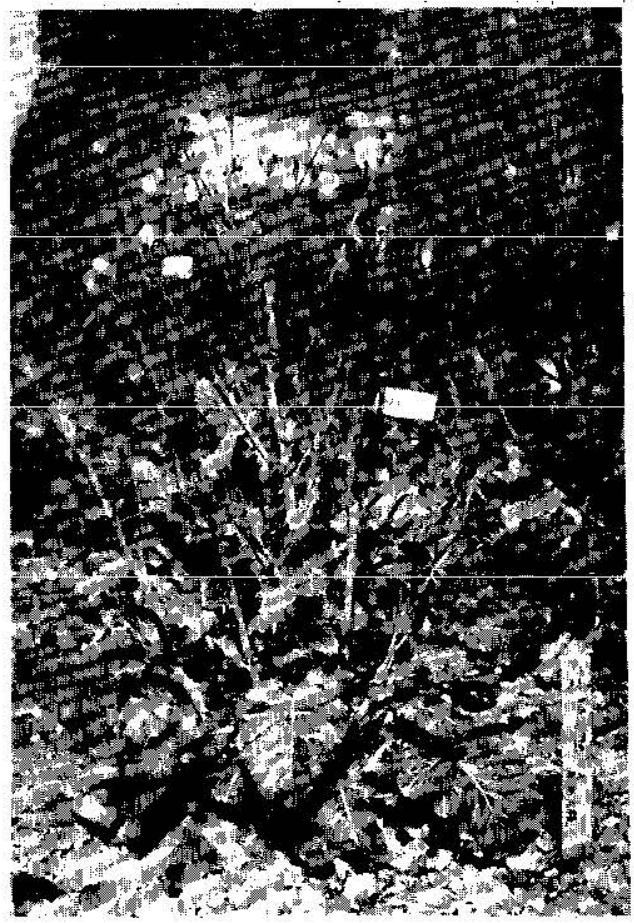

Fig. 107

Figs. 106 and 107. B. carinata $\times$ R. sativus "Harumati" $\left(\mathrm{F}_{1} \mathrm{~F}\right)$. 
Stems: The stems of $F_{1}$ have a normal pith and are glabrous with waxy efflorescence as in B. carinata. Anthocyanin pigment also appears in the nordal portions of the stem. As shown in Fig. 107, the branching habit is quite similar to that in B. carinata.

Roots: $F_{1}$ root does not show any thickening, being slender and fibrous as that of $B$. carinata is.

Leaves: The leaves of $F_{1}$ plants are much larger than those of the parents, and show a rather intermediate shape, though dissected in parts like $B$. carinata leaves, and some individual differences are noticed. $F_{1}$ leaves are slightly pubescent on the upper surface, while those of $B$. carinata are entirely glabrous. Upper stem leaves of the hybrid are narrow and their marginal serrations are more conspicuous than $B$. carinata, somewhat resembling the Raphanus strain. The leaves of $B$. carinata are of bluish green colour with strong waxy efforescence, while $F_{1}$ leaves, covered with very slight waxy efflorescence, show bright green colour. Like Raphanus, the texture of $\mathrm{F}_{1}$ leaves is rather thin.

Flowers: $F_{1}$ hybrid produces many side branches which end in flower clusters. The inflorescence of $B$. carinata is quite unique in the genus for the following conspicuous characteristics:(1) Very short peduncles taking rather erect position and the bract developing at the base of peduncles; (2) Small size and pale yellow coloration of flowers. $F_{1}$ inflorescence attains a larger length than in $B$. carinata without developing basal bracts of peduncles, though the latter are inserted more or less acutely on the cluster axis (Fig. 108). The petals of $F_{1}$ flowers are pure white in colour and attain nearly the same size as the flowers of B. carinata, but their nervures are rather inconspicuous like those of Raphanus. Conspicuous red-purple dots appearing on the anther-tips of $B$. carinata predominate in the $F_{1}$ hybrids. The stamen of $F_{1}$ hybrids develops poorly and its small anthers are almost non-dehiscent at the blooming time. Valvular part of the hybrid ovaries shortens a little, showing, in turn, a slight lengthening of non-dehiscent part which develops in Raphanus ovaries in a marked degree. A large number of hybrid ovaries fall off soon after blooming, only a few developing into pods. The parthenocarpic growing of ovaries to some extents are always observable in the $\mathrm{F}_{1}$ hybrids.

Pods: The pods developed in a low percentage of flowers are much smaller and irregular in shapes. The seed setting is 
observed in the non-dehiscent part of hybrid pods as in the $F_{1}$ hybrids between $B$. olerace $a$ and $R$. sativus treated in Part I.

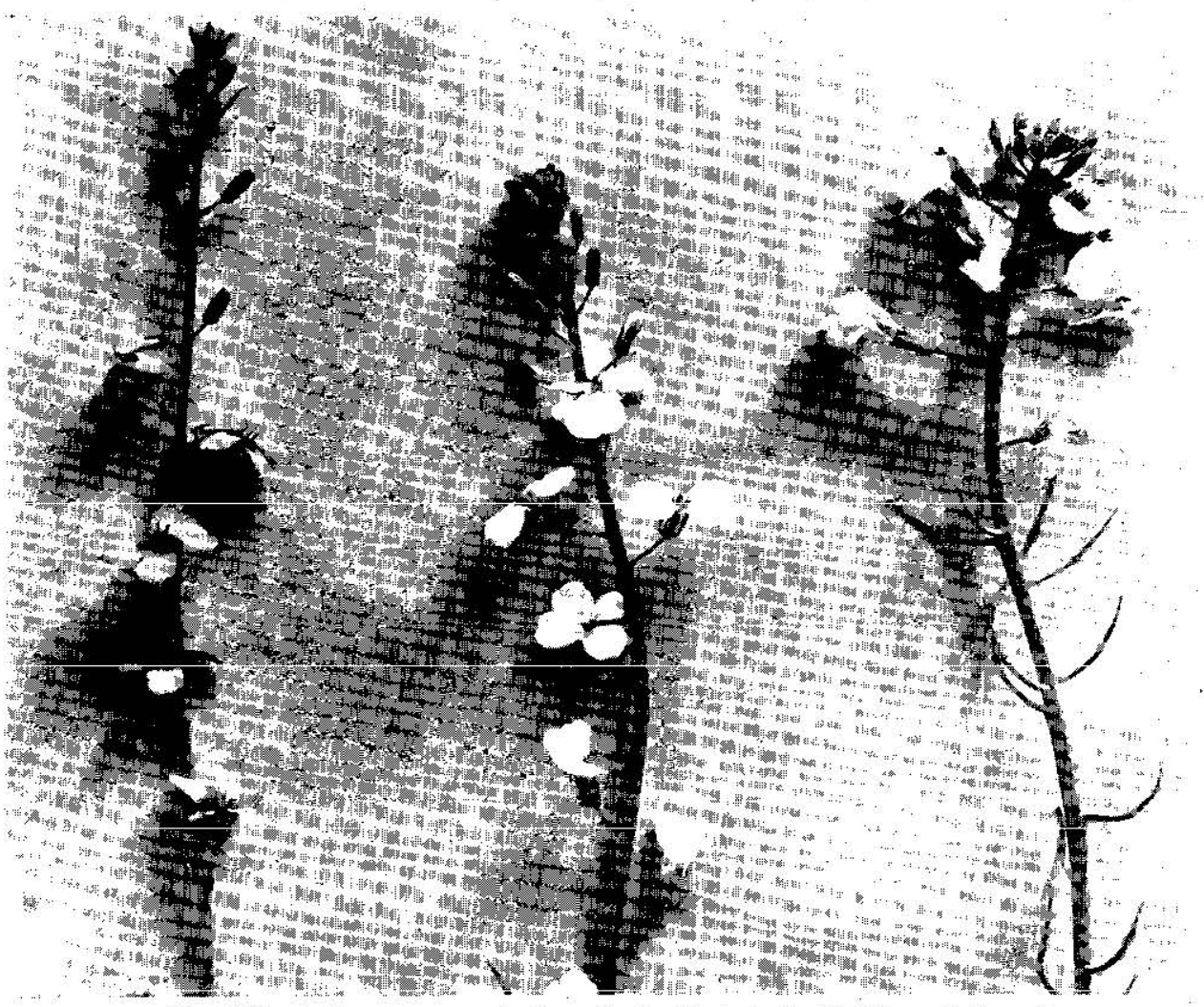

Fig. 108. Inflorescences of $B$. carinata, $\mathrm{F}_{1}$ hybrid $\left(\mathrm{F}_{2} \mathrm{~F}\right)$, and $R$. sativus "Harumati," from left to right.

\section{Fertility in $\mathbf{F}_{1}$ hybrids}

$F_{1}$ hybrids show a very high degree of sterility, each of them producing only a few seeds under open pollination (Fig. 109). From these seeds obtained, several $F_{2}$ seedlings were raised in the following season. The $F_{2}$ and their later generations have been studied also by the author. Controlled cross-pollinations between the hybrids and their parental species have been tried in vain, though slight parthenocarpic growing of some ovaries was noticed.

\section{Cytology of $F_{1}$ hybrids}

In the $F_{1}$ root-tip cells, 26 somatic chromosomes, the sum of 
the haploid numbers of the parental species, are counted exactly, but no detailed examination of chromosome morphology is carried out. As mentioned elsewhere, B. carinata has 17 bivalent chromosomes in haploid and it is composed of " $b$ " and " $c$ " genomes of Brassica. This "b" genome in B. carinata is homologous to the

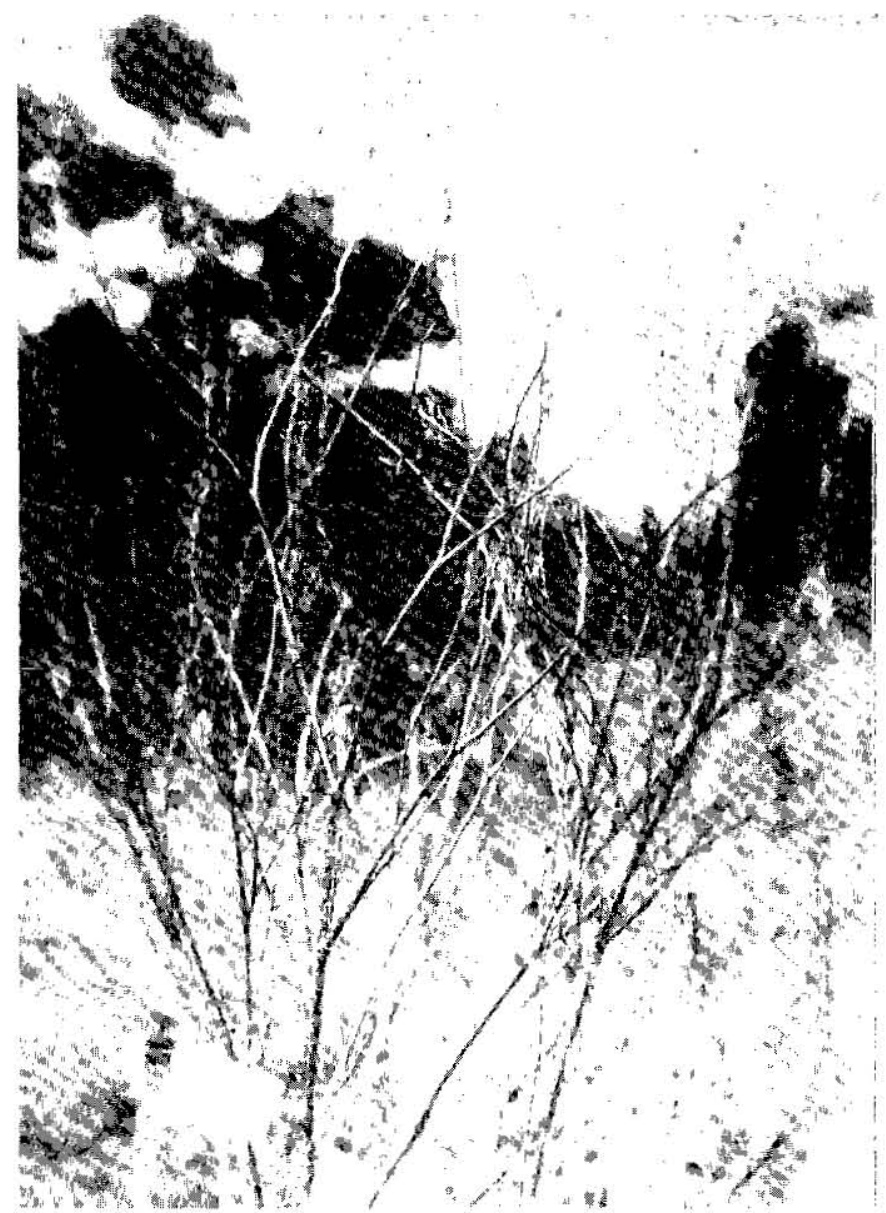

Fig. 109. B. carinata $\times$ R. sativus "Harumati" $\left(\mathrm{F}_{1}, \mathrm{~F}\right)$. Almost completely sterile branches at the end of flowering.

haploid set of $B$. nigra and it consists of 8 chromosomes, while "c" genome is homologous to the genome of both B. oleracea and B. alboglabra already described. Thus a part of the genomic con- 
stitution of the present. $F_{1}$ hybrids, i.e., "c" $\mathrm{c}$ " $\mathrm{R}$ ", is quite common with those hybrids treated in Part $I$, so that it is only on the additional genome " $b$ " for the former $F_{1}$ 's differ from the latters. Chromosomes and their behaviours in meiosis are also reexamined for $B$. carinata by the present author without detecting any irregularities.

The studies on the $F_{1}$ microsporogenesis were mainly confined to the stages after diakinesis. In the prophasic nucleus, one or two nucleoli usually appear. Irregular nuclear protrusion such as observed in $\mathrm{F}_{1} \mathrm{E}$ does not occur in the present hybrid. In diakinetic nuclei there appear one or two small nucleoli together with variable numbers of chromosomes either bivalent or univalent, showing some chromosome association occurring in the hybrid. Usually, bivalent chromosomes are clearly discriminated from univalent ones, though in some nuclei it is a rather difficult task to distinguish them, owing mainly to the too deep staining on the one hand and unsuitable directions of vision on the other. Data obtained on chromosome pairings at diakinesis is shown in Table 7. Number of bivalent chromosomes varies from 0 to 4,2

Table 7. Frequency of bivalent chromosomes in $F_{1} F$ at diakinesis (B. carinata $\times R$. sativus).

\begin{tabular}{lllllllll} 
& \multicolumn{4}{c}{ Number of bivalents } & \multicolumn{3}{c}{ Total number of } \\
& 0 & 1 & 2 & 3 & 4 & \\
\hline Frequency & 1 & 4 & 8 & 3 & 2 & 18
\end{tabular}

being the most frequent. The nucleus without associated chromosomes is of a rather rare occurrence. Figs. 110 and 111 show representative figures of diakinetic nucleus, containing respectively $4 \mathrm{II}+18 \mathrm{I}$ and $2 \mathrm{II}+22 \mathrm{I}$ chromosomes.

The course of heterotypic and later division processes, in general, are similar to those of the hybrids described in Part I. In the heterotypic metaphase, variable numbers of chromosomes appear according to the degree of chromosome associations. True associated bivalent chromosomes are more easily determined in their side views. The author examined the chromosome valencies and configurations with 116 metaphasic nuclei and the statistical data obtained are compiled in Table 8. All these nuclei used in 

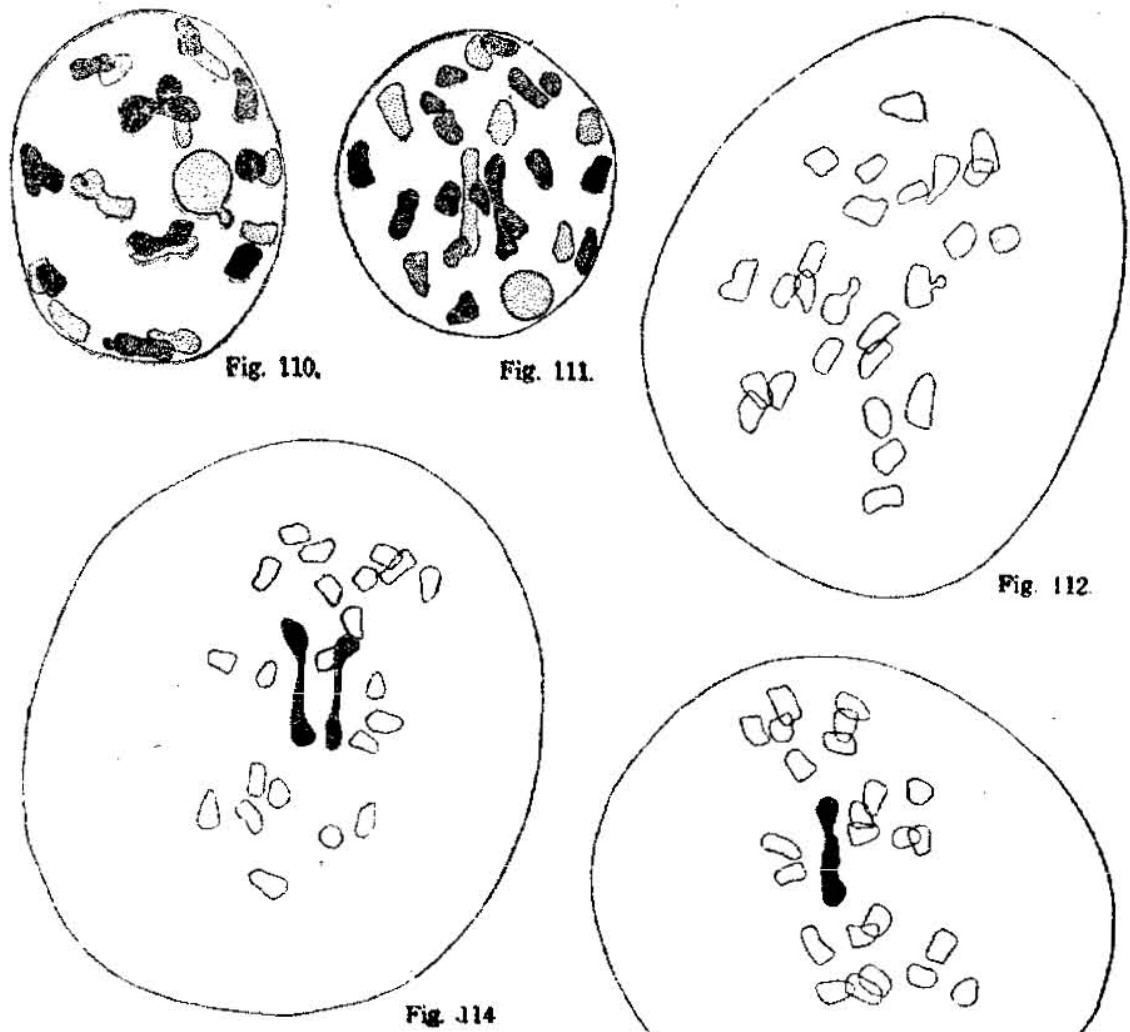

Fig. 111.

Fig. 114
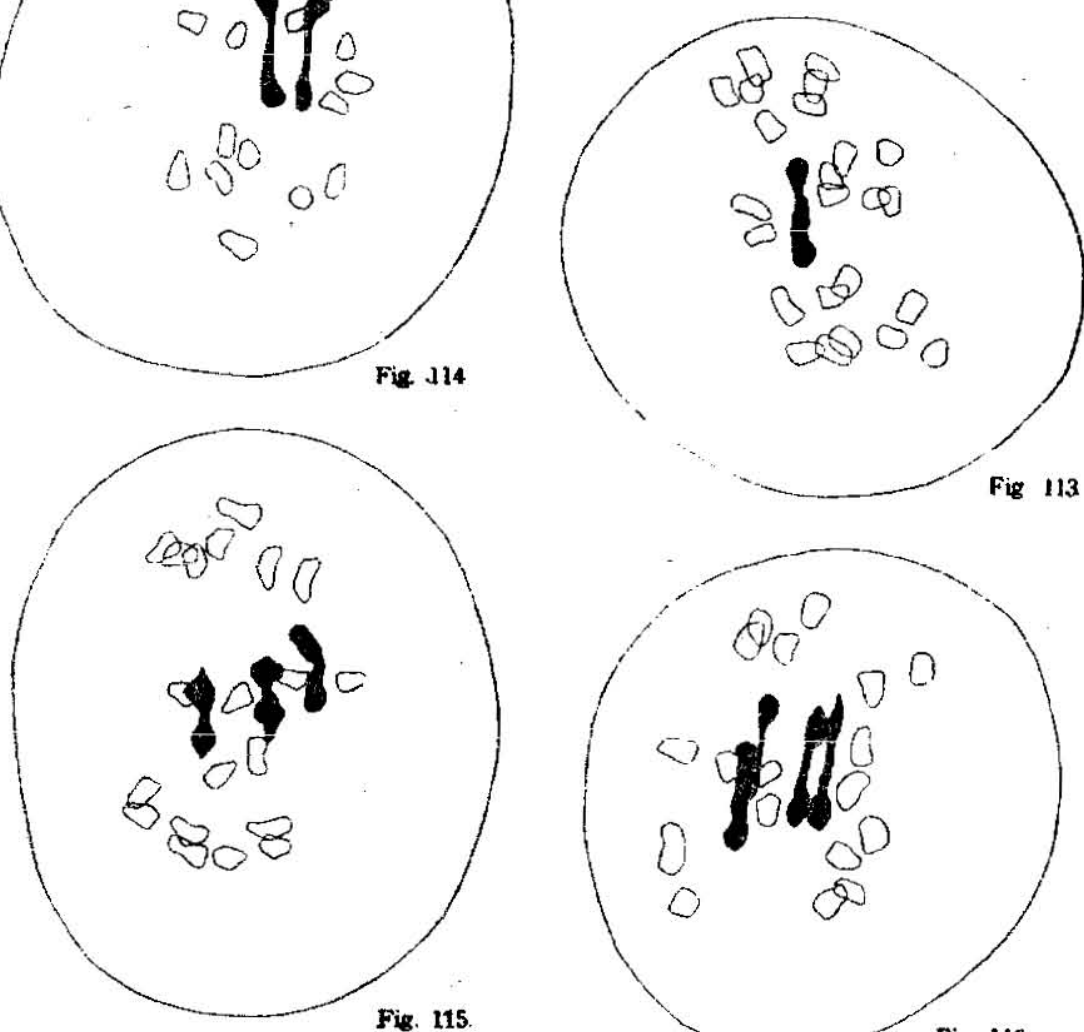

Fig 113

Fig. 115

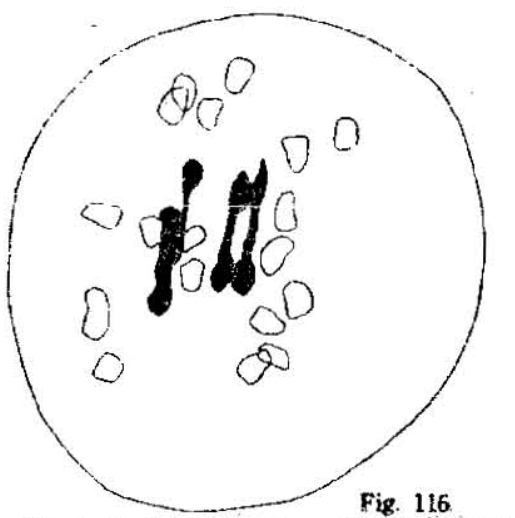

Figs. 110-116. Meiotic division of PMCs in B. carinata $\times R$. sativus $\left(\mathrm{F}_{1} \mathrm{~F}\right)$. Figs. 110 and 111 , Diakinesis. Showing $4_{\mathrm{II}}+18_{1}$ and $22_{\mathrm{I}}+22_{\mathrm{I}}$ chromosomes respectively. Fig. 112, I-Metaphase. 26 univalent chromosomes only. Figs. 113-116, I-Metaphase. 1, 2, 3 and 4 bivalent chromosomes respectively, and the corresponding numbers of univalent ones. 
the statistical surveying show exactly 26 chromosome complements in all on the respective spindles. The number of bivalent chromo-

Table 8. Frequency of various chromosome configurations of $\mathrm{F}_{1} \mathrm{~F}$ at I-Metaphase (B. carinata $\times$ R. sativus).

\begin{tabular}{lcccccc}
$\begin{array}{c}\text { Expt. No. of } \\
\text { slides }\end{array}$ & \multicolumn{4}{c}{ Configurations } & Total number of \\
& $26_{1}$ & $1_{\mathrm{II}}+24_{\mathrm{I}}$ & $2_{\mathrm{II}}+22_{\mathrm{I}}$ & $3_{\mathrm{II}}+20_{\mathrm{I}}$ & $4_{\mathrm{II}}+18_{\mathrm{I}}$ & \\
\hline $4221-2$ & 1 & 1 & 10 & 11 & 9 & 32 \\
$4218-1$ & 3 & 7 & 25 & 21 & 7 & 63 \\
$4223-1$ & 0 & 0 & 2 & 1 & 0 & 3 \\
3839 & 4 & 7 & 6 & 1 & 0 & 18 \\
\hline Total & 8 & 15 & 43 & 34 & 16 & 116
\end{tabular}

somes varies also from 0 to 4,2 being the most frequent, and the average number of bivalent chromosomes is calculated as 2.3 per one PMC. 'As far as the author's examination goes, even a single trivalent chromosome has never been ascertained with this $F_{1}$ F. Fig. 112 shows a PMC with 26 univalent chromosomes while Figs. 113-116 show PMCs with 1, 2, 3, and 4 bivalent chromosomes respectively. Figs. 117-119 also show PMCs containing 2, 3 or 4 bivalents. Each of these figures contains corresponding number of univalents in addition to the respective bivalents. The bivalent chromosome at this stage has one or two completely terminalized chiasmata, and takes either rod or ring shape, the shape of the former occurring much more frequently. Relative positions of the chromosomes on the I-Metaphasic spindle and their behaviours throughout the heterotypic division are quite similar to those observed in the "Rc" hybrids described in Part I. In Fig. 117, 20 univalent chromosemes are found arranged somewhat regularly on the equatorial plane besides two bivalent ones, and Fig. 120 also represents a side view of such a spindle having a large number of chromosomes arranged themselves on the plate. The circumstances such as shown in these two figures are met with not infrequently, and this seems to explain the actual occurrence of splitting or division of many univalent chromosomes at I-Anaphase. As special irregularities, remarkably curved 


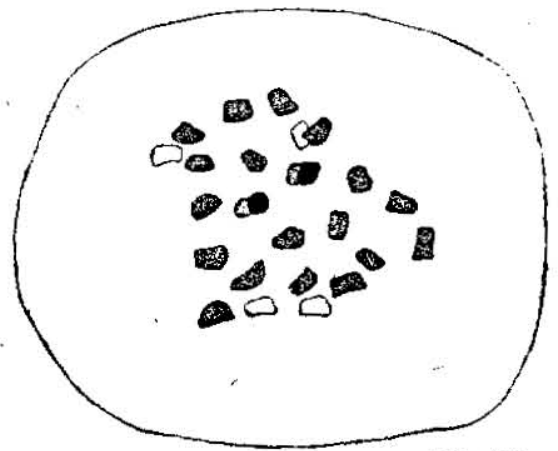

Fig. 117
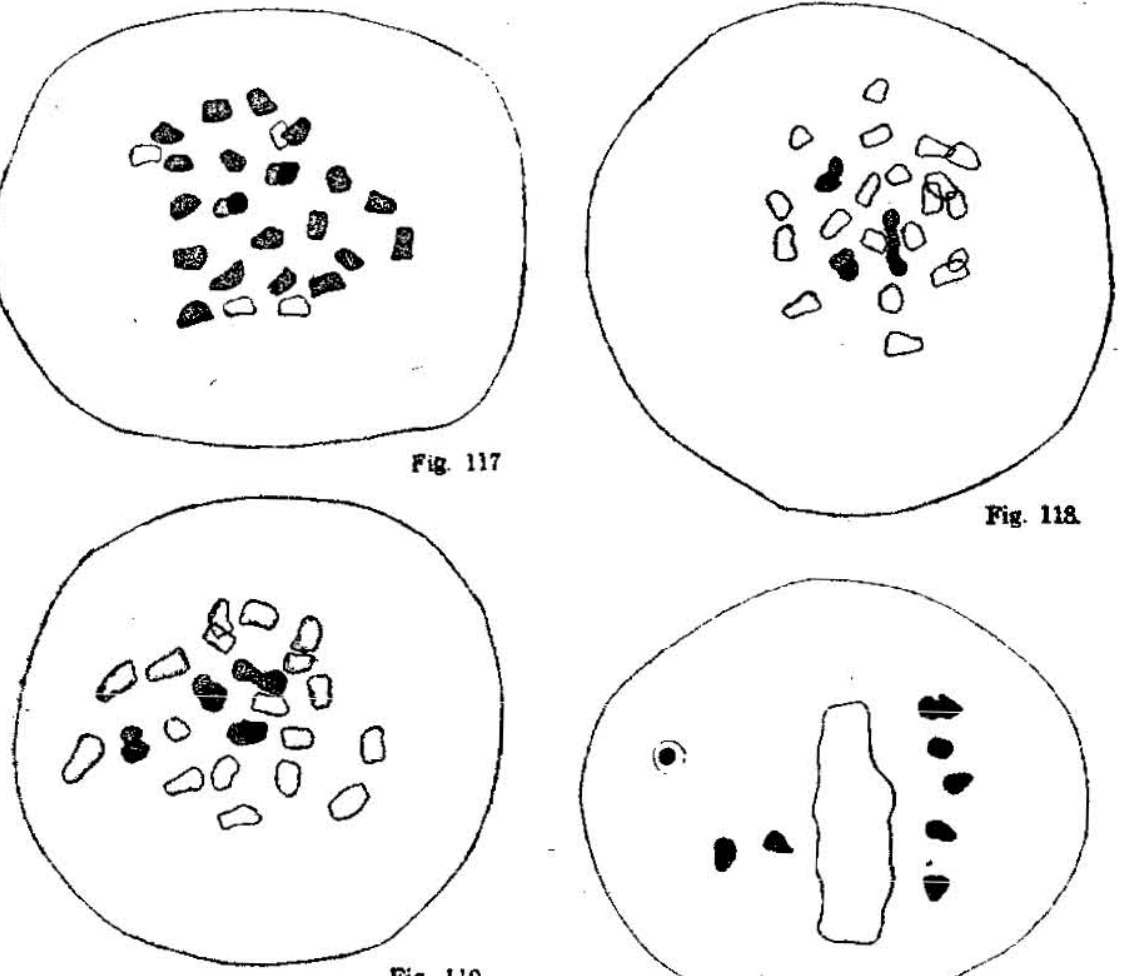

Fig. 119
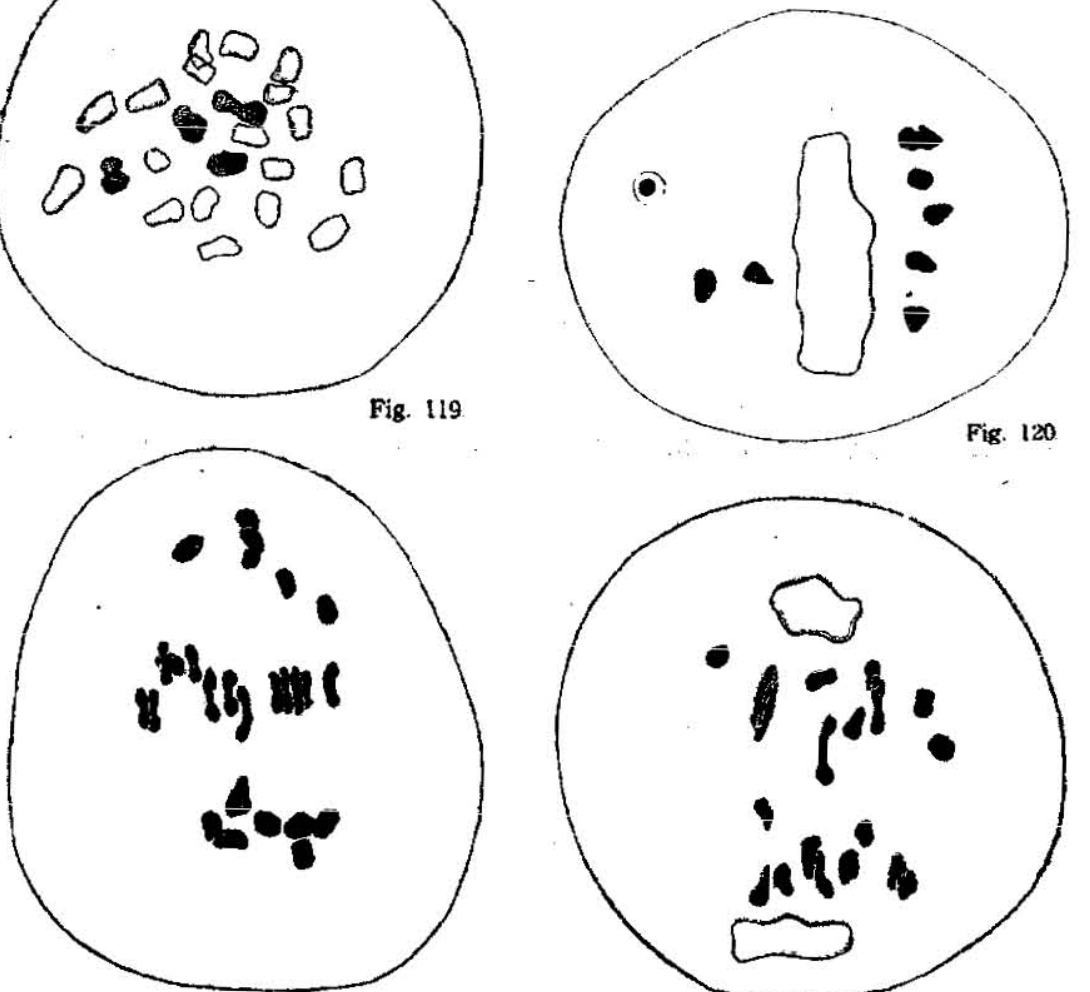

Fig. 121.

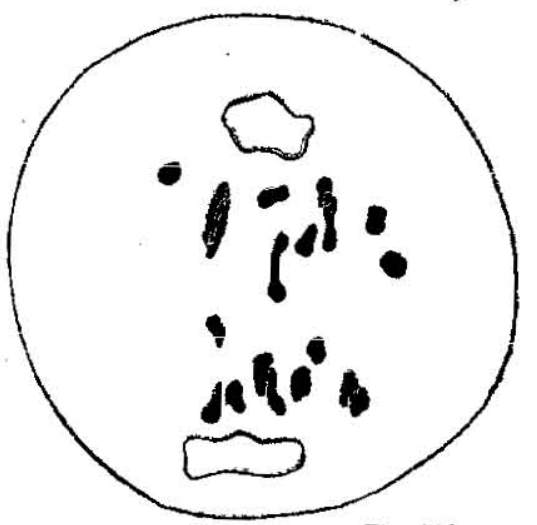

Fig. 122.

Figs. 117-122. Meiotic division of PMCs in $B$. carinata $\times R$. sativus $(\mathrm{F}, \mathrm{F})$ Figs. 117-119, I-Metaphase (polar view). Showing respectively 2, 3 and 4 bivalent chromosomes and the corresponding univalent ones. Fig. 120, I-Metaphase. Side view of a large plate mostly composed of univalent chromosomes which take rather regular arrangement. Quite similar figure as Fig. 117. Figs. 121 and 122, I-Anaphase. 12 univalents arranged rather regularly and show splitting on the spindle of Fig. 121. 
spindle or tripolar spindles are observed rarely at I-Metaphase. Though still rarely, PMCs with two independent spindles are also met with.

The division processes at the I-Anaphase are also similar to those in di-genome $F_{1}$ hybrids in Part I. Representative figures, Figs. 121 and 122, of the I-Anaphase will suffice to show the mode of division. In Fig. 121, 12 univalent chromosomes are seen arranged somewhat regularly on the equatorial region and in the stage of splitting. Restitution nucleus usually occurs- in the present hybrids, and the situation is also very much like that of the hybrids described in Part I.

PMCs in interphase show much variable appearance according to the unequal distribution of chromosomes at the I-Anaphase, to the variable number of micronuclei produced, and also to the occurrence of restitution nucleus with various frequencies. Generally, the total number of chromosomes, including diad and monad ones, amounts to more than 26 to one PMC. The maximum number of monad chromosomes observed is 32 , revealing the fact that 16 univalent chromosomes have divided at the I-Anaphase.

The homotypic nuclear division, which soon follows the interphase, proceeds through the usual course as in the hybrids already described. The author presents here but a few of typical figures. PMC in Fig. 123 has two plates, $10 \mathrm{~d}+8 \mathrm{~m}$ and $8 \mathrm{~d}+8 \mathrm{~m}$, while PMC in Fig. 124 has a large plate with $14 \mathrm{~d}+4 \mathrm{~m}$ and a small one with only 8 diads, and two diad chromosomes are found out of the spindles. Chromosomes situated out of the spheres of the spindle are derived from those excluded from nuclei at the ITelophase, and they are either monad or diad in their nature. Homotypic metaphase plates derived from the restitution nuclei contained, for example, $17 \mathrm{~d}+18 \mathrm{~m}, 18 \mathrm{~d}+16 \mathrm{~m}$ (Fig. 125), $19 \mathrm{~d}+\mathrm{Xm}$, $20 d+12 m, 21 d+10 m$, and $23 d+6 m$ (Fig. 126) respectively. The diad chromosomes divide at the II-Anaphase and their halves are assorted to the poles, while monad ones proceed intact toward either one of the poles without undergoing split. Some of these monad ones remain in the cytoplasm without participating in the formation of daughter nuclei. No clear figure of splitting of monad chromosomes at the II-Anaphase has been noticed in the present $F_{1} F$. Fig. 127 shows a polar view of 2 spindles in the II-Anaphase. Here the left spindle contains $28 \mathrm{monad}$ chromo- 

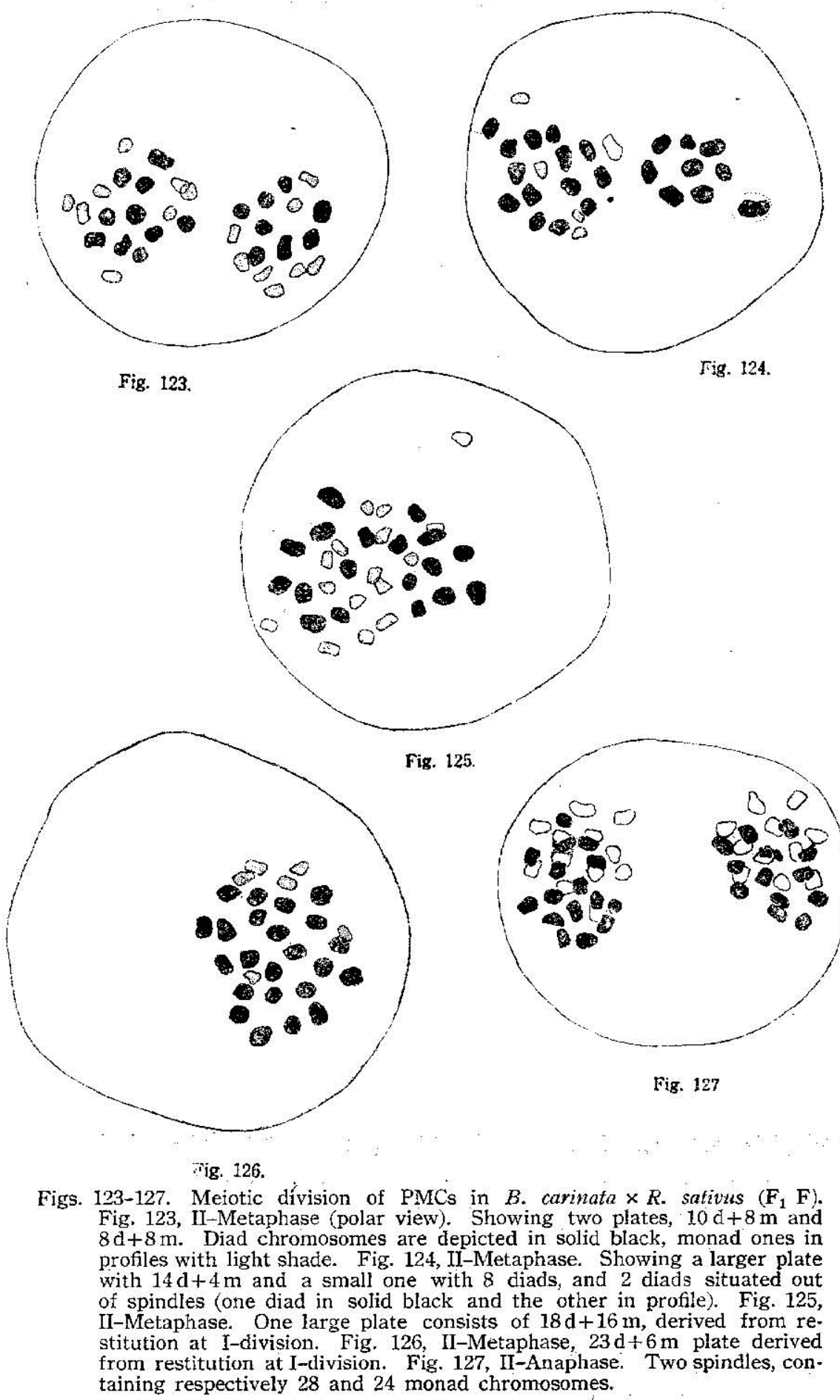
somes and the right 24 . In this figure, respective positions of chromosomes on the spindles are shown by different shades, and in each spindle two chromosome groups consisting of divided halves, 12 halves on the left and 11 halves on the right, are clearly discernible. Figs. 128 and 129 show similar PMCs in their side views. In Fig. 129, fusion of two anaphasic chromosome groups occurs on one side. Such a fusion of two chromosome groups is noticeable not infrequently.

Various kinds of sporads such as diads, triads, tetrads, pentads, and other polyads, are usually produced in the hybrids. The frequency occurrence of diads, which has important bearing to the viable gamete formation, also varies much with the flowers, or even with the anthers. General features of these sporad cells are just like that of other hybrids above mentioned. Some antherlocules, which contain comparatively larger percentage of tetrads and their derivatives, show that they have followed a more or less regualr course of the meiosis. In such an anther-locule, the forlowing frequency distribution of various kinds of sporads is observed (Table 9).

Table 9. Frequency of various kinds of sporads in an antherlocule of $\mathrm{F}_{1} \mathrm{~F}$ (B. carinata $\times R$. sativus).

\begin{tabular}{lrrrrrrrr} 
& \multicolumn{4}{c}{ Kinds of sporads* } & & $\begin{array}{c}\text { Total number of } \\
\text { sporads }\end{array}$ \\
Frequency & (2) & $(3)$ & $(4)$ & $(5)$ & (6) & $(7)$ & \\
& 2 & 3 & 44 & 18 & 5 & 1 & 73
\end{tabular}

*See remark in Table 6 (page 324).

Each of hybrid microspores produced contains, as a rule, one nucleus, but sometimes there are one or two additional ones (Fig. 130). Usually cytokinesis goes on by invagination after homotypic nuclear division, resulting in the formation of microspores. In some irregular cases, cytokinesis, however, does not proceed up to its completion or it is suspended at various stages of progress. A monad produced in this manner naturally contains all the nuclei produced after the II-division. Fig. 131 shows four such monad spores at the same stage of growth as the ordinary ones in Fig. 130. They contain four or more nuclei and show incomplete invagination. . The author encountered not infrequently the figures 

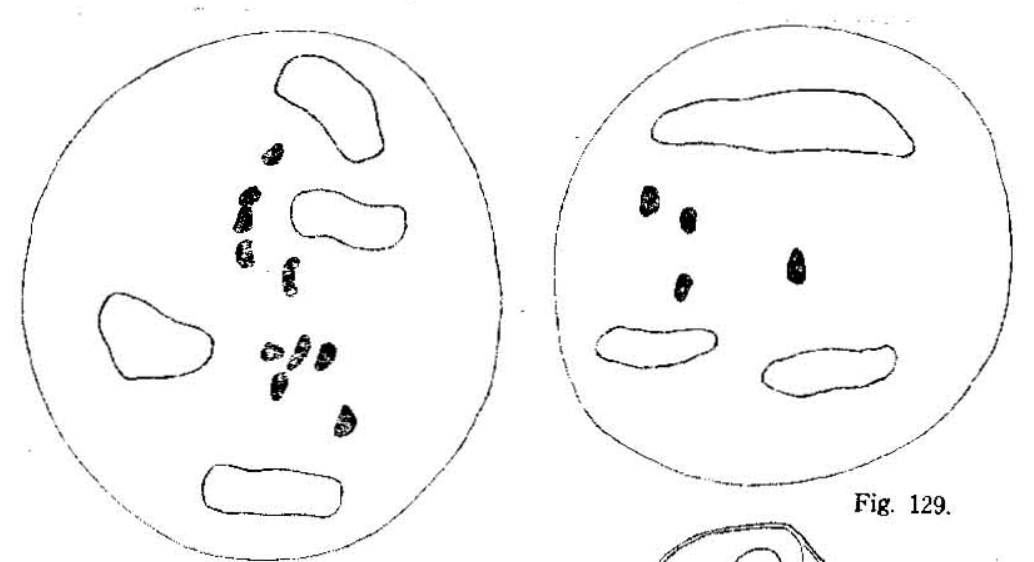

Fig. 128.
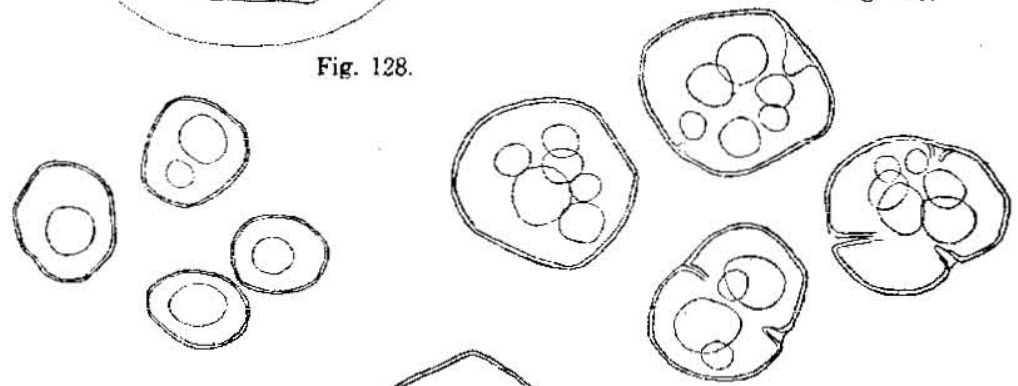

Fig. 130 .

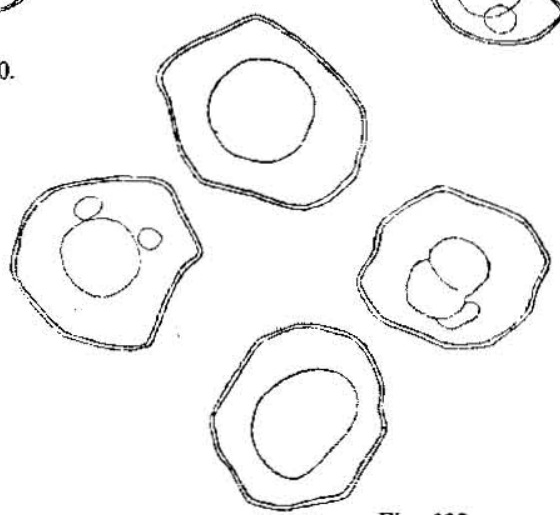

Fig. 131 .

Fig. 132.

Figs. 128 and 129, II-Anaphase of $B$. carinata $\times R$. sativus $\left(\mathrm{F}_{1} \mathrm{~F}\right)$. Lagging monad chromosomes on each spindle. Fusion of two chromosome groups is discernible in Fig. 129.

Figs. 130-132. Young microspores of $B$. carinata $\times R$. sativus $\left(F_{1} F\right)$. Fig. 130, Ordinary hybrid microspores, containing usually one nucleus. One of them contains one accessory nucleus. Fig. 131, Monad spores produced through incomplete invagination process, at the same stage of their growth as the ordinary spores in Fig. 130. Fig. 132, Monad spores in the same stage of their growth as those in Figs. 130 and 131, suggesting the occurrence of fusion of nuclei in such spores. 
which suggest the fusion of nuclei in such monad spores, resulting in true monad with a large nucleus (Fig. 132). Such a situation is also appreciated, on the other hand, from the fact that the author did not observe in the II-Anaphase any PMCs with only one large nucleus, which might have been produced by the second restitution phenomena in the II-Anaphase. As already mentioned in Part I, monad spores containing didiploid number of chromosomes are rarely produced also through another irregular course, i.e., PMCs directly growing up to spores without undergoing meiotic processes.

Because of the unbalance of chromosomes recovered in gametes and also of various other causes, a large number of microspores die out at various stages of growth. Thus a very small percentage of spores grow up to mature pollen grains, viable or functional ones being still less in number. Consequently the hybrid anthers usually do not show ordinary dehiscence of their sacs.

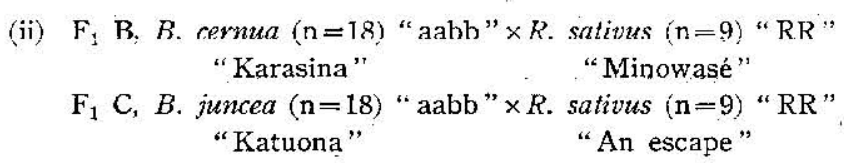

The hybrid between Brassica species with "aabb" genome constitution and Raphanus was raised for the first time by the author in 1926. So far as the author is aware, no other successful case of this cross combination has ever been reported heretofore. As mentioned elsewhere, both amphidiploid species, $\bar{B}$. cernua (Fig. 133) and B. juncea (Fig. 134), have 18 chromosomes in the haploid state, and they have been considered to be cytologically homologous or identical species. The author made studies on three sister plants of $\mathrm{F}_{1} \mathrm{~B}, 26 / 27 \mathrm{~F}_{\mathrm{l}}(26)$, and two of $\mathrm{F}_{1} \mathrm{C}, 26 / 27 \mathrm{~F}_{1}$ (11). Meioses in these two kinds of hybrids have been reported already in some details (FuKushima, 1929).

\section{The Origin of $F_{1}$ hybrids}

In 1926, the author pollinated 7 flowers of $B$. cernua with the pollens of $R$. sativus "Minowasé" and 13 flowers of $B$. juncea with the pollens of an escaped radish strain, and obtained 9 and 5 seeds respectively from three pods each matured on the crossings. From these 14 seeds sown only 5 true $F_{1}$ plants, 3 plants 
of $F_{1} B$ and 2 of $F_{1} C$, were obtained during the season of 1926/ 1927.

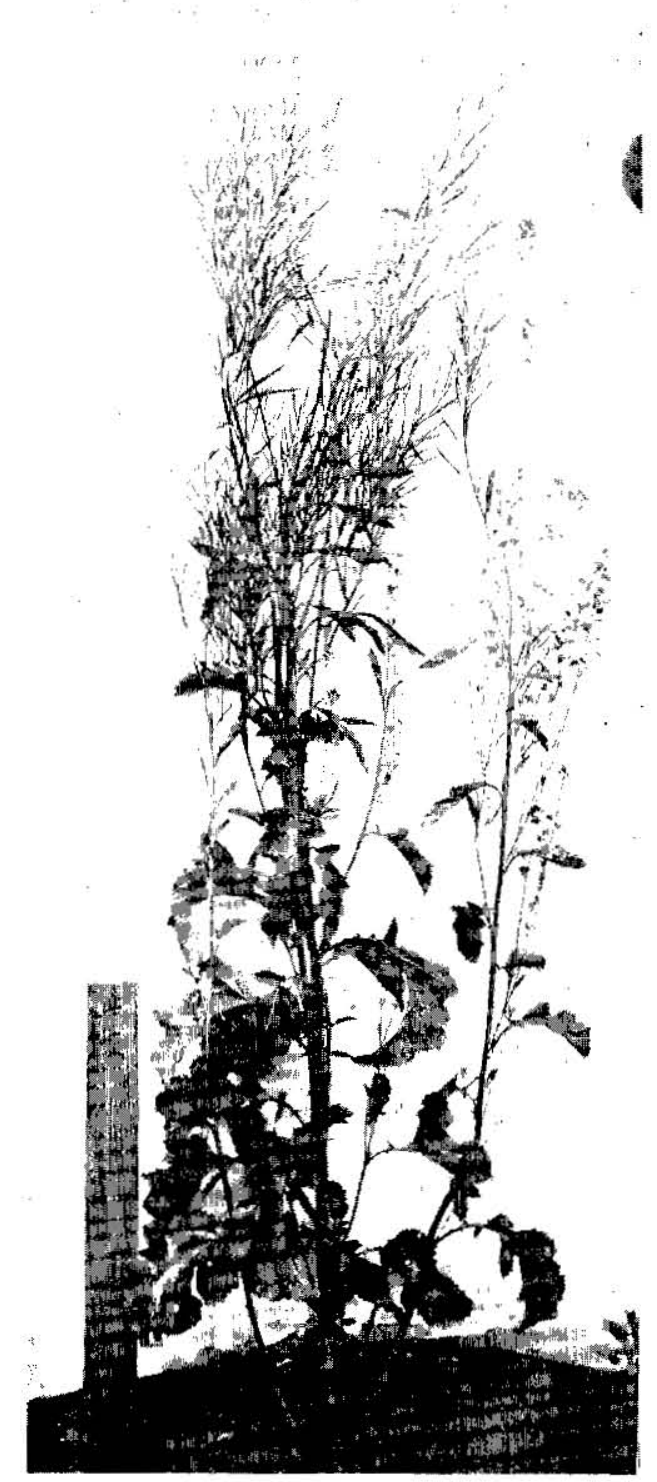

Fig. 133. B. cermua Coss. "Karasina" $(n=18)$.

\section{Characters of $F_{1}$ hybrids}

As in the $F_{1} F$ hybrids above mentioned, characters of $B$. cernua and $B$. juncea, parental species with a larger chromosome number, predominate also more or less in the $F_{1}$ hybrids, although some characters of radish can be always noticeable. The individuals of $F_{t}$ $B$ are very much like the individuals of $\mathrm{F}_{1} \mathrm{C}$ and they are also quite uniform in each group. In striking contrast to other $\mathrm{F}_{1}$ hybrids, these hybrids do not show any heterosis, but are somewhat less in vigour than the parental individuals.

The stems of the $F_{1}$ have normal pith and are glabrous with waxy efflorescence as in Brassicas. The branching of the main stem is usually poor (Figs. 135 and 136). The $F_{1}$ root showing no thickening, remains slender and fibrous to the last as in Brassicas.

The $F_{1}$ leaves rather resemble Brassica parents in form, but are smaller in size owing possibly to the weakness in vigour of 
the plants. The leaf-blade of $F_{1} B$ (Fig. 137) is more like that of B. cermua, but not recurved so strongly, while that of $\mathrm{F}_{1} \mathrm{C}$ more

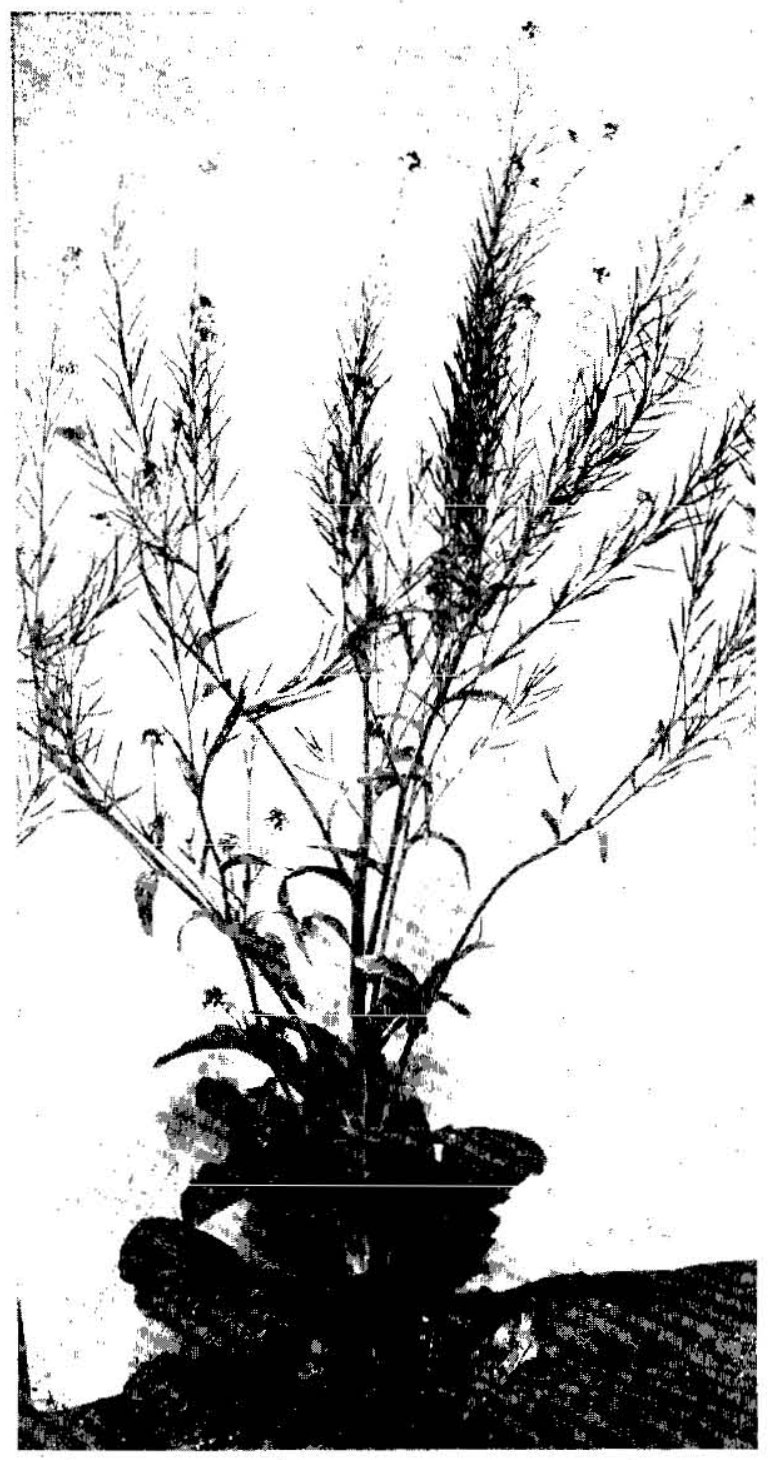

Fig. 134. B. juncea Hemsl. "Katuona" $(\mathrm{n}=18)$.

resembles that of $B$. juncea, especially in its lobing and rugosity, but somewhat narrower. Marginal serration of the hybrid 
leaves is rather conspicuous in both $F_{1} B$ and $F_{1} C . F_{1}$ leaves are slightly pubescent as in the case of those of Brassica par-

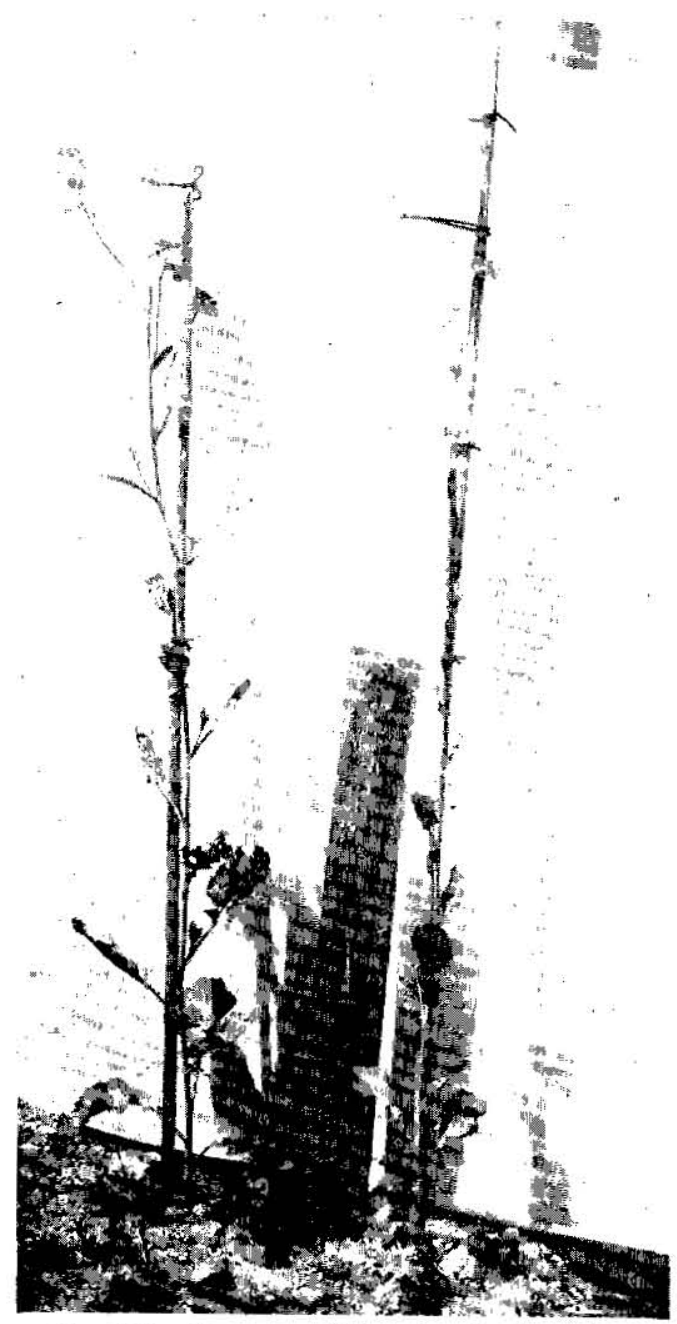

Fig. 135. B. cernua "Karasina" $\times R$. sativus "Minowasé" ( $\left.F_{1} B\right)$. ents, and are covered with waxy efflorescence, the development of which is stronger in $F_{1} B$ than in $\mathrm{F}_{\mathrm{i}} \mathrm{C}$, just corresponding to the degrees in their respective Brassica parent. Leaves of $F_{1} B$ are of bright green colour like B. cernua, while those of $\mathrm{F}$; $\mathrm{C}$ are slightly deep green like $B$. juncea. The $\mathrm{F}_{1}$ leaves are rather thin as those of the parental species.

Hybrid flowers of $F_{1}$ $\mathrm{B}$ and $\mathrm{F}_{1} \mathrm{C}$ are all quite alike, each having yellow and slightly larger and broader petals than those of the parental Brassicas (Fig. 138). Flower clusters are also like those of the Brassica parents. Resembling those of Brassica flowers, sepals of hybrid flowers are longer than the claw of petal, and diverge out at anthesis in contrast to the sepals of radish flowers, which are slightly shorter than

the claw and are converging to the last (Fig. 138). The stamen of $F_{1} B$ and $F_{1} C$ shows but a meagre development and its small anthers do not dehisce at the blooming time. Valvular part of the hybrid ovaries shortens a little and the non-dehiscent part shows, in return, a slight lengthening. 


\section{Fertility in $F_{1}$ hybrids}

Ali the hybrid ovaries fell off soon after the blooming without producing even a single matured or partially developed pod. The author obtained no seed on these $F_{1}$ plants under open pollination. Controlled cross pollinations between the hybrids and their parental species have been tried also in vain.

\section{Cytology of $\mathrm{F}_{1}$ hybrids}

As mentioned elsewhere, the results of cytological examinations of microsporogenesis of $\mathrm{F}_{1} \mathrm{~B}$ and $\mathrm{F}_{1} \mathrm{C}$ have been reported already in the previous paper (FUKUSHIMA, 1929). So the author will describe only the general mode of the meiosis in order to give facilities for comparison with other $F_{1}$ hybrids treated.

$F_{1} B$ and $F_{1} C$ plants have 27 somatic chromosomes as it is ascertained in the meiotic divisions of PMCs. As the genomic constitution of these two kinds of $\mathbf{F}_{1}$ hybrids is quite the same, it may be designated as "abR".

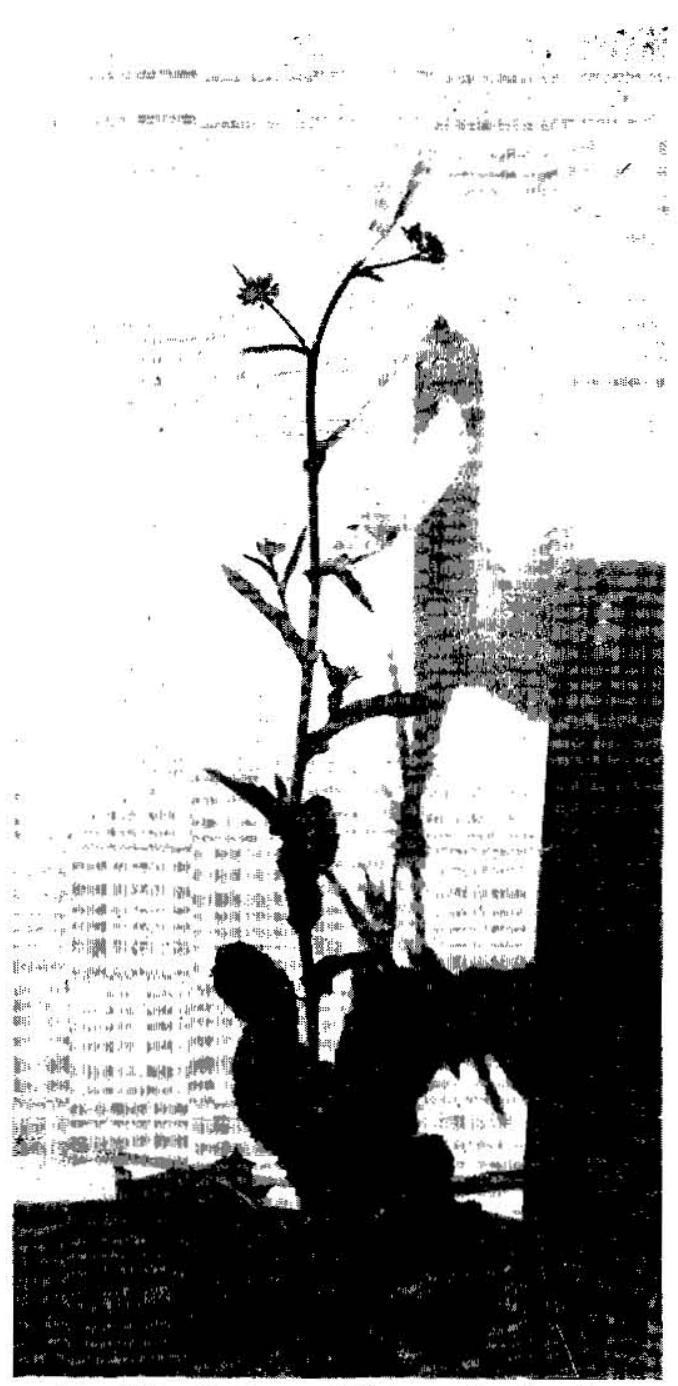

Fig. 136. B. juncea "Katuona" $\times R$. sativus "An escape" ( $F, C)$.

Here " $\mathrm{b}$ " genome is quite homologous to that of $B$. nigra, and "a" to that of Brassicas such as B. campestris, B. chinensis, B. 
japonica, B. rapa, etc., all having 10 chromosomes. Thus $\mathrm{F}_{1} \mathrm{~B}$ and $\mathrm{F}_{1} \mathrm{C}$ are especially noteworthy as they contain " $\mathrm{a}$ " and " $\mathrm{R}$ " together.

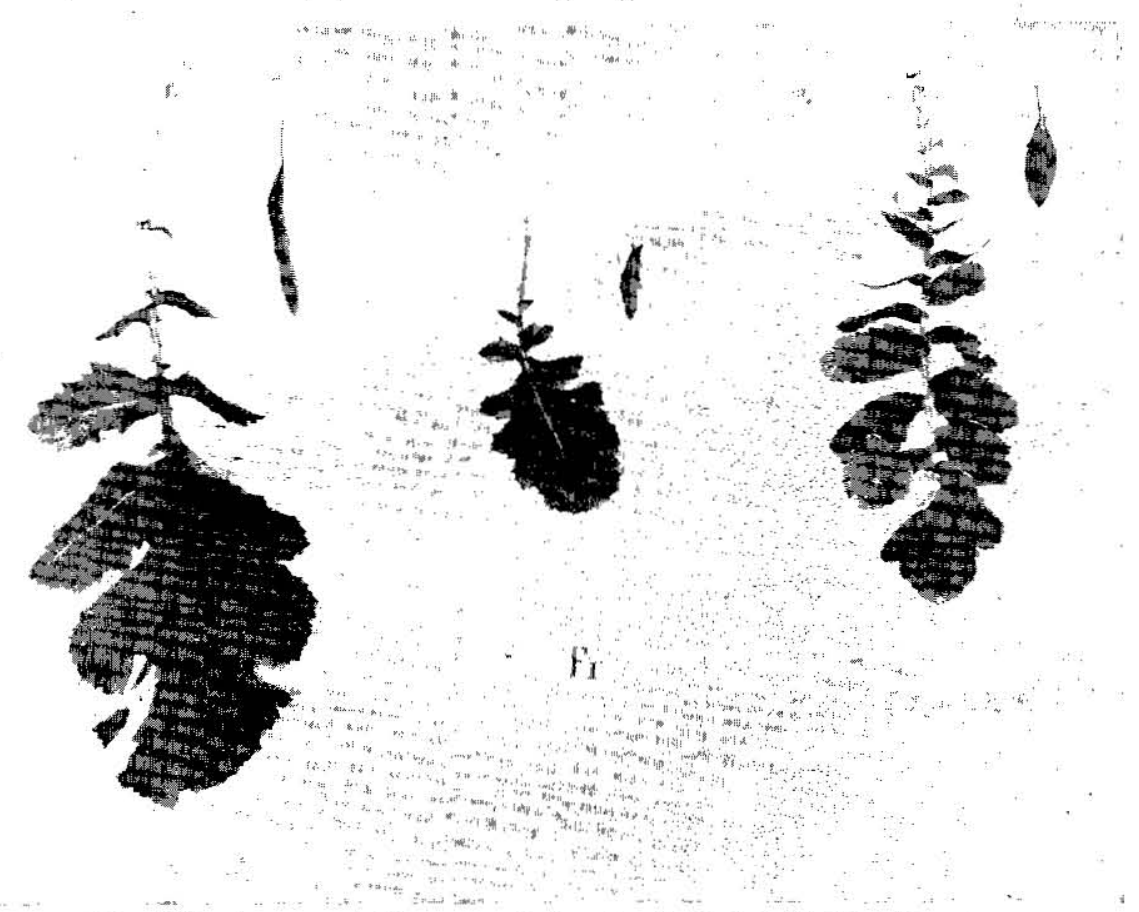

Fig. 137. Leaves of B. cernua "Karasina", $\mathrm{F}_{1}$ hybrid ( $\left.\mathrm{F}, \mathrm{B}\right)$, and R. sativus "Minowasé", from left to right.

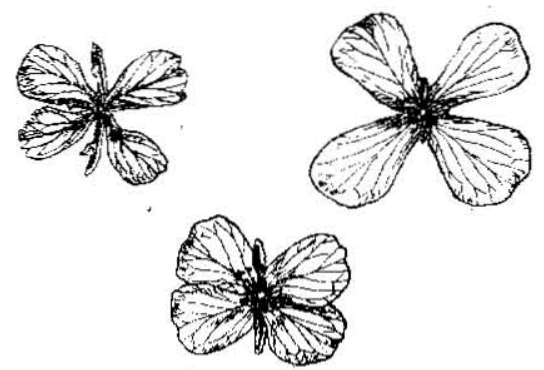

Fig. 138. Flowers of B. cernua "Karasina", $F_{1}$ hybrid $(F, B)$, and $R$. sativus "Minowasé", from left to right. $\times 1$.

$F_{1} B$ and $F_{1} C$ show quite similar mode of the I-division, and 27 univalent chromosomes appear exclusively in the I-Metaphase, showing no association of chromosomes. These univalent chromo- 
somes behave quite similarly in the I-division as in other $F_{1}$ " $R c$ " hybrids treated in Part I. Homotypic division processes, however, differ in the present hybrids, especially in the behaviour of monad chromosomes. In $\mathrm{F}_{1} \mathrm{C}$, monad chromosomes behave quite similarly as in the di-genome $F_{1}$ hybrid described in Part $I$, for 2-5 of them appearing as laggards at the II-Anaphase proceed finally to either one of the poles, without dividing completely into two halves. In $F_{1} B$, however, the whole chromosomes usually become arranged themselves on the equatorial plate at the II-Metaphase, leaving no monads scattered apart from the plate. Later all the chromosomes divide equationally, assorting their halves to the opposite poles. In this latter case, some univalent chromosomes, no doubt, undergo division twice. Restitution nuclei are also produced in both $F_{1}$ hybrids, though less frequently than in the other $F_{1}$ hybrids already described.

Cytokinesis usually follows the homotypic nuclear division, and sporads of various appearances result. Degeneration processes, however, soon set in in these sporads and the latter fail to grow up to viable pollen grains.

\section{Discussions}

\section{(1) Crossabilily}

The plant genera, which have been used successfully in obtaining intergeneric hybrids with the genus Brassica and studied cytogenetically in some details, are all confined to the subtribe Brassiceae. The names Raphanus, Eruca, and Sinapis are enumerated as such, and 'Raphanobrassica' of KARPECHENKO, which is produced artificially from the cross $R$. sativus $\times B$. oleracea, may also be regarded as one belonging here also ( $C f$. $\mathrm{U}$ et al., 1937): Genuscrosses have been carried out most extensively between Brassica and Raphanus. Raphanus sativus $(\mathrm{RR})^{\mathrm{1})}$ is the only representative species in that genus. ${ }^{2)}$ While in the genus Brassica several species have been used successfully for the cross with Raphanus; they are the following five elementary diploid species of $B$. oleracea

1) Genome constitution in somatic tissues.

2) Some other Raphanus species, i.e., R. Raphanistrum, R. acanthiformis, etc., are also described in literature, but all these species are considered to have the same genome constitution "RR." 
(cc), B. alboglabra (cc), B. Rapa (aa), B. campestris (aa) and $B$. chinensis (aa), besides three amphidiploid (or secondary polyploid) species, B. carinata (bbcc), B. cernua (aabb) and B. juncea (aabb). With the other popular cultivated Brassicas, e.g., B. Napella (aacc), $B$. napus (aacc), and $B$. nigra (bb), no true $\mathrm{F}_{1}$ hybrids between Raphanus sativus have been produced. Genus crosses between $R$. sativus and $B$. Napella or $B$. napus were tried by the author over and over again, but he failed in obtaining even a single true $F_{1}$ hybrid.

Crosses between $B$. oleracea and $R$. sativus were much more successful when the latter species was taken on the maternal side than the reverse. Crosses between Brassica species of "aa" constitution and $R$. sativus, however, were equally successful in both directions. As it is generally the case for the species-crosses, such secondary polyploid species, as B. carinata, B. cernua or B. juncea, produce true $F_{1}$ hybrids between radish only when the former are taken as seed plants.

Even in the fertile combinations of species and in the fertile mating directions above mentioned, the genus-crosses show in each case much variable degrees of success. KARPECHENKo (1927a, b; 1928) obtained rather a large number of $F_{1}$ seeds from his crosses $R$. sativus $\times$ B. oleracea, but the author and other workers obtained from the same cross combination only a very few of true $F_{1}$ seeds. Such a difference in crossability is thought to be due partly to different environmental conditions, external and internal. Especially the age of the plant may have some direct effect on the situation. There is no doubt, however, that the genotypic differences of the parents have a great and immediate bearing in this connection.

According to the varieties used, the $\mathrm{F}_{1}$ hybrids even of the same combination of species, show considerable differences in various points. The hybrid embryos develop in varying degrees, and some $F_{1}$ seeds do not germinate, while a large number of them produce either albinos or weak seedlings which perish sooner or later. All of these facts are naturally expected from the heterozygous nature of such $F_{1}$ embryos. KosTofF (1938a) observed quite a similar case of variable crossability in his Nicotiana cross, $N$. glauca $(2 \mathrm{n}=24) \times N$. Langsdorfii $(2 \mathrm{n}=18)$. His Nicotiana $\mathrm{F}_{1}$ 
embryos are said to have died out at various stages in their development.

In addition to the normal $F_{1}$ hybrids, diploid plants produced by parthenogenesis and abnormal $F_{1}$ hybrids with an extra maternal or paternal set of chromosomes were obtained by $U$ (1935), who had carried out crossings extensively between Brassica species and between Brassica and Raphanus. He considered that the extra-maternal $\mathrm{F}_{1}$ was derived from the fusion of a normal haploid sperm and an egg nucleus of which latter had already passed the first cleavage accompanying the doubling of chromosomes, and that the extra-paternal one was derived from the fusion of one egg and two sperm nuclei (U, 1935; U et. al., 1937). The deduction was made by him mainly from the following observations; (1) no occurrence of unreduced gametes in the species, or very rare occurrence if any ; ${ }^{1)}$ (2) rather frequent occurrence of diploid parthenogenesis in the species crosses in Brassica. The author has also obtained several plants quite similar to the maternal parents, along with the true $F_{1}$ plants treated in the present paper, but he has not met with any $F_{1}$ plant with one or more extra sets of chromosomes.

(2) Morphology of $F_{1}$ Hybrids

The di-genome $F_{1}$ hybrids, "Rc", show generally a strong tendency to produce heterosis in the height of plant, in the number of side flowering branches and also in the number and size of leaves. Similar di-genome $F_{1}$ plants raised by KARPECHENKo (1924), however, contained a number of dwarf plants which did not come up into flowering even at the end of the season. Trigenome $F_{1}$ hybrids, excepting those of " $R b c$ " $\left(F_{1} F\right)$, did not show such vigorous growth as the di-genome "Rc." On actual breeding experiments only, one can tell whether heterosis appears or not in a certain intergeneric hybrids of Brassica and Raphanus.

Generally speaking, the morphological characters of those digenome $F_{1}$ individuals are in some measure intermediate, though a certain parental characters predominate somewhat in the hybrid plants. In the tri-genome hybrid plants, however, the characters

1) The author encountered, though rather rarely, some individuals or strains, both of pure species and of hybrids between Brassica and Raphanus, which produce a certain percentage of unreduced male gametes with diploid, tetraploid, or a still greater number of chromosomes. 
of the parental species with higher chromosome number, i.e., of Brassica parents, usually predominate. Strictly speaking, hybrid characteristics differ to some extents even in the same species combination according to the genotypic constitution of the respective plants.

KARPECHENKo's $F_{1}$ hybrids, $R$. sativus $\times B$. oleracea, showed markedly polymorphous appearances, as cited elsewhere. But the author did not encounter with such a polymorphic situation in any of his cross combinations, though the number of sister individuals raised was always very small. The author, moreover, did not observe any clear differences between the reciprocal $F_{1}$ hybrids of the similar cross combination, i.e., between $F_{1} \mathrm{H}$ and $F_{1} \mathrm{~K}$. The author's materials seemed to be in less heterozygous condition than those of KARPECHENKO.

The prolongation of the blooming duration and the enlargement of flower clusters of $F_{1}$ hybrids are, no doubt, caused physiologically in connection with their high sterility.

Some $F_{1}$ plants of $R$. sativus $\times B$. oleracea did not die out after flowering, outliving two or three seasons or more. This character was perhaps inherited from the cabbage parent, as the latter showed such a tendency strongly.

(3) Meiosis of $F_{1}$ Hybrids

Chromosome pairing and its variability: Chromosome pairing in species- or genus-hybrids gives the most reliable and important clue for the solution of the problem of genome interrelationships among the species. The author studied the association of chromosomes in the heterotypic division with $8 F_{1}$ hybrids between $R$. sativus and $B$. oleracea (including $B$. alboglabra), namely $F_{1}$ 's $A$, $\mathrm{H}, \mathrm{I}, \mathrm{J}, \mathrm{D}, \mathrm{G}, \mathrm{K}$, and $\mathrm{E}$, and with 3 tri-genome $\mathrm{F}_{1}$ hybrids, $B$. carinata $\times R$. sativus, B. cernua $\times R$. sativus and $B$. juncea $\times$ $R$. sativus, namely $F_{1}$ 's $\mathrm{F}, \mathrm{B}$, and $\mathrm{C}$. The number of the total $\mathrm{F}_{1}$ individuals investigated amounted to 22 . As is clearly shown in Table $5, F_{1}$ individuals with the same genome combination " $R c$ " show different amounts of paired chromosomes at meiosis according to the varieties or strains used. In the plants $F_{l} A, F_{1} D$ and $F_{1} E$, the author could obtain no positive evidence of chromosome pairing, as all of those $F_{1}$ plants showed exclusively 18 univalent chromosomes. While in all the other $\mathrm{F}_{1}$ plants of " $\mathrm{Rc}$ " combina- 
tion, i.e., $F_{1} H, F_{1} I, F_{1} J, F_{1} G$ and $F_{1} K$, there appeared always variable number of bivalent chromosomes at the I-Metaphase, the maximum number of bivalents in one spindle being $5,4,6,3$ and 5 respectively. The frequency distribution of bivalent chromosomes on each spindle is shown in Fig. 30. On the other hand, trigenome $F_{1}$ hybrids, $F_{1} B$ and $F_{1} C$, each with "Rac", produced no bivalent chromosome, while $\mathrm{F}_{1} \mathrm{~F}$ with " $\mathrm{Rbc}$ " produced variable number of bavalents, ranging from zero to 4 (See Tables 7 and 8).

The amount of chromosome pairing also varies within certain limits with individuals as well as flowers. Thus the chromosome pairing shown in the present hybrids depends not only on the genotype but also on the environmental conditions, external and internal.

KARPECHENKO $(1924 ; 1927 \mathrm{a}, \mathrm{b} ; 1928)$ reported non-pairing of chromosomes in his $\mathrm{F}_{1}$ hybrids with "Rc" genomes. Several other workers, however, observed variable numbers of bivalents in their respective $F_{1}$ plants of the same genome combination. Thus $(0-$ 6) II, (0-3) II and (1-5) II were observed respectively by RICHHARIA $(1937 \mathrm{a})^{1)}$, U et al. (1937). and HowaRd $(1938 \mathrm{~b})^{22}$. In the case of tri-genome $F_{1}$ hybrids " $\mathrm{Rbc}$ ", $\mathrm{U}$ (1935) reported 26I exclusively, while RICHHARIA (1937a) ${ }^{3)}$ reported (2-9)ח and (0-9)I. KARPECHENKo (1937a) also observed (0-9) II association in the same kind of hybrid.

It is rather difficult to determine, from the above findings only, whether the bivalent chromosomes there observed are of autosyndetic or of allosyndetic nature. This question will be dealt with in some details later on in this chapter.

It is worthy of note here that the frequency distribution of bivalents such as shown in Fig. 30 may not tell the exact situation. First of all, some spindles with no bivalent chromosome tend to be overlooked, so that their number may be estimated slightly less than actually is, as the superposition of chromosomes makes it difficult to identify them correctly as such. Each frequency distribution polygon in Fig. 30, however, does not follow the chance distribution even with due consideration of the situation

\footnotetext{
1) Ricmiaris (1937a) counted $9_{I I}$ as the maximum association at I.Metaphase. But, as cited elsewhere, his data on I-Metaphase seem to be not quite reliable. For that reason the data obtained by him at late diplotene stage are cited in the text.

2) HoWARD (1938b) represents no I-Metaphase figure with $\mathrm{O}$ association.

3) Some secondarily associated univalents might be confused with the true bivalent chromosomes.
} 
above quoted. The distortion of polygons is considered to have been caused by the fact that each pair of associated chromo. somes has somewhat different power of association or pairing potentiality, e.g., each pair of A-A', B-B', C-C', D-D', etc. appears with different frequency. Thus each pair of these chromosomes seems to have partially homologous segment in common, and such homologous segment evidently varies with pairs in amount or in length. Taking into account the general mode of frequency occurrence of the paired chromosomes, those homologous parts, however, seem to be not so large (or so long).

As described above, the $\mathrm{F}_{1}$ plants of "Rc" genome constitution which are raised by the author or other workers from the same species combination, show considerable differences among themselves in the pairing potentialities, i.e., from complete absence of pairing to (0-6) II pairs. Such a difference in pairing is, no doubt, attributable mainly to certain genetical differences existing between the varieties or strains concerned in the crossings. This situation will be discussed more in detail later on in connection with the problems of evolution.

RICHHARIA (1937a) made a report on the chiasma formation and its behaviour in the paired chromosomes of his "Rc" hybrid. According to him, terminalization of chiasma occurred rather early, and most of $F_{1}$ pairs were already in end-to-end association at a late diplotene stage, usually giving the bivalent chromosomes at the I-Metaphase completely terminalized chiasmata. In the "Rc" hybrid of HOWARD (1938b), as in those of the present author, terminalization of chiasma was not so complete as in RICHHARIA's case, and it showed some incompletely terminalized bivalents even at the I-Metaphase. HowARD also observed that each $F_{1}$ pair had only one chiasma, while that of parental species had 1-3 chiasmata in each bivalent.

The author obtained the results similar to HowARD's, namely the $F_{1}$ bivalent at the I-Metaphase had usually one chiasma, though the case of having two chiasmata was not excluded absolutely. RICHHARIA, however, observed two chiasmata in 11 out of 99 pairs, but he did not meet with those having three chiasmata. The latter author observed, in turn, in the parental species, $R$. sativus and $B$. oleracea, 13 and 11 pairs with three chiasmata respectively out of 99 pairs: 
HowARD (1938b) observed occassionally trivalent chromosomes in his "Rc" hybrid. Though some of those trivalents were considered to be the secondarily associated II +I chromosomes erroneously interpreted, he no doubt observed some true trivalent ones with a triple chiasma. So one of the haploid chromosome sets of parental species might contain a reduplication of a chromosome or a chromosome segment. The author observed in " $\mathrm{Rc}$ "hybrids 4 metaphasic figures in all, each of which contained one true trivalent, no higher multivalents being encountered. On the other hand, the author observed not only occasional multivalent chromosomes, mostly tetravalents, in some strains of $R$. sativus, $B$. oleracea, and $B$. alboglabra (Unpublished), but also several spontaneous occurrences of interchange heterozygote in $R$. sativus (FuKUSHIMA, 1937). Thus the origin of the trivalent chromosomes in the "Rc"-hybrids may be explained by the spontaneous chromosome alterations such as translocation or the like.

It is well known that the formation of bivalent chromosomes and its measure have more or less direct effects upon the genotypic constitution of gametes, so also that of zygotes produced by those $F_{1}$ hybrids. In consequence, a considerable effect of bivalent formation upon the fertility of $F_{1}$ hybrids is expected.

Usual course of $F_{1}$ meiosis: The usual course of $F_{1}$ meiosis is quite similar in both the di-genome and tri-genome hybrids. When paired chromosomes appear, they take regular position on the equator at the I-Metaphase, and at anaphase they soon disjoin, assorting their components to either pole. Univalent chromosomes behave in heterotypic division quite as usual, a part of univalents splitting at the I-Anaphase and the rest at the II-Anaphase. Cytokinesis by invagination follows the homotypic nuclear division, resulting in sporads. The majority of sporads are higher polyads rather than ordinary tetrads. They contain supernumerary micronuclei which are produced by laggards excluded from the ordinary nuclei.

In these $F_{1}$ plants there occurs not infrequently restitution of division at the I-Anaphase. The occurrence of such restitution nuclei depends upon the strains of $F_{1}$ hybrids, or the genotypic differences of the hybrid individuals. Its frequency occurrence, however, seems to be affected much by some environmental conditions, external or internal, as it varies not only with the materials 
taken from one and the same individual at different dates, but also with the anthers even of the same flower examined on the same day (Cf. page 325 ). Restitution nucleus appears, in general, when the PMC contains comparatively a few bivalents or no bivalent chromosomes at all. Whether the restitution occurs or not in a particular PMC seems to depend mainly on the behaviour of univalents as a whole in the I-Anaphase. And the behaviour of univalents in the I-Anaphase depends, in all probability, more on a certain environmental conditions than the intrinsic nature of the hybrid. The amount of viable gametes produced after meiotic divisions depends to some extent on the frequency of restitution, and it, in turn, has more or less direct connection with the dehiscence of anther-sacs. All of these situations naturally relate closely to the fertility of the hybrid plants.

The author did not notice any chromosome bridge formation in his materials". On similar Cambridge materials, "Rc"-hybrids, however, RICHHARIA (1937a) observed rarely the occurrence of a bridge, and HOWARD (1938b) could notice one or two bridges in 81 per cent. of the PMCs at the I-Anaphase examined by him. The latter author also noticed a persistent bridge in the restitution, but he did not meet with any bridge formation in the parental species concerned. SIKKA (1940) also observed rare occurrences of bridges in some interspecific $F_{1}$ hybrids; i.e., univalent bridges at the I-Anaphase in B. Tournefortii $\times B$. trilocularis, and second division bridges in $B$. juncea $\times B$. campestris.

Megasporogenesis and the mode of female gametophyte formation were studied by the author on the $\mathrm{F}_{1} \mathrm{D}$ plant. Megasporogenesis proceeds in a manner quite similar as the microsporogenesis. Some irregular division and degeneration processes occurred are described elsewhere.

Some irregular phenomena occurred in $F_{1}$ meiosis: The author observed several irregular meiotic behaviours in the present $F_{1}$ hybrids as described already. Some of those irregular phenomena will be dealt with again in the following paragraph.

In $F_{1} E$ plants, "Rc", the author observed not infrequently the prophasic PMC whose nucleus was protruding a part or parts like buds. And in certain I-Metaphasic cells of the same material,

1) The author, however, observed several cases of the bridge formation in some strains of $B$. olevacea and, $R$. sativus (Unpublished). 
there were noticed two spindles, or even more than two in some occasions, giving quite similar figures as depicted by BLEIER (1930) on his wheat-rye hybrids. BLEIER maintains that his figures were caused by a general tendency of hybrid nucleus to divide its complex into componental parts, and so he termed the phenomena "Kryptogonomerie". BLEIER showed PMCs with two completely separated spindles, each consisting of just the parental number of chromosomes. The author, however, failed to obtain any figure with two such spindles. BLEIER's view has hitherto been severely criticized, chiefly by KATTERMANN (1933), MATSUMOTO (1933), and KIHARA and LILIENFELD (1934). These authors insist that BLEIER's figures could have been derived from cytomixis in a wide sense or "Kerneinwanderung", and that some of BLEIER's I-Metaphasic spindles might be the strongly curved ones misinterpreted. The present author could not make clear with his $F_{1}$ E plants, "Rc", the occurrence of cytomixis or "Kerneinwanderung". Instead he found such prophasic nuclei forming a narrow neck as shown in Figs. 20 and 21 . Thus he rather considers that those abnormal metaphasic figures with two spindles are caused by the budding of nucleus in prophasic stage. This presumption is also supported by the fact that two such spindles, though not always equal in size, usually contain in all 18 chromosomes. The author observed also PMCs with small supernumerary nuclei distributed in cytoplasm or closely associated with the main nucleus. Similar nuclear budding was reported by McCLINTOCK (1929) in PMCs of triploid maize plants. SAKAMURA (1920) is the first who reported the occurrence of nuclear budding, or "Knospung" according to his designation, and KATTERMANN (1933) regarded cytomixis as a special case of nuclear budding. SHIMotomaI (1931, 1933) also observed in his Chrysanthemum hybrids, similar figures, "Nebenkernbildung", as those of KiHARA and Lilienfeld (1934), but he referred those to some irregularities in archesporial nuclear and cell divisions, but not to cytomixis. Each PMC of $F_{1} E$ with budding nuclei usually contains the whole diploid chromosomes, 18 in number, on the two or more spindles, showing no transference of any chromosomes to or from the adjacent cell. Therefore, the spindles, two or more in number, in such abnormal PMCs are smaller than the normal metaphasic one.

Syndiploid PMCs are observed rarely in the present $F_{1}$ 
hybrids. Giant PMCs with two diploid nuclei were observed by several workers before, for instance by KARPECHENKo (1927a, b) in $R$. sativus $\times$ B. oleracea hybrid, GATES and REES (1921) in Lactuca, INARIYAMA (1929) in Iris, and NANDI (1936) in Oryza species. RUTTLE (1928), observed such giant cells in root-tip cells of a haploid plant of Nicotiana, and he referred that, as NANDI (1936) did, to the complete transference of the chromatin of one nucleus to the adjoining cell. Recently, SIKKA (1940) noticed such syndiploid PMCs in his Brassica hybrids, and delivered the same opinion for their origin as the latter authors. On the data presented in the previous paper (FukUSHIMA, 1931), the author, on the contrary, considers the occurrence of those syndiploid cells as due to the irregular archesporial cell divisions rather than the cytomixis.

In some $F_{1}$ anthers, interruption of division occurs at various stages of meiosis and such PMCs soon degenerate. The interruption of this type occurs, though neither frequently nor in the same extent, in all $\mathrm{F}_{1}$ hybrids of different cross combinations. In exceptional cases, PMCs degenerate at premciotic archesporial stages. In $F_{1} A$ plants, "Rc", all the PMCs degenerate soon after the IAnaphase without proceeding into homotypic division. Generally, however, the $F_{1}$ PMCs undergo usual meiotic divisions as stated before, and the sporad stage follows. Nearly all of the $F_{1}$ young microspores thus produced cease to grow sooner or later owing perhaps to the genetic unbalance of their nuclear contents.

In some rare $F_{i}$ anthers, the author observed some spores produced directly from archesporial cells without undergoing meiosis. Such monad spores have also been described in Fuchsia by WARTH (1925). The production of polyploid spores in this manner may have some important relation to the fertility of the $F_{1}$ hybrids. The author, however, cannot obtain any positive data on the future destiny of these giant spores. As described elsewhere, giant gametes are also produced when cytokinesis after the second nuclear division is suspended and nuclear fusion follows. Further, polyploid PMCs which are derived from giant archesporial cells produced through irregular division processes, such as already reported by the author in B. japonica (Fukushima, 1931), are also met with rarely in the present $F_{1}$ hybrids. 


\section{(4) Fertility in $F_{1}$ Hybrids}

Though the present intergeneric $F_{1}$ hybrids are of extreme low sterility, there can still be noticed some difference in fertility among them. Some $F_{1}$ plants were completely sterile, but the most fertile ones could produce several $F_{2}$ seeds under open pollination. The degree of viable gamete formation in each $F_{1}$ plant, no doubt, plays the most important part in deciding the fertility grade of the plant, and it is generally recognized that the viable gametes result when they have established a balanced gene relation concerning the viability. Owing to the irregularities occurring in $F_{1}$ meiosis, nearly all of the $F_{1}$ gametes will contain chromosomes in an unbalanced condition and so are also the genes. Thus the chance for the $F_{1}$ gametes to recover perfectly or nearly perfectly either one of their parental chromosome complexes or both of those may be practically negligible in the present hybrids. As stated above, the $F_{1}$ hybrids, however, produce occasionally polyploid gametes which, no doubt, conatin chromosomes in balanced functional condition, and so are viable. Of those polyploid gametes described elsewhere, those produced by restitution may not contain exactly the diploid or both parental chromosomes, on account of the splitting of some univalents before restitution. Various kinds of special irregularities which produce viable polyploid gametes are greatly affected by the environmental conditions, external or internal, thus the quantity of viable $F_{1}$ gametes, and, in consequence, the fertility of the hybrids, are affected in that measure by the complex environmental conditions.

The author raised two sister plants of $F_{1} D$ hybrid, $R$. sativus $\times B$. oleracea, and one of them was completely sterile, while the other partially fertile. The chromosome behaviours of these two sister individuals were quite similar, showing no definite differences throughout the meiotic processes. Such more or less greater differences existing among sister individuals were also noticed in $F_{1}$ hybrids of the same species combination by KARPECHENKO (19241928) and by RichHARIA (1937a) (Cf. LeHMANN, 1936).

The author obtained several $F_{2}$ plants from certain $F_{1}$ hybrids, i.e., $\mathrm{F}_{1} \mathrm{H}, \mathrm{F}_{1} \mathrm{D}$, and $\mathrm{F}_{1} \mathrm{G}$ from the cross $R$. sativus $\times$ B. oleracea, $\mathrm{F}_{1} \mathrm{E}$ from $R$. sativus $\times B$. alboglabra, and $\mathrm{F}_{1} \mathrm{~F}$ from $B$. carinata $\times R$. sativus, but he failed to obtain any $\mathrm{F}_{2}$ seed from the rest of 
$F_{1}$ hybrids investigated. The author also could not detect any clear causal relations existing between the meiotic behaviours and the amounts of $F_{2}$ seeds produced. Fertility problems, such as the actual chromosomal contents of viable $F_{1}$ gametes, the zygotic unbalance in chromosomes or in internal genes, later elimination of zygotes, etc., will be dealt with in a future paper on the later progenies of these $F_{1}$ hybrids.

\section{(5) Species Formation in Brassica and Raphanus}

The evolutionary development of the species, elementary or polyploidal, may be duely ascribed to the differentiation in the respective genomes. This genome differentiation may be understood as the differentiation of genes as well as of chromosomes. The former differentiation will result through the accumulation of $\dot{a}$ simple gene mutation. A group of many Brassica species, each with 10 chromosomes in haploid, may have been differentiated mainly by such process (Cf. MoRINAGA, 1929a, b; 1931; RICHHARIA, 1937b; SIKKA, 1940). The chromosomal change may take place in either one of the two ways, namely, structurally or numerically. Structural variations are known as segmental interchange, duplication, inversion, deletion of a portion, etc. Though some of these variations are not accompanied by any direct phenotypical variations, they, none the less for that, have an important significance as the basis of future differentiations.

Numerical changes, being classified into polyploidy and poly. somy or aneuploidy, are often recognized as the most favourable changes in nature, for more than half the species and varieties of flowering plants in nature belong to various polyploid series ( $C f$. DARLington, 1937; KostofF, 1939).

The genus Brassica contains many species, the haploid chromosome number of which being $8,9,10,11,12,17,18,19$ and 24 respectively. Thus in this genus a remarkable development of aneuploidy prevails, as in some other genera as Crepis and Crocus (Cf. BABCOCK and NAyAShin, 1930; Mather, 1932).

For the formation of polyploid species various ways have been made clear to some extent by the cytological or other lines of studies, but our knowledge on the origin of aneuploid species is still very meagre. Thus, the studies on the genus Brassica are of 
a considerable significance, in connection with the general problem of the origin of aneuploidy.

The conception that a new genome is originated from an old one through its differentiation and bringing about of a new balance, has been first proposed as the theory of "secondary balance" by DARLINGTON and MofFetT (1930), in connection with their cytogenetical studies on the Pomoideae section of Rosaceae. According to DARLington (1937), secondary balance is "a new balance derived by change in the proportions of genes, as in a secondary polyploid from an old balance, and capable of competing with it." In consideration of further differentiations of secondarily balanced forms thus produced, the establishment of aneuploidy may be most easily comprehended ${ }^{11}$. Though our knowledge and experimental evidences for the mechanism of secondary balancing or şecondary polyploid formation which gives such a wide variation in polyploidy itself, are very meagre, the following examples of artificially produced secondary polyploid forms may be of service in suggesting the possibility of occurrence, of such a phenomenon in nature. Clausen (1926) obtained a new "species" Viola hyperchromatica with approximately $2 \mathrm{n}=42-45$ chromosomes, from the cross $V$. arvensis $(2 \mathrm{n}=34) \times V$. tricolor $(2 \mathrm{n}=26)$, and Collins et al. $(1929)$ obtained Crepis artificialis $(2 \mathrm{n}=24)$ from the cross $C$. biennis $(2 \mathrm{n}=$ $40) \times C$. setos $a(2 \mathrm{n}=8)$. The latter new and true breeding forms are thought to have ten pairs of biennis and two of setosa chromosomes. From a cross Nicotiana rustica $(2 \mathrm{n}=48) \times N$. paniculata $(2 \mathrm{n}=24)$ a new race, having $\mathrm{n}=30 \mathrm{n}$, was obtained by LAMMERTS (1932), and it bred true through many selfed generations. WEBBER (1930) also obtained, in $F_{6}$ generation of a similar cross $N$. tabacum $(2 \mathrm{n}=48) \times N$. sylvestris $(2 \mathrm{n}=24)$, a pentaploid plant with $\mathrm{n}=25 \mathrm{II}$, consisting of the complete unreduced compiement of the seed parent and a haploid set of the pollen parent. The plant showed as high fertility and good growth as the pure species. On the other hand, analytical data obtained by various methods on some natural species also support indirectly the view above stated.

Cytology gives the most conclusive clue for the explanation of the origin of polyploid species, but there also exist various other

1) The theory of "secondary balance" has hitherto been applied rather extensively by various workers in combination with "secondary association", a hypothesis advanced by DARLINGTUN and his colleague. The author will refer to the hypothesis in some details elsewhere in the text. 
indirect means which have been applied to solve the phylogenetic relationships of such species. Gene analysis is considered as one of such indirect methods. Genetical studies have made clear the presence of several duplicate factors in Brassica oleracea (PEASE, 1926 ; Kristofferson, 1927 ; Magruder and Myers, 1933 ; MoHAMMAD and SikKa, 1937; also Cf. MatsuUra, 1933). And such genetical data are taken by some authors as an indirect proof of the polyploidal nature of that species. The incompatibility interrelationships in cabbage, determined by DETJEN (1927), KAKIZAKI (1930), and SEARS (1937), and those in Raphanus sativus determined by the author (Unpublished) are also considered to suggest the polyploidal nature of those species. The latter problem has been discussed at length by LAWRENCE (1930).

As another non-cytological way to explain the species interrelationships serological method is adopted sometimes. The author investigated the precipitin reaction of protein with several species of Brassica and Raphanus and made clear the problem to some extent (Fukushima and MaruYama, 1929).

Cytological methods may be divided into direct and more or less indirect ones. As the indirect methods which give indirect source of evidences to make clear the polyploid nature of species, the following three kinds of investigations have been pursued; (1) investigations on the nucleoli and SAT-chromosomes, (2) investigations on the morphology of somatic chromosomes, and (3) investigations on the "secondary association" of chromosomes at meiosis.

SIKKA (1940) observed in each somatic nucleus of B. nigra $(n=8)$, the species with the smallest number of chromosomes in the genus, 4 satellited chromosomes and 4 nucleoli, and took the facts as strongly suggestive of the tetraploid nature of the species. But he could notice only one pair of nucleoli and satellited chromosomes in other Brassica forms with a larger number of chromosomes, $\mathrm{n}=18,20$, or 24 , and considered that the latter condition had been derived by the loss of extra pairs, inferring the phenomenon of "amphiplasty" first observed by NAVASHIN (1934) in his Crejis crosses. Admitting that the hybridity has such an amphiplastic effect, the actual occurrence of extra pairs of nucleoli and of satellited chromosomes in some Brassica may have a direct bearing on the allopolyploid nature of such species. SIKKA (1940) also refers to the cases of rice plants, where two nucleoli-varietics 
are considered to have been derived from four nucleoli-varieties (RAMANUJAM, 1937a).

Since the chromosomes of Brassica forms are very small, their morphological analyses are very much limited. CATCHESIDE (1934) studied root-tip cells of his ' $B$. napus' $(2 \mathrm{n}=36)$ and $B$. Rapa (2n $=20$ ), and could discriminate four kinds of chromosomes according to the length and position of constrictions; i.e., nearly median $(2 \mu)$, median $(1-1.8 \mu)$, subterminal $(1-1.8 \mu)$ and very short $(0.5 \mu)$ ones. AlAm (1936) obtained similar results of analyses in B. trilocularis, B. campestris, B. juncea and Eruca sativa. Of the data obtained in this line of study, RichHARIA's $(1937 \mathrm{a}, \mathrm{b})$ are more or less extensive. As shown in Table 10, he distinguished six or seven different types of chromosomes in certain Brassica species.

Table 10. Chromosome complements of some Brassica species, showing morphologically distinct types of chromosomes (compiled from RICHHARIA, 1937a, b).

Species

B. oleracea $(n=9)$

B. chinensis $(\mathrm{n}=10)$

B. Rapa $(\mathrm{n}=10)$

B. pekinensis $(\mathrm{n}=10)$

R. sativus $(\mathrm{n}=9)$
Haploid set of chromosomes

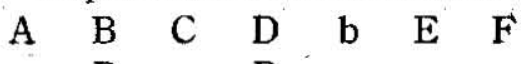

B D

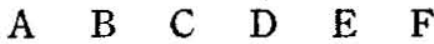

D. E,$F$

A $\quad B \quad C \quad D \quad E \quad F$

D E F

E

A B C D E F

D E F

$\mathrm{F}$

$\begin{array}{llllll}\text { A } & \text { B } & \text { C } & \text { D } & \text { E } & \text { F } \\ & \text { B } & & \text { D } & & \text { F }\end{array}$

The distinction of types, however, was rather difficult for him as there was a transitional type between $\mathrm{B}$ and $\mathrm{D}$, and $\mathrm{E}$ and $\mathrm{F}$ were fairly alike. In short, even in those Brassica forms of 10 chromosomes, it is likely that there are repetitions in some 
types of chromosome, though it cannot be taken as a decided evidence.

As another indirect cytological method of solving the problem, the investigation of "secondary association" of meiotic chromosomes is highly appreciated by some workers. The fact that the meiotic chromosomes sometimes show differential approximation at I- and II-Metaphase has been known in a large number of plant genera. But DARLINGTON and his colleague are the first who have taken this postsynaptic phenomenon as a result of generalized attraction between related chromosomes in a distant phylogeny (Cf. Darlington, 1928; Darlington and Moffett, 1930; Lawrence, 1931). Owing to a remarkable prevalence of aneuploidy throughout the genus, Brassica species have been adopted by several workers as favourable objects of studies in this category. The theory of "secondary association" is, in the author's view, yet an unproved premise, and it cannot be accepted positively as that of experimental cytology at the present state of our knowledge. Data of "secondary association" reported in several Brassica forms will be dealt with later on.

Now, the "genome-analysis" based mainly on the cytological examinations of interspecific or intergeneric hybrids can be taken up as only one method which is well established and offers direct evidences toward the origin of species. "Genome analysis" reveals the interrelationship between the genomes concerned in the basis of the actual "primary pairing" of hybrid chromosomes. Data of autosyndetic pairing in the haploid individuals, no doubt, have important bearings on this connection. The author will discuss in this place the problem of species formation in Brassica and Raphants from the data obtained by him on his intergeneric $F_{1}$ hybrids, referring to the results of other workers on the similar intergeneric $F_{1}$ hybrids as well as other interspecific ones raised among Brassicas.

There is a group of Brassica species which contain 10 chromosomes as gametic complement, i.e., B. campestris, B. Rapa, $B$. chinensis, B. japonica, B. pekinensis, etc. These species show remarkable differences in various characteristics, but can be hybridized easily among them, resulting in the production of quite fertile $F_{1}$ hybrids. The meiosis in such hybrids is as regular as in the parental forms, showing complete pairing of respective chromo- 
somes (Cf. Morinaga, 1928; RichHaria; 1937b; Sikka, 1940), and genetical examinations on some interspecific crosses within the group show the Mendelian segregation of various characters ( $C f$. MOHAMmAD and SiKKa, 1937; MorinaGa and Kubota, Unpublished). Thus the differences among these species are considered as a sort of simple gene mutations as it had been interpreted by BAUR (1932, and others) for Antirrhinum species. Such a genome composed of 10 chromosomes has been termed "a" by MorinaGa. In addition to " $\mathrm{a}$ " two other genomes, " $\mathrm{b}$ " and " $\mathrm{c}$ ", are known as the primary ones in Brassica. The " $\mathrm{b}$ " genome consists of the haploid chromosome set of $B$. nigra $(\mathrm{n}=8)$ and the " $\mathrm{c}$ " of B. oleracea $(\mathrm{n}=9)$ (MoRINAGA, 1928-1934). "Three amphidiploid natural forms, i.e., "aabb", "aacc", and "bbcc", derived each from the two of the three primary genomes, are also made known by Morinaga, SASAOKA (1930) and U (1935). No such a form containing all these three genomes together, i.e., "aabbcc" plant, however, is encountered with nor is artificially produced as yet. Artificial formation of some amphidiploid Brassica forms has been also achieved by some workers. U (1935) succeeded in artificial raising of a form quite like natural $B$. napus (aacc) from the cross $B$. campestris (aa) $\times B$. oleracea (cc). MorINAGA (Unpublished) has also obtained amphidiploid forms "aacc" and "bbcc" respectively from the hybrids, $B$. chinensis (aa) $\times B$. alboglabra (cc), and $B$. oleracea $(\mathrm{cc}) \times B$. nigra $(\mathrm{bb})$. The former form is $B$. napus (aacc) in all its morphological respects, but produces white flowers, while the latter form is nothing but $B$. carinata (bbcc), though it differs in minor points from any carinata forms in his collection (Cf. KARPECHENKo and Bogdanova, 1937). Success in artificial production or synthesis of the above mentioned forms seems to prove positively the genome constitution hypothesis of Brassica proposed by MoRINAGA (1934). B. cheiranthos $(2 n=48)$ is the only species with the highest number of chromosomes in the genus. It is suggested by SIKKA (1940) that this species may have been originated from a certain hybrid between species with 12 haploid chromosomes, such as $B$. monensis and $B$. Wrightii, through chromosome doubling.

The genus Raphanus, in striking contrast to Brassica, contains only one genome " $\mathrm{R}$ ", which is composed of 9 chromosomes of R. sativus. 
Manners of chromosome association in meiosis of various intergeneric $\mathrm{F}_{1}$ hybrids hitherto worked out between Raphanus and Brassica are summarized in Table 11. Those of other RaphanusBrassica hybrids with extra set of parental chromosomes appeared among normal $F_{1}$ plant or in later generation of the latter, and those of $F_{1}$ plants obtained from the crosses with artificially raised 'Raphanobrassica' of ḰARPECHENKO as one parent, are given in Table 12.

Table 11. Chromosome pairing in meiosis of various intergeneric $\mathrm{F}_{1}$ hybrids between Brassica and Raphanus species.

Hybrids ${ }^{1 /}$

$R$. sativus $\times B$. oleracea

$2 \mathrm{n}=18$, "Rc"

$F_{1}$ ( 3 ind.)

$\mathrm{F}_{1}$ 1-UN

$\mathrm{F}_{1}$ 11-12

$F_{1} 7-3^{*}$

$F_{1} 10-9^{*}$

$F_{1} 10-14^{*}$

$F_{1} 11-11^{*}$

F's 2,4 and 42

$F_{1}$ 's 17 and 22

$\mathrm{F}_{1} \mathrm{~A}$

$\mathrm{F}_{1} \mathrm{H}$

$F_{1} I$

$F_{1} \mathrm{~J}-1$.

$F_{1} \mathrm{~J}-2$

$F_{1} G$

F, D (2 ind.)

$B$. oleracea $\times R$. sativus

$$
2 \mathrm{n}=18 \text {, “ } \mathrm{cR} \text { " }
$$

$\mathbf{F}_{1}$ (? ind.)

$F_{1} \mathrm{~K}$

$R$. sativus $\times B$. alboglabra

$2 \mathrm{n}=18$,

"Rc"
Chromosome pairing

$$
\begin{gathered}
18_{\mathrm{I}} \\
(0-6)_{\mathrm{II}}+(18-6)_{\mathrm{I}} \\
(0-6)_{\mathrm{II}}+(18-6)_{\mathrm{I}} \\
(0-8)_{\mathrm{II}}+(18-2)_{\mathrm{I}} \\
(0-6)_{\mathrm{II}}+(18-6)_{\mathrm{I}} \\
(0-9)_{\mathrm{II}}+(18-0)_{\mathrm{I}} \\
(1-8)_{\mathrm{II}}+(16-2)_{\mathrm{I}} \\
(0-4)_{\mathrm{II}}+(18-10)_{\mathrm{I}}^{* *} \\
(0-5)_{\mathrm{II}}+(18-8)_{\mathrm{I}}^{* *} \\
18 \\
(0-5)_{\mathrm{II}}+(18-8)_{\mathrm{I}} \\
(0-4)_{\mathrm{II}}+(18-10)_{\mathrm{I}} \\
(0-6)_{\mathrm{II}}+(18-6)_{\mathrm{I}} \\
(0-5)_{\mathrm{II}}+(18-8)_{\mathrm{I}} \\
(0-3)_{\mathrm{II}}+(18-12)_{\mathrm{I}} \\
18_{\mathrm{I}}
\end{gathered}
$$$$
(0-3)_{\mathrm{II}}+(18-12)_{\mathrm{I}}
$$$$
(0-5)_{\mathrm{II}}+(18-8)_{\mathrm{I}}
$$

U et al. (1937)

Furcshima

$$
\text { Authority }
$$

KaRPEChenKo (1924)

Richiaria (1937a)

How ARD (1928b)

Furushima (1929)

Ferushima

,"

,

,

$"$
$F_{1} E(5$ ind.)
$18 \mathrm{I}$
FuKeshima

1) Chromosome number' and genome constitution in somatic tissues are described for each kind of cross-combinations. Original experiment No. or notations of $F_{1}$ individuals are represented. When more than two sister plants were raised, the number of sister inividuals examined is shown in parenthesis, and (? ind.) denotes the case where the number of sister plants was not reported in the original literature. 
B. chinensis $\times R$. sativus

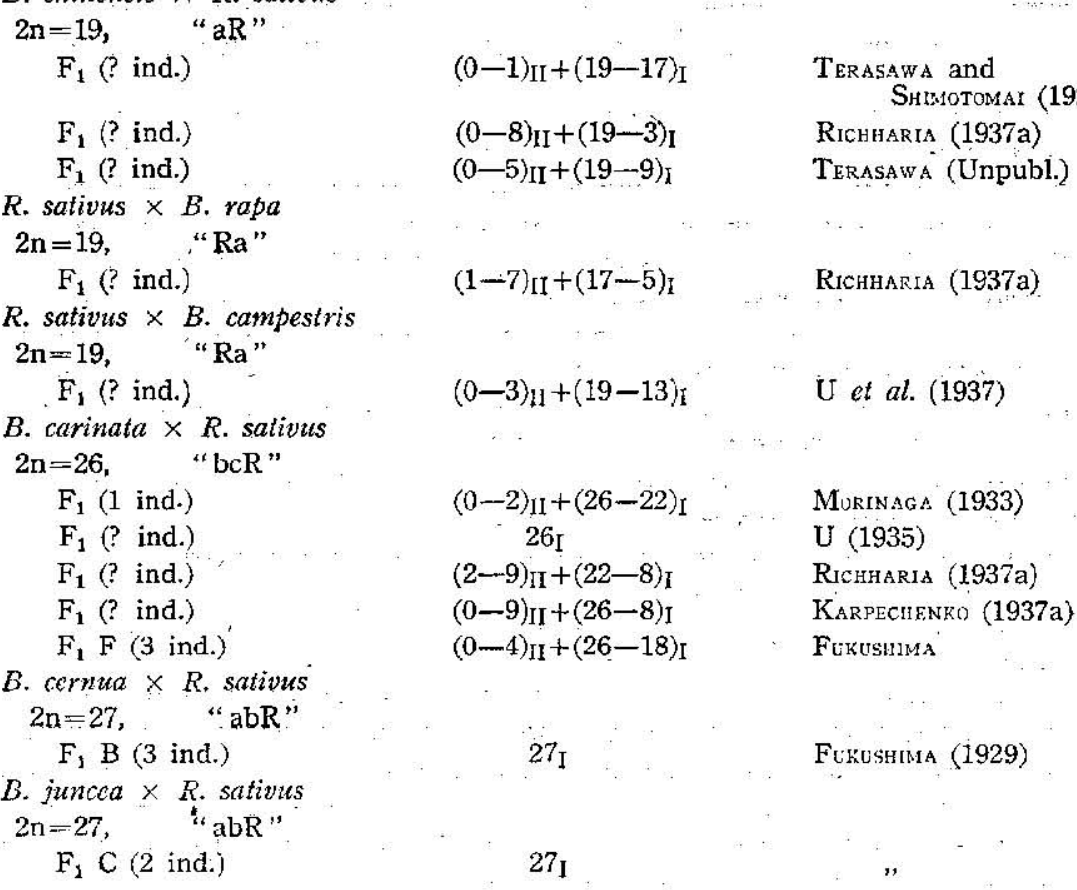

* With these $F_{1}$ hybrids, Richiraria usually obtained slightly larger amount of II-chromosomes at I-Metaphase than at late diplotene, owing to misinterpretation of secondarily associated univalents as stated elsewhere.

** Howard did not show, in his statistic data, the frequency of I-Metaphase spindles with non-pairing, but the actual occurrence of such spindles is inferred from his descriptions.

Table 12. Chromosome pairing in meiosis of various BrassicaRaphanus hybrid plants with extra set of parental chromosomes and of various $\mathrm{F}_{1}$ hybrids obtained from crosses with 'Raphanobrassica (RRcc)' as one parent.

\section{Hybrids ${ }^{1)}$}

$R$. sativus $\times$ B. oleracea
Chromosome pairing

$$
\begin{gathered}
9_{\text {II }}+9_{\text {I }} \\
18_{\text {II }} \\
18_{I I}+9_{I}
\end{gathered}
$$

Authority

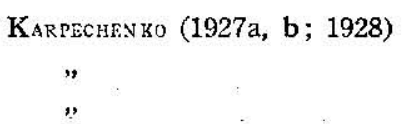

$B$. oleracea $\times R$. sativus

$$
9_{\mathrm{II}}+9_{\mathrm{I}} \quad \text { U et al. }(1937)
$$

1) Chromosome number and genome constitution in somatic tissues are represented for each kind of the hybrid individuals. 
B. chinensis $\times R$. sativus

$F_{5} 2 \mathrm{n}=38$, "aaRR" 19 II

$R$. sativus $\times$ B. campestris

$\mathrm{F}_{1} 2 \mathrm{n}=28$, "RRa" $\quad 9_{\mathrm{II}}+10_{\mathrm{I}} \quad \mathrm{U}$ et al. (1937)

Raphanobrassica $\times R$. sativus

$F_{1} 2 n=27$, "RRc" $\quad 9_{\text {II }}+9_{I} \quad$ Karpschengo and Suchavinskata (1929)

Raphano' assica $\times R$. raphanistrum

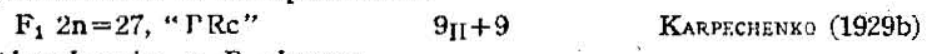

Raphanobrassica $\times B$. oleracea

$\mathrm{F}_{1,2} \mathrm{n}=27$, "Rcc" $\quad 9_{\mathrm{II}}+9 \quad$ Karpechenko and Sichavinskata (1929)

Raphanobrassica $\times$ B. campestris

$F_{1} 2 \mathrm{n}=28$, "Rac" $(5-6)_{\mathrm{II}}+(18-16)_{\mathrm{I}} \quad \mathrm{K}_{\mathrm{ARPECHenko}}(1929 \mathrm{~b})$

Raphanobrassica $\times$ B. carinata

$F_{1} 2 \mathrm{n}=35, " \mathrm{Rbcc} " \quad\left(9-17_{1 \mathrm{I}}+(17-1)_{\mathrm{I}}\right.$

$4 n-$ B.oleracea $\times$ Raphanobrassica

$\mathrm{F}_{1} 2 \mathrm{n}=38$, "Rccc" $(0-8)_{\mathrm{HI}}+(9-1)_{\mathrm{II}}+(18-10) \mathrm{K}_{\mathrm{ARPECHENKo}}(1937 \mathrm{~b})$

$\mathrm{F}_{1}$ hybrids, " $\mathrm{Rc}$ " or " $\mathrm{cR}$ ", between $R$. sativus and $B$. oleracea (including B. alboglabra) show variable types of chromosome association as represented in Table 11, ranging from the complete absence of pairing (0II) to the complete pairing (9II). Types (0-8)ri and (0-9)II are obtained only by RICHHARIA (1937a) at the I-Metaphase of his $F_{1}$ plant. As it has been discussed, his data in the I-Metaphase, which give a larger maximum number of paired chromosomes than in late diplotene, do not seem to be reliable. The maximum association range, i.e., (0-6)II, obtained by the present author with those $F_{1}$ 's at the I-Metaphase is quite concurrent with that of RICHHARIA's $F_{1}$ hybrids at late diplotene.

When variable number of bivalent chromosomes appear, the frcquency occurrences of paired chromosomes do not show usually any chance distribution. Thus the $F_{1}$ 's with the same maximum number of paired chromosomes, e.g., 4, or 5, do not necessarily show a same type of frequency distribution of paired chromosomes, showing usually some discrepancies according to the differences in varietal cross-combinations ( $C f$. Fig. 30 ). Association potentialities of the respective pairs of chromosomes, no doubt, vary more or less with the differences in genotypes.

It is generally recognized that, with the progress of differentiation, the quantity of association between two genomes, which have been derived from a perfectly homologous one, decreases as a whole, and that at last there may occur no longer any paired chromosomes at all. An autotetraploid plant in which duplicated 
genomes are at this stage of differentiation will no longer be detected as such on the basis of chromosome association. Thus a polyploid form may become a new form of functional diploid, though its chromosomes are of polyploid in amount. Many gradational series of stages are conceivable to occur before the above situation is reached. From the premise that the homology interrelationship between two sets of chromosomes (or genomes) is established by the total sum of the homology relationships existing between each pair of all the corresponding homologous chromosomes, HAGA (1940) tried to demonstrate the grades of partial homologous relationships between the genomes by the percentage ratios of the average amounts of pairing to the complete association of all the chromosomes concerned. Such association indices calculated with all " $\mathrm{Rc}$ " $-\mathrm{F}_{1}$ 's examined by the present author are respectively $16.2,16.3,20.0,25.9,26.7,27.3,29.9,30.0$, and 39.8 per cent., while the indices obtained by other workers are 16.9, $21.8,22.8,25.8,32.3$ and 35.8 per cent. respectively. The existence of such variable degrees of chromosome pairing among the same species cross is also noticed in other intergeneric hybrids raised between $R$. sativus and various Brassica species other than $B$. oleracea and $B$. alboglabra (See Tables 11 and 12).

It may be duely approved that the association of a corresponding pair of chromosomes is possible when these chromosomes are entirely similar in kind and amount, and in arrangement of the genes throughout their whole length, or when they have such a portion or portions in common as above mentioned, though the pairing potentiality in the latter case may vary according to the length of such portions or segments. Differentiation of chromosome will be recognized first as the mutation of gene or of chromosome. With the accumulation of such changes the pairing potentiality of a certain homologous chromosomes will decrease, and with the accumulation of such changes in a group of chromosomes (or in a genome) the index number of association quantity as described before, no doubt, decreases, causing gradational series of such indices. When a decrement is noticed in the pairing potentiality of a certain homologous chromosomes, or in the association index of a certain homologous genomes, the homology of those chromosomes or genomes is understood to have decreased in that extent. As one of the remarkable cases of such gradational varia- 
tion of association quantity, the results obtained by SKovsted (1937) with the diploid $\mathrm{F}_{1}$ hybrids $(\mathrm{n}=13)$ of Gossypium species may be cited. SKovsted obtained a continuous series of average number of bivalent chromosomes, which ranged from 2.45 to 13 , respective number found in the series being $2.45-3.20-4.35-5.35-$ 5.10-7.65-8.80-9.68-10.90-11.35-12.45-13.00. A similar situation is also noticed in a large number of diploid $F_{1}$ hybrids raised by intra- and inter-genus crosses covering Aegilops, Triticum and some allied forms (KIHARA and LILIENFELD, 1932; 1935; Cf. KIHARA's "Studies on Wheat Plants", 1938). In all probability, the minor intra-specific differentiation within a certain species also proceeds along a line quite similar to that of the interspecific situation mentioned above. Namely, there may exist no intrinsic distinctions between these two ways of genome differentiation. The results of examinations on intergeneric $F_{1}$ hybrids among different kinds of varieties or races of $R$. sativus and $B$. oleracea will be taken as evidences that will give positive supports to the consideration above stated.

It is worthy of note here, however, that the differences in the amount of association cannot be wholly attributed to the different grades of genetic differentiation, especially of structural one, among species or varieties. Therefore, when we discuss the chromosome association in connection with phylogeny we must carefully consider, at least, the following points; that the chromosome pairing and other meiotic behaviours are to some extent affected by temperature or other environmental conditions ( $C f$. Nakamura, 1936; Matsuura, 1937; Michaelis, 1926; Sax, 1937; StRAUB, 1937a, b), and that the influence of external conditions may be exaggerated in the hybrids composed of genomes having only remote homology from each other. The author have discussed elsewhere upon such variable modes of chromosome pairing with some of the present $F_{1}$ hybrids. KiHARA (1929), KiHARA and LILIENFELD (1935), and MATHER (1935) also reported on the occurrence of similar cases in their $\mathrm{F}_{1}$ hybrids in Triticum and Aegilops.

On the other hand, there are several cases in which nonassociation of chromosomes is governed by a special gene (BEADLE and McClintock $(1928,1933)$ in maize; Bergner, Cartledge and Blakeslee (1934) in Datura; Clausen, J. (1930) in Viola; Clausen, R. E. (1931) in Nicotiana; Huskins and HEARNe (1933) in oats and 
wheat; HUSKINS and SMTTH (1934) in Sorghum; KolleR (1938) in Pisum). Such genetical non-association of homologous chromosomes is also observed by the author in some strains of Brassica, Raphanus, and their hybrids (Unpublished). Thus even the homologous chromosomes fail to pair when such a gene exists. Moreover, the effect of such a gene may be affected by a modifying gene or genes, or by some environmental factors. Further, the phenomenon of "differential affinity" of homologous chromosomes, which has been noticed sometimes in the polyploid species or hybrids, is worthy of attention in this connection (Cf. DARLINGTON, 1928). U (1935) discusses this phenomenon in his Brassica hybrids.

These conditions stated above will all modify, in some occasions, the pairing of homologous chromosomes, or that of chromosomes with homologous segment. On the contrary, there is a peculiar case of association of non-homologous chromosomes, which is first presented by KostofF (1938b). KostofF (1938a, b; KOSTOFF and ARUTIUNIAN, 1938) thinks that this type of association or connection occurs between the inert regions of the chromosomes. All these facts will surely give certain limitations on the considerations pertaining to the problems of chromosome pairing.

$\mathrm{F}_{1}$ hybrids with " $\mathrm{Rc}$ " genome combination show 6 paired chromosomes at the maximum association. Whether each of these paired chromosomes is of allosyndetic one between " $R$ " and " $c$ ", or of autosyndetic one within " $R$ " or " $c$ ", cannot be confirmed exactly. The nature of these paired chromosomes may be determined or presumed only in connection with the pairing behaviours in various other $F_{1}$ hybrids containing Brassica and Raphanus genomes. The following Table 13, which is compiled from the data given in Tables 11 and 12, shows all kinds of genome combinations hitherto obtained together with the corresponding modes of chromosome pairing at their meiosis. The type of chromosome pairing at the maximum range of variation is represented in the table for each genome combination. Similar data hitherto obtained for various interspecific $F_{1}$ hybrids, including two or three kinds of Brassica genomes, are given in Table $14(\mathrm{C} f$. Tables 4 and 6 in HAGA, 1938b).

As shown in these tables, the pairing of the homologous genomes is always complete throughout the four kinds of genomes, " $a$ ", " $b$ ", " $c$ " and " $R$ ". When a hybrid, which is composed of 
two homologous genomes and a single non-homologous one, produces trivalent chromosomes besides bivalents and univalents, and the total number of trivalents and bivalents corresponds to the chromosome number of the homologous genome, the number of those trivalents will show the actual amount of allosyndetic pairings which occur between these two kinds of genomes. For instance, the occurrence of $0-5$ trivalent chromosomes in "acc". plant reveals the fact that the maximum amount of allosyndetic pairs between "a" and " $c$ " genomes is five. Such a method is

Table 13. Chromosome pairing in meiosis of plants with various combinations of the genomes of - Brassica and Raphanus.

$\begin{array}{lc}\begin{array}{c}\text { Genome constitution } \\ \text { of plants }\end{array} & \text { Chromosome pairing in meiosis }{ }^{2} \\ \text { R a } & (0-8) \mathrm{II}+(19-3) \mathrm{I} \\ \text { R c } & (0-6)_{\mathrm{I}}+(18-6)_{\mathrm{I}} \mathrm{I} \\ \text { R a b } & 27 \mathrm{I} \\ \text { R a c } & (5-6) \mathrm{I}+(18-16) \mathrm{I} \\ \text { R b c } & (0-9) \mathrm{I}+(26-8) \mathrm{I} \\ \text { R c c } & 9 \mathrm{II}+9 \mathrm{I} \\ \text { R c c c } & (0-8)_{\mathrm{II}}+(9-1) \mathrm{II}+(18-10) \mathrm{I} \\ \text { R b c c } & (9-17)_{\mathrm{II}}+(17-1) \mathrm{I} \\ \text { R R a } & 9 \mathrm{II}+10 \mathrm{I} \\ \text { R R c } & 9 \mathrm{II}+9 \mathrm{I} \\ \text { R R a a } & 19 \mathrm{II} \\ \text { R R c c } & 18 \mathrm{II} \\ \text { R R R c c } & 18 \mathrm{II}+9 \mathrm{I}\end{array}$

rather indirect but there is no other kind of data at present which will give more direct sources of evidence to the interrelationships existing among those four kinds of genomes, "a", " $b$ ", " $\mathrm{c}$ " and " $R$ ". The maximum number of bivalent chromosomes in "ac".plant is 8 , and the number would show the maximum number of allosyndetic pairs (or allo-pairs) between "a"- "c", if there fails any occurrence of autosyndetic pairs (or auto-pairs) in the genomes concerned. However, if we take 5 pairs out of 8 appeared in

1) Genome constitution in somatic tissues is represented.

2) Type of chromosome pairing at the maximum variation is presented. 
Table 14. Chromosome pairing in meiosis of plants with various combinations of Brassica genomes. ${ }^{1)}$

Genome constitution of plants ${ }^{2}$
a a
c c
a b
a c
a a b
a a $c$
a b b
b b c
a c c
b c c
a b c.
a a c c
a a b c
$\mathrm{a} b \mathrm{~b} c$
$\mathrm{a} b \mathrm{~b} c$
b c c c

Chromosome pairing in meiosis?2)

$$
\begin{gathered}
10 \mathrm{II} \\
9 \mathrm{II} \\
(0-3)_{\mathrm{II}}+(18-12)_{\mathrm{I}} \\
(0-8)_{\mathrm{II}}+(19-5)_{\mathrm{I}} \\
10 \mathrm{II}+8 \mathrm{I} \\
10 \mathrm{II}+9 \mathrm{I} \\
8 \mathrm{II}+10 \mathrm{I} \\
8 \mathrm{II}+9 \mathrm{I} \\
(0-5)_{\mathrm{III}}+(9-4)_{\mathrm{II}}+(10-5)_{\mathrm{I}} \\
9 \mathrm{II}+8 \mathrm{I} \\
(9-1) \mathrm{II}+(9-25)_{\mathrm{I}} \\
19 \mathrm{II} \\
10 \mathrm{II}+17 \mathrm{I} \\
(8-16)_{\mathrm{II}}+(19-3)_{\mathrm{I}} \\
(0-6)_{\mathrm{II}}+(9-3)_{\mathrm{II}}+(18-12)_{\mathrm{I}} \\
(9-5)_{\mathrm{II}}+(0-4)_{\mathrm{II}}+(8-12) \mathrm{I}
\end{gathered}
$$

"ac"-plant as allo-pairs between "a"- " c", as the maximum number of trivalents in "acc"-plant is five, the maximum number of auto-pairs will become 3 for "ac" genomes. "aabc"-plants show exclusively $10 \mathrm{II}+17 \mathrm{I}$ configuration, so that no allo-pairs between " $b$ " and " $c$ " are expected. Thus 6 trivalents appeared in "abcc"-plant may indicate the possibility of 6 allo-pairs between " a" and "c". "abbc"-plant produces complete 8 pairs by "b"" $\mathrm{b}$ " and additional 8 pairs at maximum. And at least 5 out of the latter 8 pairs are similarly allo-pairs between " $a$ " and " $c$ ", as the plant may produce 3 auto-pairs at maximum from "a" and " $c$ " genomes. The maximum number of bivalents in "ab"-plants is 3 , and this number may be taken as the maximum number of allo-pairs between "a"- "b", though the chance of allo-pairing in "a" is not excluded. Of 9 maximum pairs appeared in "abc"-plant

1) 'B. napus' $(\mathrm{n}=18)$ of CATCheside (1934) and of FrANDSEN and WiNGE (1932) is considered to be different from $B$. napus $(\mathrm{n}=19)$ or $B$. Napella $(\mathrm{n}=19)$, which are treated by the author and other workers, so that data with ' $B$. napus' are not compiled in the table.

2) See remarks in Table 13 . 
the following considerations will be made: If we admit that the allo-pairs between " $a$ " and " $b$ " range between $0-3$, and 3 autopairs are possible in "a" and " $c$ ", the number of allo-pairs between "a"- " c" will become 6-3, concurring well with "a"-."c" relation above suggested. If " $a$ "-_" c" allo-pairs are presumed to be 6-8 and auto-pairs none, "a"-_ " $b$ " allo-pairs will become 3-1, the number also concurring with those suggested by "ab"-plant. Chiefly from those considerations, the number of allo-pairings between two of the three Brassica genomes are presumed as follows:

(From 5 to 8 allosyndetic pairs may occur between " $a$ ", and " $c$ ", From 1 to 3 allosyndetic pairs may occur between " a" and " $\mathrm{b}$ ", None (or undecided) pair may occur between " $\mathrm{b}$ " and " $c$ ".

The possible number of auto-pairs within the respective genome may be suggested as follows:

fOne or 2 autosyndetic pairs for each of " $a$ " and " $c$ ", (None (or undecided) autosyndetic pair for " $b$ ".

From the homology interrelationships above suggested among Brassica genomes and from the results of pairing behaviours of intergeneric Raphanus-Brassica hybrids compiled in Table 13, the following intergeneric genome relationships may be provisionally obtained on the assumption of non-occurrence of autosyndesis within " $R$ " genome: The allo-pairs between " $R$ " - " $c$ " may be $4-6$, as the maximum number of bivalents in "Rc"-plants is 6 and 0-2 auto-pairs within " $c$ " may have a probable occurrence. Allo-pairs between " $\mathrm{R}$ "-_" a" may be $6-8$, as the maximum number of paired chromosomes in " $\mathrm{Ra}$ "-plants is 8 , and as $0-2$ auto-pairs within " $a$ " may have a probable occurrence. Allo-pairs between " $R$ "- " $b$ " may be $3-5$, since the maximum number of bivalents in " $\mathrm{Rbc}$ "-plants is 9 and 4-6 allo-pairs may occur between " $\mathrm{R}$ "" $c$ " as above presumed, and none of " $\mathrm{b}$ " auto-pair is probable. "Rbcc"-plant produces excessive 0-8 pairs in addition to 9 occurring by the complete pairing of "c" " " $c$ ", so that the former $0-8$ pairs may be taken as the allo-pairs between " $R$ "- " $b$ ".

The author, however, observed a rare occurrence of one trivalent chromosome in some "Rc"-plants. In a similar hybrid, HowaRD (1938b) also reported such a trivalent chromosome. The occurrence of these trivalent chromosomes may be duely attributed to autosyndesis in " $c$ " genome. But the chance of their produc- 
tion by autosyndesis of " $R$ "-chromosomes is not excluded, because the author encountered very rarely with one tetravalent chromosome in $R$. sativus and also with several radish strains which are interchanged heterozygotes (FukUsHIMA, 1937). Thus the author cannot give any decisive conclusion on this point.

Studies of chromosome behaviour in the haploid individuals may, no doubt, give some significant contributions of genome analysis. Haploid mutant of $B$. Napella (aacc) is a unique example in Brassica and its relatives (MoRINAGA and FukUSHIMA, 1933). Raising of various other haploid mutants of Brassica and Raphanus species is thus most desirable in this connection.

Genome interrelationships supposed above among " $a$ ", " $b$ ", " $c$ " and " $R$ " are represented schematically in Diagram 1, though

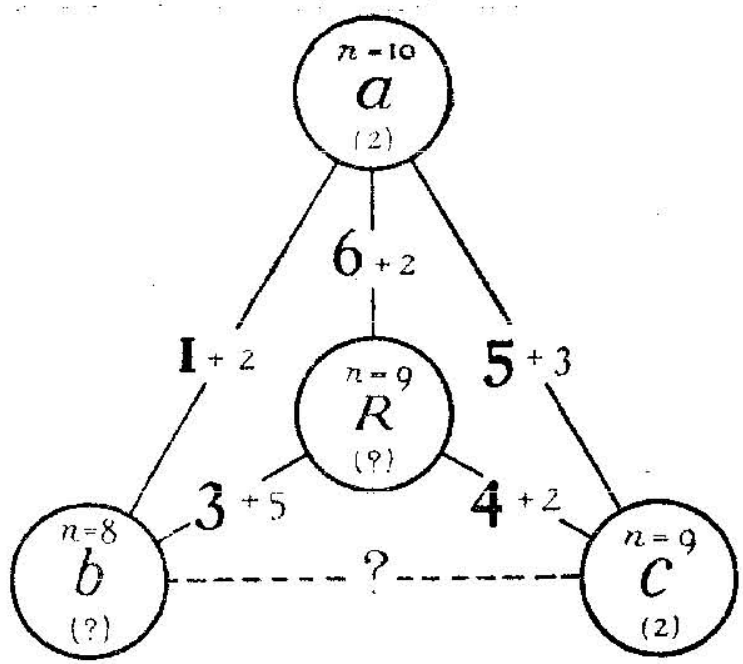

Diagram 1.

Genome interrelationships among genomes of Brassica and Raphanus, "a". " $b$ ", "c" and " $\mathrm{R}$ ", showing the numbers of paired chromosomes. Numbers in thick letters represent the probable minimum numbers of paired chromosomes, and the sum of numbers in thick and thin letters shows the probable maximum number of pairing chromosomes. Numbers in parentheses show the probable maximum amount of autosyndetic pairs.

the analyses are deficient in some measure and not quite enough in minor details. 
Since partial homologous relationships are established between " $a$ "- c $c$ " and between " $a$ "- " $b$ ", and each of " $a$ ", " $b$ " and " $c$ " is in a partial homologous relation with " $R$ ", so " $b$ " and " $c$ " are supposed to be in a similar partial homologous relation too, though any positive source of evidences could not be obtained for actual " $b$ "-." $c$ " pairings. Now it will be recognized very easily that all these genomes which show a remarkable aneuploidy relationships are originated from an "Urgenom" or a common basic genome.

The maximum number of pairs occurring between genomes in a partial homologous relation shows only the upper variation limit of association and does not necessarily represent the actual number of partially homologous chromosomes existing between the respective genomes. Therefore, it must be kept in mind that the actual number of such homologous chromosomes may be, in general, somewhat larger than those taken into the above considerations.

The above discussions are undertaken by the author absolutely on the results of actual chromosome pairings. On the other hand, explanations of aneuploid condition in Brassica and Raphanus have been tried by several workers on the ground of "secondary association" hypothesis as mentioned before. CATCHESIDE (1934, 1937), Alam (1936), RichHaria (1937a) and HaGa (1938a) studied the "secondary association" of meiotic chromosomes with various species of Brassica, namely those with 8, 9, 10 and 18 haploid chromosomes, and of Raphanus, attaining a similar conclusion that these various genomes are supposed to have been derived from an "Urgenom" which has $\mathrm{n}=6$ as the primary basic number. Supposed composition formulæ given to the respective genomes, however, are more or less different according to the authors. From the results of his studies on the "secondary association", also well referring the data of genome analyses undertaken by other workers, HAGA (1938a) advanced the view that the aneuploidy relationships among Brassica genomes may be most easily recognizable when we give them the following formulæ of genome constitution:

$$
\text { “ a " }=\left[\begin{array}{llllll}
A & B & C & D & E & F \\
A & B & C & D & &
\end{array}\right]
$$




$$
\begin{aligned}
& " b "=\left[\begin{array}{llllll}
A & B & C & D & \underset{E}{E} & F \\
& & & & F & F
\end{array}\right] \\
& \text { "c } "=\left[\begin{array}{llllll}
A & B & C & D & E & F \\
A & B & C & & &
\end{array}\right]
\end{aligned}
$$

Recently Sikka (1940) examined three species of Brassica and obtained five groups of chromosomes at the maximum "secondary association" and gave the following composition formulæ to the respective species:

$$
\begin{aligned}
& \text { B. nigra }(\mathrm{n}=8)=\left[\begin{array}{lllll}
\mathrm{A} & \mathrm{B} & \mathrm{C} & \mathrm{D} & \mathrm{E} \\
\mathrm{A} & \mathrm{B} & \mathrm{C} & &
\end{array}\right] \\
& \text { B. } \text { sinapistrum }(\mathrm{n}=9)=\left[\begin{array}{lllll}
\mathrm{A} & \mathrm{B} & \mathrm{C} & \mathrm{D} & \mathrm{E} \\
\mathrm{A} & \mathrm{B} & \mathrm{C} & \mathrm{D} &
\end{array}\right] \\
& \text { B. monensis }(\mathrm{n}=12)=\left[\begin{array}{lllll}
\mathrm{A} & \mathrm{B} & \mathrm{C} & \mathrm{D} & \mathrm{E} \\
\mathrm{A} & \mathrm{B} & \mathrm{C} & \mathrm{D} & \\
\mathrm{A} & \mathrm{B} & & & \\
\mathrm{A} & &
\end{array}\right.
\end{aligned}
$$

Thus SIKKa suggested the primary basic number of Brassica to be $n=5^{13}$, and on this assumption he supposed that three species with $2 \mathrm{n}=30$ in the genus Erucastrum of Brassicinae to be of hexaploid origin, and that a polyploid series of chromosome numbers, $2 \mathrm{n}=$ 30,60, 90 and 120, which prevail in the genus Crambe of Raphiniae to be of multiples of 5 or of multiples of 30 . Further, he stated the situation of Brassica as follows: Up to the present time the chromosome number of 19 species of Brassica has been determined. Of those, 7 species have $2 n=20,32 n=18,22 n=24,12 n=16$, and the remaining ones are amphidiploid derivatives of species having lower numbers of chromosomes, so that about half of these Brassicas may be considered to be of the secondary tetraploid ( 5 as basic chromosome number) in origin. Thus Sikka insists on the significant development of tetraploidy on the evolution of Brassica. On the disparity between these two basic numbers, 5 and 6 cited above, SikKa thinks that it may possibly be explained by the fact that the forms examined by other workers may be of remote origin, so that structural differentiation of some homologous chromosomes has occurred to some extent, and that their affinity is no

1) Catcheside (1934) also observed very rare occurrence of 5 groups of chromosomes in $B$. oleracea, but the fact was not much accounted of and he attributed this to some superimposed structural changes. 
longer enough to cause attraction and, accordingly, the maximum secondary pairing amounting to true basic number may be of a very remote possibility in such cases. The application of the hypothesis of the "secondary association" has in fact a serious limitation in this way. Moreover, as mentioned elsewhere, the hypothesis itself, according to the author's view, cannot be approved as a thoroughly proved one of experimental cytology. This hypothesis seems to have been applied only with important unproved premises, and we cannot give a similar weight to the results obtained from "secondary association" as to those obtained from genome analysis which is based on actual chromosome pairing.

There are several well known cases of artificially raised secondary polyploids, including 'Raphanobrassica' of KARPECHENKO and ' $B$. napocampestris' of FRANDSEN and WINGE (1932), but there is no clear example yet which can duely compete with the natural species. Though these examples are not quite sufficient yet to reveal the mechanism of such species formation, it is generally believed that the phenomenon of secondary balance established through hybridization and chromosome doubling might have played a very important part in species formation. Thus, it becomes very desirable to have any direct method of inquiry upon the chromosomal constitution of the secondarily balanced genomes. We have no direct source of evidences to assume that the secondary association occurs by the same causal mechanism as the primary pairing. And the problems in this connection have hitherto been discussed with the species which are likely presumed as secondary polyploids on genetical and other more or less indirect source of evidences. Through future developments of investigations on the polyploid plants, especially on the artificially raised polyploid ones, the hypothesis of secondary association may be established on a more concrete foundation of experimental cytogenetics.

In the above considerations it is made known clearly that the secondary balance has played a very important part in the evolution of genomes in the genera Brassica and Raphanus. The question, in what way such genomes are generally possible to result, however, is not yet answered sufficiently, though the establishment of such a secondary balance is suitably recognized as one of the im. portant ways of evolutionary development of organisms.

Now the author will refer to the state of differentiations or 
developments in various Brassica genomes, whose establishment has been already reflected upon in the above discussion. The direction of such a differentiation is traced within the group of species with either 10 or 18 chromosomes. Differentiation of species within these groups is considered to have been derived mainly through the accumulation of simple genic changes. This interspecific differentiation is quite similar in nature as that which is characteristic for intraspecific one, though it clearly differs in its extent. Genetic behaviours of the hybrids between these species were dealt with elsewhere.

The differentiation in Brassica in the second direction has been found in the natural amphidiploid forms produced by the hybridization of elementary species accompanying the doubling of chromosomes. As mentioned before, a few examples of artificially raised amphidiploid forms resembling the natural ones in various characters will suffice to show the species evolution along such a direction in nature. For the production of such amphidiploid forms from hybrid plants the following three main ways are considered as probable; (1) by the union of unreduced gametes, (2) by the somatic doubling, or (3) by the gametic doubling (Cf. DARLINGTON, $1937 ; \mathrm{U}, 1935)$. But it is a rather difficult task to determine which one of these three ways was followed by each of those Brassica amphidiploid forms. An artificially raised amphidiploid $B$. napocampestris is considered to have been produced by somatic doubling (FRANDSEN and WINGE, 1932). The origin of Raphanobrassica of KARPECHENKO (1927a, b; 1928, 1929a) is attributed to the union of unreduced gametes. U (1935) considers his ' $B$. napus' as originated somatically through the endoduplication which occurred in the earliest cleavage stage. The author has already reported the natural occurrence in certain strains of $B$. japonica of unreduced and still higher polyploid gametes derived from giant mother-cells produced through irregular archesporial divisions (FUKUSHIMA, 1931). Moreover, the author has hitherto encountered, in some other Brassica species and in Raphanus, a similar spontaneous production of giant gametes with various polyploid number of chromosomes, though its frequency is very low. By fusion of unreduced gametes thus produced, a sudden occurrence of autotetraploid forms in pure species or of amphidiploid ones in hybrids may be naturally expected ( $C f$. RAMANUJAM, 1940; MoRINAGA and 
KuRIYAMA, 1937). New species formation along this line was first advocated by WINGE (1917), and since then many data obtained with a large number of plant genera have been adduced in support of his view. It is generally recognized that allopolyploids are more favourable in nautre than autopolyploids and that these polyploid forms usually have much greater potentiality for variation through mutations and structural changes than is possessed by the diploid forms. Hybridization is considered, therefore, to have played an important rôle in the species formation in Brassica.

The third direction of the variation system in Brassica is noticed in the structural changes of chromosomes. With clearcut contrast to gene mutations, structural change is characterized by its bringing about of rather rapid evolutionary changes. Structural changes ultimately bring about hindrance of pairing of homologous chromosomes and intersterility results. This intersterility would place the new type thus produced at a new centre of variations, through which such a type will get to a new species in the long run (Cf. Gates, 1938; Dobzhansky, 1937; GoldschmidT, 1940). Out of various structural changes of chromosomes segmental interchanges and inversions are generally considered to have most significant bearing on the species formation, as ring-forming plants or inversion heterozygotes occur not infrequently in nature. In Brassica. SiKKa (1940) observed a frequent occurrence of a ring of four chromosomes in his $F_{1}$ hybrid between $B$. Tournefortii and $B$. trilocularis. He also observed in his $B$. nigra and $B$. Wrightii a higher multivalent formation which may partially be due to reciprocal translocation. The author encountered with a spontaneous occurrence of interchange heterozygotes in some strains of $R$. sativus (FukUSHIMA, 1937). SIKKA (1940) observed inversions in his two interspecific hybrids, $B$. juncea $\times B$. campestris and $B$. Tournefortii $\times B$. trilocularis, and in one pure species $B$. Wrightii. The author also met, in some rare occasions, with bridge formation in $B$. oleracea, $B$. alboglabra and $R$. sativus.

In conclusion, the author will indicate particularly one of the characteristic features revealed by the present investigation. Various $\mathrm{F}_{1}$ plants obtained between $R$. sativus and $B$. oleracea show variable amounts of chromosome pairing according to varieties or races used in the crosses. Such differences among varieties or races, as described elsewhere, are naturally ascribed to be a mani- 
festation of the variable degrees of genetic differentiation among them. Such intraspecific genetic differentiation is considered not to be detected in varietal or racial crosses, as each pair of relatively changed chromosomes to such a minor degree may associate, resulting in a bivalent chromosome of normal appearance. Therefore, the studies of intergeneric or interspecific hybridization with many different racial combinations may be inferred as one of the fruitful means to make clear the progress of such intraspecific differentiation which cannot be fully elucidated through genetic analyses of varietal or racial crosses.

\section{Summary}

(1) During the period of 1926-1937, the author tried a large number of genus-crosses between Japanese radishes (Raphanus sativus) and various cultivated Brassica species, and succeeded in obtaining true $F_{1}$ hybrids in the following 11 different crosses, the number of $F_{1}$ individuals raised amounting to 22 in all (Cf. Table 2):

Di-genome $F_{1}$ hybrids ("Rc");

(1) R. sativus $\mathrm{L} .(\mathrm{n}=9) \times B$. oleracea var. capitata $\mathrm{L} .(\mathrm{n}=9) \ldots \quad \ldots \quad \ldots\left(\mathrm{F}_{\mathbf{1}} \mathrm{A}\right)$

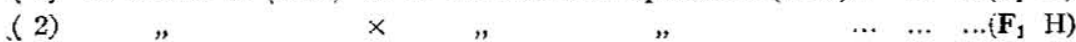

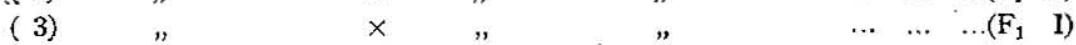

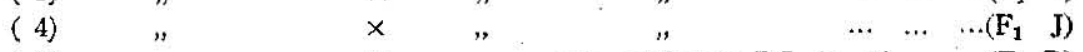

(5) $" \quad \times \quad " \quad$ var. cattorapa DC. $(n=9) \ldots \ldots\left(F_{1} D\right)$

(6) $\quad \times \quad " \quad, \quad \ldots \quad \ldots \quad \ldots\left(F_{1} G\right)$

(7) B. oleracea var. capitata $\mathrm{L} .(\mathrm{n}=9) \times R$. sativus $\mathrm{L} .(\mathrm{n}=9) \ldots \ldots \ldots(\mathrm{F}, \mathrm{K})$

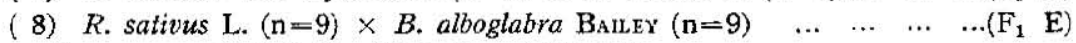

Tri-genome $F_{1}$ hybrids ("Rbc" and "Rab");

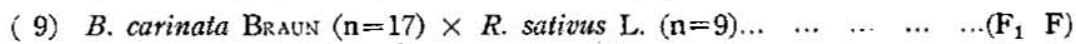

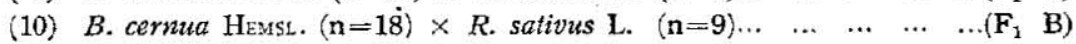

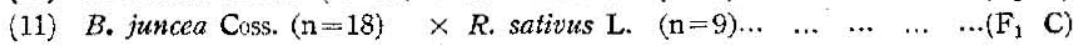

All the $F_{1}$ hybrids covering (1)-(8) had the same genome constitution " $\mathrm{Rc}$ " and so they were treated in Part I, while the remaining three $F_{1}$ hybrids, (9)-(11) with "Rab" or "Rbc" genomes, were treated in Part II.

(2) Remarkable differences prevailed in degree of success in obtaining those intergeneric $F_{1}$ hybrids, depending, on one hand, directly on the species, strains, or individuals concerned, and, on the other, on various environmental conditions surrounding the mother plants. Crosses between $B$. oleracea and $R$. sativus 
were much more successful when the latter species was taken as the seed parent. Only one reciprocal hybrid $B$. oleracea $\times R$. sativus $\left(F_{1} K\right)$ was obtained by the author, and he could not notice any differences in characters between those reciprocals. As usually the case with the interspecific crosses, $F_{1}$ hybrids between Raphanus and amphidiploid Brassicas, namely, B. carinata, B. cernua, or $B$. juncea, were only obtainable when the latter species of larger chromosomal number were taken on the maternal side.

(3) Morphological characters of those $F_{1}$ hybrids differed to some extents even in the same species combination, in both di- and tri-genome hybrids, according to the genotypic constitution of the respective plants. From very early stage of growth on, there were noticed marked heterozygous nature existing in the hybrid organisms raised from the same cross. The development of $F_{1}$ embryos, and the size and the germinating power of $F_{1}$ seeds differed remarkably. Weak seedlings including albinos and other chlorotic ones, which soon died out, were produced to a certain extents together with normal vigorous sister individuals.

(4) Di-genome "Rc"-hybrids showed a strong tendency of heterosis, in the height of plant, in the number of side flowering branches, and in the number and size of leaves. Every morphological character of those $F_{1}$ plants was in some measure intermediate, though a certain parental characters predominated in the $F_{1}$ plants.

(5) Tri-genome $F_{1} F$ plants, "Rbc", also showed as vigorous a growth as the "Rc"-plants, while $F_{1} B$ and $F_{1} C$ plants of "Rab" did not. The morphological characters of the Brassica parent, which has an amphidiploidal number of chromosomes, usually predominated in $F_{1}$ hybrids, the situation being quite similar to that generally recognized in the interspecific hybrids.

(6) Marked prolongation of the blooming duration and the enlargement of flowering clusters occurred in "Rc"-and " $\mathrm{Rbc}$ "- $\mathrm{F}_{1}$ plants. These characters were, no doubt, partly caused physilologically in connection with the nearly complete sterility of those $F_{1}$ hybrids. Some $F_{1}$ individuals of $R$. sativus $\times B$. oleracea showed a strong regenerative activity, outliving two or three seasons or more.

(7) The intergeneric $F_{1}$ hybrids were extremely sterile. But there could be still noticed some differences in the degree of 
fertility among them. Some "Rc"- $F_{1}$ plants were completely sterile, and the most fertile one produced several viable $F_{2}$ seeds. Furthermore, one of the two sister $F_{1}$ individuals raised from a certain cross $K$. sativus $\times$ B: oleracea, $\mathrm{F}_{1} \mathrm{D}$, was completely sterile, while the other was partially fertile, though there could be noticed no definite difference in their chromosome behaviours in meiosis. $F_{1}$ 's $H, D$, and $G$ plants obtained from a similar cross $R$. sativus $\times$ B. oleracea, $F_{1}$ E plants from R. sativus $\times$ B. albogtabra, and $F_{1}$ $F$ plants from $B$. carinata $\times R$. sativus, produced several $F_{2}$ seeds respectively, and the author succeeded in raising $F_{2}$ progenies from these crosses. Fertility problems were also discussed in connection with the karyological behaviours of those $F_{1}$ hybrids.

(8) Karyological studies were carried out with all the $F_{1}$ individuals, 22 in number, above mentioned. Chromosome numbers were reascertained for all varieties and strains used in hybridization, revealing no irregularities at all.

(9) All the $F_{1}$ hybrids between $R$. sativus and $B$. oleracea, including $\mathrm{F}_{1} R$. sativus $\times$ B. alboglabra, had exclusively 18 chromosomes in diploid state. Somatic number of chromosomes of trigenome $F_{1}$ hybrids, $B$. carinata $\times, R$. sativus $\left(F_{1} F\right)$, B. cernua $\times$ $R$. sativus $\left(\mathrm{F}_{1} \mathrm{~B}\right)$ and $B$. juncea $\times R$. sativus $\left(\mathrm{F}_{1} \mathrm{C}\right)$, also showed exactly the sum of the haploid parental numbers, namely, 26, 27, and 27 .

(10) Studies of the $F_{1}$ microsporogenesis were mainly confined to the stages after diakinesis. Special attention was payed on the association of chromosomes in the heterotypic division. $F_{1}$ hybrids, $R$. sativus $\times B$. oleracea, B. oleracea $\times R$. sativus, and $R$. sativus $\times$ $B$. alboglabra, all of which having the same " $\mathrm{Rc}$ " genome constitution, showed variable chromosome pairing according to the parental varieties or strains used ( $C f$. Table 5 and Fig. 30 ).

(11) Of those "Rc"-F hybrids, $F_{1}$ 's A, D and E plants did not show any positive evidence of chromosome pairing, producing exclusively 18 univalents, while the remaining $F_{1}$ 's $\mathrm{H}, \mathrm{I}, \mathrm{J}, \mathrm{G}$ and $\mathrm{K}$ produced variable number of bivalents, maximum variation being respectively $(0-5) \mathrm{II},(0-4) \mathrm{II},(0-6) \mathrm{II},(0-3) \mathrm{II}$, and $(0-5) \mathrm{II}$.

(12) $\mathrm{F}_{1} \mathrm{~B}$ and $\mathrm{F}_{1} \mathrm{C}$ plants, each with "Rac" constitution, also produced no bivalent chromosome, while $F_{1} F$ plants with "Rbc" produced variable number of bivalents, the number of which ranged between zero and four ( $C f$. Tables 7 and 8 ). 
(13) The amount of chromosome pairing also varied, within certain limit, with individuals as well as flowers. Thus it was ascertained that the chromosome pairing depended not only on the genotype but also on the environmental conditions, external and internal. Nature of those paired chromosomes, whether they are of autosyndetic or of allosyndetic, was discussed and suggested.

(14) Each frequency distribution polygon of paired chromosomes represented by Fig. 30 did not follow the type of chance distribution, but took generally a more or less distorted form. Such a distortion of distribution was accounted for by the presumption that each pair of those associated chromosomes had more or less different pairing potentiality or it had different amount of partially homologous segment or segments in common.

(15) Considerable differences existing in the amount of pairing potentialities in " $\mathrm{Rc}$ "- $\mathrm{F}_{1}$ hybrids, namely, from complete absence of pairing to (0-6) II pairs at maximum, are attributable mainly to certain differences existing between the varieties or strains concerned in crossings. This situation was discussed in connection with the problems of intraspecific evolution.

(16) The bivalent chromqqsomes appeared in the present $F_{1}$ hybrids had usually one chiasma and bivalents with two chiasmata were encountered very rarely. Terminalization of chiasmata was nearly complete at the I-Metaphase.

(17) The author found, in "Rc"-hybrids, five metaphasic figures, each containing one trivalent chromosome. Two figures were found in $F_{1} H$, one figure in $F_{1} I$ and two figures in $F_{1} K$. No higher multivalents were encountered at all. Such trivalent chromosomes would have been caused by the spontaneous chromosome alterations such as translocation or like.

(18) Usual course of meiosis in PMCs was similar with all the $F_{1}$ hybrids examined. Bivalent chromosomes took a regular position on the equator at the I-Metaphase, and they disjoined later regularly into their halves. Univalent chromosomes behaved in two ways, a part of them splitting at the I-Anaphase and the rest at the II-Anaphase. Behaviour of chromosomes in homotypic division also followed the typical way, and the diad chromosomes divided equationally at the II-Anaphase, while the monad ones were lagging behind. Some of the lagging chromosomes showed splitting, but they did not divide again. 
The author, however, obtained an exceptional case of II-division in $\mathrm{F}_{1} \mathrm{~B}, \mathrm{~B}$. cernua $\times R$. sativus, where all II-Metaphasic chromosomes, both diad and monad ones, appeared arranged themselves on the equatorial plane and they divided equationally. Thus some of those monad chromosomes, no doubt, had undergone division twice.

(19) The majority of $F_{1}$ sporads were higher polyads rather than tetrads, containing supernumerary small spores produced by the lagged chromosomes excluded from the ordinary major nuclei. Nearly all of the $F_{1}$ microspores thus produced ceased to grow sooner or later and degenerated finally, owing perhaps to the genetic unbalance of their nuclear contents.

(20) Restitution at the I-Anaphase occurred not infrequently, and its frequency occurrence varied with the kinds of crosses and so also with the genotypic differences of the hybrid individuals, though it seemed to be more or less affected by some environmental conditions (See Table 6). The amount of diads produced by such restitution must have an intimate relation to the fertility of the hybrid individuals.

(21) Following several irregularities were noticed in the $F_{1}$ meiosis, though some of those irregularities may not be attributed directly to the hybridity itself :

(i) The occurrence of giant (polyploid) PMCs among the normal diploid ones was noticed not infrequently. The mode of occurrence of this irregularity was quite similar to that already reported by the author in a certain strain of $B$. japonica.

(ii) Syndiploid PMCs were observed in some rare occasions. Such irregular PMCs were also considered to have been derived, like (i), by the irregular premeiotic cell division.

(iii) Plasmodium-like cells or tissues were noticed rarely in some anther-locules of $F_{1} A$ and $F_{1} D$ plants.

(iv) PMC with two or three minor spindles instead of the ordinary one was observed not infrequently in $F_{1} \mathrm{E}$ plants, $R$. sativus $\times$ B. alboglabra. Total number of chromosomes appeared on such minor spindles in a PMC was always exactly 18, i.e., the diploid number of that $F_{1}$ hybrid. The origin of these abnormal spindles was attributed to the nuclear budding, which was observed rather frequently in the hybrid nucleus at meiotic prophase, but not to cytomixis. 
(v) Cytokinesis after the second nuclear division did not complete in some occasions, or rather frequently in $\mathrm{F}_{1} \mathrm{E}$ hybrid, $R$. sativus $\times B$. alboglabra. In some monad spores thus resulted, fusion of micronuclei was detected to occur. A giant nucleus caused by such fusion contained nearly di-diploid number of chromosomes.

(vi) In some $F_{1}$ anthers, interruption of division processes occurred at various stages in meiosis, and such PMCs soon degenerated. In some exceptional cases, PMCs degenerated at their premeiotic stages without undergoing division processes.

(vii) In some rare $F_{1}$ anthers, monad spores were produced directly from the archesporial cells without undergoing meiosis. The author could not tell the future destiny of such abnormal spores.

(22) Megasporogenesis and female gametophyte formation were studied in some details in the case of $F_{1} D$ hybrid, R. sativus $\times B$. oleracea, though they occurred only in a slight percentage of $F_{1}$ ovules. Megasporogenesis seemed to proceed quite similarly as the microsporogenesis. After meiosis, one of the four cells produced, the one lying at the chalazal end, usually underwent further divisions and produced an embryo-sac in quite a usual manner. The mature embryo-sac had the typical appearance, containing in it two synergids, three antipodals, one egg-cell and two pole nuclei. The formation of such a matured embryo-sac occurred only in a very small percentage of the ovules produced. Degeneration occurred at various stages of both the megasporogenesis and the female gametophyte development. Some EMCs degenerated without undergoing meiosis. Various kinds of abnormal ovules examined were also described in some length.

(23) In conclusion, the author discussed various problems pertaining to the species formation in Brassica and Raphanus, inferring the data obtained by the present investigation as well as the result of works hitherto carried out by other authors. In the genus Brassica there prevails a remarkable development of aneuploidy, as shown in Table 1, therefore the studies on the genus are of very deep significance in connection with the general problem of the origin of aneuploidy.

(24) Genome differentiation in minor order may be understood as a differentiation of genes. The differentiation of this 
category will result through an accumulation of simple gene mutations. The group of Brassica species with 10 chromosomes ("a") or 18 ("ab") may have developed mainly through such genome differentiation.

(25) Another category of genome differentiation occurs through chromosomal variations, which proceed in two ways, structural and numerical. Structural variations will produce a group of genomes which show various established interrelationships among them. The variable amounts of chromosome pairing noticed among the $F_{1}$ hybrids raised between $R$. sativus and $B$. oleracea are ascribed as an expression of such genetic differentiation of the genomes concerned. Those minor intraspecific structural variations seem to the author to be so meagre in order that they cannot be detected by the ordinary varietal or racial crosses, as each pair of chromosomes relatively changed to that minor extent may possibly associate. With the progress of such differentiation, association quantity between two genomes decreases, showing a gradational series of variation, and at last there may no longer occur any paired chromosomes at all. The formation of a quite new genome will result in this manner. Thus the author suggested that the minor intra-specific differentiation of a certain species may also proceed in a way quite similar as in the inter-specific situation, though less in its extent, leaving no intrinsic distinctions between those two situations of genome differentiation.

(26) In connection with the "secondary balance" of genomes, the hybridization, accompanying the doubling of chromosomes, has, no doubt, played a great rôle on the species formation in Brassica. As the decisive case of such "secondary balance" in nature, three amphidiploid species derived from each two of the three primary genomes, i.e., " a", "b" and "c", are well known in the genus Brassica. Examples of artificial raising of some amphidiploid forms and of some new Raphano-Brassica amphidiploid forms are also reported by several workers.

(27) There exist four different kinds of elementary genomes, namely, "a ", "b", "c" and "R", among Brassica and Raphanus, and these genomes are consisting of $10,8,9$ and 9 chromosomes respectively. Cytology is considered to give a conclusive clue to explain the origin of those genomes, of which chromosome num- 
bers are in such a marked aneuploidy relation, though there also exist various other ways of approach.

As the most reliable and direct cytological mean, the author has taken up "genome analysis", based on the actual primary pairing of chromosomes in interspecific or intergeneric hybrids. Doing thus the author discussed the interrelationships existing among the genomes above mentioned from the data obtained on the present intergeneric $F_{1}$ hybrids, referring also to the results of other wokkers on the similar hybrids and on various interspecific ones raised among Brassica species. The author also pointed out in that connection several factors which may affect the chromosome pairing.

(28) Manner of chromosome pairing in meiosis of various intergeneric $F_{1}$ hybrids hitherto worked out between Raphanus and Brassica and also those of various other Brassico-Raphanus hybrids, as well as of various interspecific Brassica hybrids, are summarized in Tables 11-14.

(29) Genome interrelationships, which are suggested from the above chromosome analyses, are represented schematically in Diagram 1 (page 381). Though the diagram is yet neither perfect in certain points nor sufficient in minor details, it may suggest the fact that all those genomes, "a", "b", "c" and "R", are originated from a common basic genome or an "Urgenom".

(30) The author has also made a discussion on the proposals to make clear such a basic chromosome set or common basic genome of Brassica and Raphanus on the ground of "secondary association" hypothesis. But the hypothesis itself, according to the author's view, cannot be approved yet as a thoroughly proved one of experimental cytology.

(31) As described above, it is clearly made known that the "secondary balance" has played a very important part in the evolution of genomes in Brassica and Raphanus. The author discussed, in that connection, on the general problems concerning the establishment of "secondary balance", through which a series of genomes in aneuploid relation might have been produced.

\section{ACKNOWLEDGFMENTS}

By far the greater part of the present work was carried out 
while the author was still a member of the Plant Breeding Laboratory of Kyusyu Imperial University. The author wishes here to express his sincerest gratitude to Prof. T. MoRINAGA, under whose supervision the work was carried through, and who has kindly provided the author with the materials necessary in the pursuit of his work besides giving him many helpful suggestions and criticisms during the course of study. The author's thanks are also due to Prof. H. ITo of the Horticultural Institute of the university for providing him with valuable facilities and advices for the execution of the present investigation. The author is also indebted to Messrs K. TAKahara and H. KURIYAMa of the former institution for their invaluable aids rendered him in raising hybrid plants and making cytological preparations.

(This work was undertaken partly with the help of Scientific Research Expenditure of the Department of Education).

\section{IITERATURE}

AŁAM, Z. 1936 Cytological studies of some Indian oleiferous Cruciferae. III. Ann. Bot. $50: 85-102$.

Bazcncx, E. B. and Navashin, M. 1930 The genus Crepis. Bibl. Genet. 6: 1-90.

BAUR, E. 1922 Einführung in die experimentelle Vererbungslehre. Berlin.

- 1932 Artumgrenzung und Artbildung in der Gattung Antirrhinum, Section Antirrhinastrum. Z. ind. Abst.- u. Vererb.-Lehre 63: 256-302.

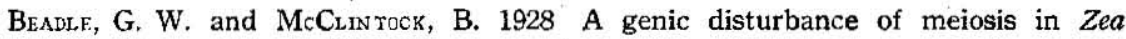
Mays. Science 68: 433.

- and 1933 Further studies of asynaptic maize. Cytologia 4: 260-287.

Bergxier, A. D., Cartledge, J. L. and BlakesLeE, A. F. 1934 Chromosome behaviour due to a gene which prevents metaphasic pairing in Datura. Ibid. 6: 19-37.

BLEIER, H. 1930 Untersuchungen über das Verhalten der verschiedenen Kernkomponenten bei der Reduktionsteilung von Bastarden. Cellule 40: 85-144.

Catcheside, D. G. 1934 The chromosomal relationships in the swede and turnip groups of Brassica. Ann. Bot. 48: 601-633.

1937 Secondary pairing in Brassica oleracea. Cytologia Fujii Jub. Vol. : 366378.

Clnusen, J. 1926 Genetical and cytological investigations in Viola tricolor L. and V. arvensis MURR. Hereditas 8: 1-156.

- 1930 Male sterility in Viola orphanidis. Ibid. 14: 53-72.

CI.AusEn, R. E. 1931 Inheritance in Nicotiana Tabacum. XI. The fluted assemblage. Amer. Nat. 65: 316-331.

Colins, J. L., Hollingshead, L. and Avery, P. 1929 Interspecific hybrids in Crepis. 
III. Constant fertile forms containing chromosomes derived from two species. Genet. 14: 305-320.

Darlington, C. D. 1928 Studies in Prunus. I and II. J. Genet. 19:213-256.

- 1937 Recent advances in cytology. 2nd. Ed. London.

- and Moffert, A. A. 1930 Primary and secondary chromosome balance in Pyrus. J. Genet. 22 : 129-151.

Detjen, L. R. 1927 Sterility in the common cabbage (Brassica oleracea L.) Mem. Hort. Soc. N. Y. $3: 277-280$.

-Dobzhansky, T. 1937 Genetics and the origin of species. New York.

Fоске, W. O. 1881 Pflanzen-Mischlinge. Berlin.

Franden, H. N. and WingE, O. 1932 Brassica Napocampestris, a new constant amphidiploid species hybrid. Hereditas 16: 212-219.

Funusums, E. 1929 Preliminary report on Brassico-Raphanus hybrids. Proc. Imp. Acad. Japan 5: 48-50.

1930 Formation of diploid and tetraploid gametes in Brassica. Japan. J. Bot. 5: 273-283.

1937 "On the chromosomal variants in Japanese radish." (A preliminary note in Japanese) Japan. J. Genet. 13; 222-223.

- - and Maruyams, Y. 1929 Preliminary report of the serological examination of Brassica. Proc. Imp. Acad. Japan 5: 473-476.

GATES, R. R. 1938 The species concept in the light of cytology and genetics. Amer. Nat. $72: 340-349$.

- - and ReEs, E. M. 1921 A cytological study of pollen development in Lactuca. Ann. Bot. 35: 365-398.

GäRTNR, F. 1849 Versuche und Beobachtungen über die Bastarderzeugung im Pflanzenreich. Stuttgart.

Goldscimidt, R. 1940 The material basis of evolution. New Haven.

Grawatr, F. 1914 A radish-cabbage hybrid. J. Hered. 6: 269.

HAsA, T. 1938a Relationship of genom to secondary pairing in Brassica (A preliminary note). Japan. J. Genet, 13: 277-284.

- $1938 \mathrm{~b}$ "On the genoms in the genus Brassica." (A collective review in Japanese) Ibid. $14: 74-90$.

- 1940 "A critique on the conception of the genom." (In Japanese) Ibid. 16: 211-227.

Howard, H. W. 1938a The chromosome number of the swede, Brassica napus L. J. Genet. $35: 383-386$.

1938b The fertility of amphidiploids from the cross Raphanus sativus $\times$ Brassica oleracea. Ibid. $36: 325-340$.

Huskins, C. L. and Hearne, E. M. 1933 Meiosis in asynaptic dwarf oats and wheat. J. Roy. mic. Soc. 53: 109-117.

— and Smrth, S. G. 1934 A cytological study of the genus Sorghum Pers. II. The meiotic chromosome. J. Genet. 28: 387-395.

Inariyama, S. 1929 Karyological studies of Iris Kaempferi Sier. Japan. J. Bot. 4 : 405-426.

KAKIZAKI, Y. 1927 An instance of radish-cabbage hybrids. J. Sci. Agric. Soc. Tokyo No. 298: 438-446.

1930 Studies on the genetics anp physiology of self- and cross-incom. 